MPIfG Discussion Paper 16/5

\title{
Financial Fraud
}

A Literature Review

Arjan Reurink 
Arjan Reurink

Financial Fraud: A Literature Review

MPIfG Discussion Paper 16/5

Max-Planck-Institut für Gesellschaftsforschung, Köln

Max Planck Institute for the Study of Societies, Cologne

May 2016

MPIfG Discussion Paper

ISSN 0944-2073 (Print)

ISSN 1864-4325 (Internet)

(C) 2016 by the author

About the author

Arjan Reurink is a doctoral researcher at the Max Planck Institute for the Study of Societies, Cologne. Email: reurink@mpifg.de

\section{Downloads}

www.mpifg.de

Go to Publications / Discussion Papers

Max-Planck-Institut für Gesellschaftsforschung

Max Planck Institute for the Study of Societies

Paulstr. 3 | 50676 Cologne | Germany

Tel. +49 $2212767-0$

Fax +49 $2212767-555$

www.mpifg.de

info@mpifg.de 


\begin{abstract}
This paper describes the empirical universe of financial fraud as it has been documented in the academic literature. More specifically, it describes the different forms of fraudulent behavior in the context of financial market activities, the prevalence and consequences of such behavior as identified by previous research, and the economic and market structures that scholars believe facilitate it. To structure the discussion, a conceptual distinction is made between three types of financial fraud: financial statement fraud, financial scams, and fraudulent financial mis-selling. What emerges is a picture of financial fraud as a complex phenomenon that can take very different forms, depending on the market segments in which it occurs, the financial instruments it pertains to, and the actors involved. Moreover, the findings of the literature review highlight a number of recent developments that scholars think have facilitated the occurrence of financial fraud, including: (1) the development of new fundamental conflicts of interest and perverse incentive structures in the financial industry; (2) an influx of unsophisticated, gullible participants in the financial marketplace; (3) the increasing complexity involved in financial market transactions as a result of rapid technological, legal, and financial innovation and an ever-widening menu of financial products; (4) an increase in the use of justified secrecy in the form of strict confidentiality rules around banking and legal services and the use of off-balance-sheet constructions and shell companies located in secrecy jurisdictions.
\end{abstract}

\title{
Zusammenfassung
}

Das Discussion Paper beschreibt die empirische Vielfalt des Finanzbetrugs anhand eines Literaturvergleichs. Im Einzelnen untersucht es verschiedene Formen betrügerischen Verhaltens im Kontext von Aktivitäten auf dem Finanzmarkt, die Verbreitung eines solchen Verhaltens und sich daraus ergebende und bereits durch vorhergehende Forschung bekannte Folgen sowie Wirtschafts- und Marktstrukturen, die betrügerisches Verhalten möglicherweise fördern. Um die Diskussion zu strukturieren, werden drei Formen von Finanzbetrug unterschieden: Bilanzfälschung, Finanzschwindel und Verkaufspraktiken mit betrügerischer Absicht. Es entsteht ein Bild des Finanzbetrugs als komplexes Phänomen, das sehr verschiedene Formen annehmen kann - jeweils abhängig vom Marktsegment, in dem es auftritt, von den betroffenen Finanzinstrumenten und den beteiligten Akteuren. Darüber hinaus heben die Ergebnisse dieses Literaturüberblicks eine Reihe neuerer Entwicklungen hervor, die im Verdacht stehen, Finanzbetrug zu fördern: (1) die Entstehung neuer grundsätzlicher Interessenkonflikte und Fehlanreize in der Finanzindustrie; (2) der Zustrom von uninformierten und naiven Teilnehmern in den Finanzmarkt; (3) die steigende Komplexität von Finanzmarkttransaktionen als Ergebnis rasanter technologischer, rechtlicher und finanzieller Innovationen und einer sich ständig erweiternden Palette von Finanzprodukten; (4) ein verstärkter Rückgriff auf Geheimhaltung in Form von strengen Vertraulichkeitsregeln für Bankgeschäfte und juristische Dienstleistungen sowie von außerbilanziellen Konstruktionen und Briefkastenfirmen in Offshore-Finanzplätzen. 


\section{Contents}

Preface 1

1 Introduction 4

2 Financial statement fraud $\quad 8$

$\begin{array}{llr}2.1 & \text { General characteristics } & 8\end{array}$

2.2 Financial statement fraud in the context of publicly listed corporations

2.3 Rogue traders: Accounting fraud at the proprietary trading desks of financial firms

2.4 Mortgage origination fraud: Financial statement fraud in the context of loan applications

2.5 Mortgage securitization fraud: Financial statement fraud in the context of structured finance investments

3 Financial scams, cons, and swindles 35

3.1 General characteristics 36

3.2 Investment scams: Sham business ventures and Ponzi schemes 39

3.3 Financial identity scams: Phishing, pharming, and payment scams 47

4 Fraudulent financial mis-selling 53

4.1 General characteristics $\quad 54$

4.2 Predatory lending: The mis-selling of (mortgage) loans 58

4.3 The mis-selling of life insurance and pension schemes 63

$\begin{array}{ll}\text { 4.4 The mis-selling of interest rate derivatives } & 68\end{array}$

4.5 The mis-selling of synthetic CDOs 73

$\begin{array}{lll}5 & \text { Conclusion } & 76\end{array}$

$\begin{array}{ll}\text { References } & 81\end{array}$ 


\section{Financial Fraud: A Literature Review}

\section{Preface}

Over the last 35 years, the financial industry has been plagued by consecutive waves of financial crime. The looting of thrifts and the insider-trading scandals related to the mergers-and-acquisition boom of the 1980s, the boiler room practices and IPO manipulations in the 1990s, the accounting fraud in major corporations like Enron and Ahold at the turn of the millennium, the stock options scandal and the episode of late-trading and market-timing practices involving mutual funds in the early 2000s are only a few in a long list of possible examples. More recently, the aftermath of the financial crisis of 2007-2008 revealed rampant fraud in the mortgage industry, Ponzi schemes perpetrated in major investment funds, illegal manipulation of key benchmark rates, and widespread mis-selling of complex financial derivatives instruments to both unknowledgeable and naive investors. Although financial crimes are not a new phenomenon in any sense, both the frequency with which they occur and their scope and impact seem to have increased over the last few decades. Commentators have suggested that illegal conduct is more endemic in the financial sector than in any other sector of the economy (Freeman 2010; Fligstein/Roehrkasse 2013: 38) and that criminality in the financial markets now occurs on such a large scale that it can no longer be regarded as exceptional (Ferguson 2012). Some have even argued that financial markets have turned into a de facto "criminal playground" (Michel 2008).

The abovementioned observations raise serious questions with regard to the social legitimacy of the contemporary financial industry and the specific form of finance capitalism in which it operates. However, the ubiquity of financial crime is not only relevant from a social or distributive justice perspective. It also carries academic relevance for those studying financial markets. Despite the ubiquity of illegal conduct in financial markets, research on financial markets in the fields of economic sociology and political economy has long failed to seriously engage with the phenomenon of financial crime. While unavoidably skeptical of the social utility of much of the activity the financial industry engages in and acutely aware of the crisis potential inherent in speculative financial markets, few commentators have dwelt on the issue of legality (Nesvetailova/

\footnotetext{
I would like to thank Jens Beckert, Renate Mayntz, Patrick Köppen, Tod van Gunten, and Benjamin
} Braun for helpful comments on previous versions of this paper. 
Palan 2013: 357). Such disregard for market behaviors that fall outside the realm of legality represents a significant blind spot that is of considerable theoretical and empirical relevance in these disciplinary fields.

Theoretically, the neglect of examining financial crime - a term used here not in a strictly legal sense but in a more general one to refer to financial market conduct that violates any kind of legal stipulation, be it regulatory rules, statutory law, civil law, or criminal law - excludes a wide range of real-world behaviors and market dynamics from being used as empirical input for theoretical advances. For example, neoclassical economic theories of regulation, which provide the theoretical underpinning for the regulatory frameworks that govern financial markets in most of the Western world, clearly lose credibility if we account for the widespread opportunistic and often illegal behavior that prevails in contemporary financial markets. The empirical relevance of financial crime is probably best exemplified by the role it has played in the recent financial crisis. As scholars working in the field of white-collar crime have long proclaimed (e.g., Freeman 2010; Friedrichs 2010; Ryder 2014) and as much of the research discussed here underscores, law-violating behavior was a significant, albeit largely overlooked, contributing factor in the build-up to the financial crisis of 2007-2008. Mainstream accounts of the factors that contributed to the financial crisis have focused on: the poor but legal management of risk; problems of complexity, liquidity, and volatility; increasing leverage in the banking and shadow banking systems; the rapid expansion of credit and falling credit standards; irrational exuberance; and ineffective regulatory policies (Ryder 2014: 19). Accounts that recognize the role played by financial crime add to this the active manipulation of information resulting in a massive misallocation of capital, an unknown and involuntary accumulation of risk, and a widespread disregard for laws and regulations.

This paper is motivated by the desire to bring the phenomenon of financial crime into mainstream thinking about financial markets in the fields of economic sociology and political economy. In order to do so, two precursory endeavors are needed. The first is to develop a meaningful conceptual approach to the study of financial crime. As I discuss elsewhere (Reurink forthcoming), we lack both a generally agreed upon definition of the term "financial crime" as well as a meaningful conceptual framework for the study of such crimes. An important step in conceptualizing financial crimes is to develop a more refined understanding, on the one hand, of the meaning of the categories legality and illegality and, on the other, of the relationship between the dimension (formal) legality and (social) legitimacy (Mayntz 2016). A simple understanding of illegality as the violation of legal norms fails to appreciate the different forms that illegality may take, depending on the kinds of legal rules that have been violated - i.e., regulatory rules, civil laws, or criminal laws. The implicit assumption that what is legal is also legitimate fails to account for those behaviors that simply fall outside the scope of existing legal rules. This becomes especially relevant if we consider the rapid pace of innovation and the emergence of novel financial instruments and practices in contemporary financial markets. A more refined understanding of these categories also forces us to better con- 
ceptualize the distinction between laws per se and the processes of law making and law enforcement, which allows us to improve our understanding of the legal, social, and political dimensions of the contentious processes through which the categories of legality and illegality (in its different guises) are attributed to specific acts and behaviors.

A second preliminary endeavor that needs to be embarked upon in order to integrate the study of financial crime into mainstream thinking about financial markets is to come to grips with the empirical reality of the phenomenon. This requires researchers to examine the complex and arcane character of financial crime, specifically, to appreciate the scope of the problem, to get an idea of the way in which financial crimes are committed, and to come to a deeper understanding of the market structures that facilitate their commission. This paper embarks upon this second endeavor. It does so by reviewing the English-language literature on financial crime in the fields of finance, accountancy, economics, criminology, sociology, psychology, and law. To cover the whole family of financial crime would require an entire volume. A possible typology of illegal conduct that occurs in the financial markets includes behavior as diverse as financial fraud, insider trading, market manipulation, bribery, self-dealing, and the facilitation of illegal financial flows - i.e., money laundering, terrorist financing, tax evasion, and corruption. Therefore, to keep the endeavor manageable, the paper limits itself to discussing only one type of financial crime that was especially relevant in the context of the 2007-2008 global financial crisis, namely financial fraud.

Before I present the results of the literature review, a few notes on the scope of the project are in order. As I explain in greater detail in the introduction, for the purpose of this project I understand financial fraud to be acts and statements through which financial market participants misinform or mislead other participants in the market by deliberately or recklessly providing them with false, incomplete, or manipulative information related to financial goods, services, or investment opportunities in a way that violates any kind of legal rule or law, be it a regulatory rule, statutory law, civil law, or criminal law. This implies that the meaning of fraud as a behavioral category is not derived from a legally prescribed offense. This would be impossible for practical reasons: not only does the legal concept of fraud lack coherence within legal systems, but there are also differences among national jurisdictions in determining the specific kinds of behavior subsumed under the offense of fraud. It also implies that the financial crimes that are discussed are not all necessarily criminal in a legal sense - i.e., violations of criminal law. Finally, language issues have acted as a constraint on the scope of the findings presented here. Only the English language literature on financial fraud has been included in the literature review. As a consequence, the representativeness of the presented findings is skewed heavily towards the Anglo-Saxon world. 
This paper explores the phenomenon of fraud in the context of financial market activities. Increasingly, it appears, financial fraud has moved from the fringes of financial market activity to become a widespread type of behavior throughout the industry. The aftermath of the financial crisis of 2007-2008 revealed a great number of scandals in which financial market participants infected the markets with fraudulent information to gain personal advantage. Despite the clear observability of this trend in the news media and the significant empirical implications accompanying it, mainstream academic research on financial markets has so far largely failed to account properly for this trend.

As an important preliminary step in bringing the phenomenon of financial fraud closer to the center of financial market research in the fields of economic sociology and political economy, this paper describes the empirical universe of financial fraud as it has been documented in the literature in a wide variety of disciplines. The main purpose is not to present an all-encompassing analysis of the entire scope of the literature on financial fraud, but to provide a descriptive account of the different forms of fraudulent behavior in the context of financial market activities, the prevalence and consequences of such behavior as identified by previous research, and the market structures that scholars believe facilitate this behavior. Before I present the results of the literature review, it might be useful to demarcate the boundaries of the phenomenon under study.

As a behavioral category, fraud is a complex and elusive concept. In the social sciences literature, many definitions of fraud have been proposed, ranging from such cursory ones as "the obtaining of goods and/or money by deception" (Levi 2009: 224) to more elaborate ones that claim fraud is "a human endeavor, involving deception, purposeful intent, intensity of desire, risk of apprehension, violation of trust, rationalization, etc." (Ramamoorti/Olsen 2007, quoted in Yu, 2013: 447). The law is just as ambiguous about the phenomenon, and legal scholars have at times referred to the body of law dealing with fraud as a "conceptual morass" (Green 2007b: 231). Fraud does not exist as a coherent or single activity or statutory offence and has no single legal definition (Doig 2006: 19; Pickett/Pickett 2002: 1). The law only possesses is "a concept of fraud, a broad notion (broader indeed than the layman's) of what it means to defraud someone" (Doig 2006: 19, emphasis in original). This legal concept of fraud appears in various guises in a wide range of laws across different jurisdictions (Green 2007b: 229), and the meaning and definition of fraud may change, depending upon the specific statute in which the word appears (Podgor 1999: 737). ${ }^{1}$

1 The concept of fraud also appears in varying roles within legal statutes. In addition to fraud being conduct subject to punishment, it can present itself as the state of mind required for certain acts to impose civil or criminal liability. In such cases, statutes might use the term "fraudulently" to describe the actor's intent. Other statutes use the term "defraud" or require an "intent to defraud." Finally, some provisions speak in terms of a "scheme or artifice to defraud" (Podgor 1999: 730-731). 
In the context of financial market activities - banking, securities, and insurance - fraud is attributed a more specific meaning and best understood as the unlawful falsification or manipulation of financial information (Fligstein/Roehrkasse 2013: 7). Financial information acts as the linchpin for financial market transactions. Participants in financial markets merely exchange intangible rights (and obligations), the present and future value of which depends entirely on the status and future performance of the issuer of those rights (Lomnicka 2008). To assess the current status and future performance of the issuer and ultimately to establish the perceived value of a financial instrument, both accurate information and the expertise necessary to interpret that information are essential. Therefore, no type of financial market participant can make proper decisions with regard to engaging or not engaging in financial contracts and to buying or disposing of financial instruments unless they

- are adequately informed about the specificities of the contracts and instruments under consideration;

- are adequately informed about the status of the issuer of those rights;

- are adequately informed about the broader market dynamics that might have an impact on the contract or instrument in the future; and

- have at least a certain degree of competence necessary to interpret and extract meaning from all this information with regard to the future performance of the contract.

To facilitate the provision of information to the market and to safeguard the integrity of such information, state authorities issue legal rules - regulatory rules, statutory laws, civil laws, and criminal laws - and prescribe sanctions that are then enforced by the courts and the designated authorities. Three sets of legal rules are of specific significance with regard to the phenomenon of financial fraud. First, to facilitate the provision of information to the market and to ameliorate the problem of information asymmetries, financial regulators have imposed disclosure requirements as a central pillar of financial market regulation in all developed financial markets. Disclosure requirements prescribe that issuers of financial instruments and providers of financial services disclose to the market and their counterparties all relevant information, that they do so in a timely manner, and that they make sure that all market participants have equal access to this information.

Second, to protect those financial market participants who are deemed to have insufficient expertise to interpret the available information from being exploited by more sophisticated market players, legal systems may impose fiduciary duties or suitability requirement on certain market participants. Fiduciary duties and suitability requirement, which are especially pertinent in retail financial markets, prescribe that financial service providers and financial advisers share some of the knowledge and expertise they hold so that clients or customers can make informed decisions with regard to financial transactions. Whether or not a fiduciary duty or suitability requirement applies as well as the nature and extent of the duty in any particular case is established by reference to the character of the parties involved in a specific transaction or cooperation and the underlying contractual relationship between those parties. 
Third, legal systems prohibit certain deceptive behavior through general fraud laws, which may appear in both civil and criminal bodies of law. As has been recognized by a number of authors, fraud is among the most serious, costly, stigmatizing, and punitive forms of liability imposed on actors in modern corporations and financial markets (Buell 2011; Green 2007a). In many jurisdictions the law also provides a number of legal statutes that target certain kinds of financial fraud more specifically. Most importantly, financial fraud in the securities markets is usually targeted by countries' securities law regimes. Other statutes may specifically target financial statement fraud in the banking or insurance sector, fraud perpetrated using mail and wire communications, or fraud perpetrated through the use of a computer or the internet. Although both types of behavior that are targeted by these different statutes and the sanctions they prescribe vary across legal systems and between statutes, all of these laws and statutes require the presence of a number of elements for civil or criminal liability to be imposed on a misrepresenting actor. ${ }^{2}$

However, disclosure requirements, fiduciary duties, and general fraud laws do not always prevent ill-disposed market participants from corrupting the flow of information in financial markets in order to induce market participants to enter into contracts where, given perfect information, they would not have done so. Where market participants willingly and knowingly provide the market or counterparties in specific transactions with false, incomplete, or manipulative information in a way that violates any of the three sets of legal rules mentioned above or any other kind of legal rule - be it a regulatory rule, statutory law, civil law, or criminal law - we enter the domain of illegality and, more specifically, financial fraud. ${ }^{3}$ Illegality is thus understood here as a characteristic of a course of action that provides sufficient grounds for a regulatory enforcement

2 For example, for criminal fraud to be established in the US: the misrepresentation needs to be material - meaning that it has "a natural tendency to influence, or is capable of influencing, the decision of the decision-making body to which it was addressed" (Shepherd/Wagner/Williams 2001: 851); the misrepresentation must have been made knowingly and with the intention to deceive; the misrepresentation needs to be directly related to the transaction and to be relied upon by the victim; the victim must have good reason to trust the statement is true; and the victim ends up being injured as a consequence of the misrepresentation (Finan et al. 2011: 1133; Harrington 2012: 395).

3 It needs to be emphasized here that illegality is not an objectively determined characteristic of a fraudulent act. In many cases, the legal procedures involved - those establishing whether a certain deceptive or manipulative act violates any of the legal stipulations intended to curb fraud and, if so, whether it is a breach of regulatory, civil, or criminal rules - are complex, subjective, and contentious processes relying on interpretation and requiring the availability of evidence to determine the outcome. Not only does the fraudulent act itself need to be interpreted and evaluated, it needs to be determined which legal rules have allegedly been breached and the necessary evidence required by these rules has to be demonstrated if the act is to be declared illegal. Moreover, whether or not such legal procedures are set in motion in the first place is contingent on political decisions about allocating sufficient resources to market policing and law enforcement agencies (Pontell 1984). Although these are unmistakably issues of great relevance for the study of financial fraud (and financial crime more generally), they fall outside the focus of this paper. 
action, successful private litigation, criminal prosecution in the courts, or all of these. For the purpose of this study, financial frauds can then be defined as acts and statements through which financial market participants misinform or mislead other participants in the market by deliberately or recklessly providing them with false, incomplete, or manipulative information related to financial goods, services, or investment opportunities in a way that violates any kind of legal rule or law, be it a regulatory rule, statutory law, civil law, or criminal law. In legal and regulatory parlance, such acts are often described in terms of "misrepresentations," "misreporting," "false disclosure," "non-disclosure," or "fraud."

Concrete acts of financial fraud vary widely in their representations, depending on the market segments in which they are perpetrated, the financial instruments they pertain to, and the actors involved. Reflecting this diversity, the literature dealing with the phenomenon of financial fraud as defined above displays a plethora of often overlapping terms and concepts. Examples of such terms are fraud (e.g., Biegelman 2013; Goldmann 2010), financial fraud (e.g., Pontell/Frid 2000; Young 2006; Harrington 2012; Gough 2013), securities fraud (e.g., Cronin/Evansburg/Garfinkle-Huff 2001; Wang 2010; Straney 2011; Yu 2013), corporate fraud (e.g., Comer 2003; O'Gara 2004), management fraud (e.g., O'Gara 2004), accounting fraud (e.g., Henselmann/Hofmann 2010; Kat/ Lakeman 2010), financial statement fraud (e.g., Zack 2013), financial institution fraud (e.g., Pontell/Calavita/Tillman 1994; Shepherd/Wagner/Williams 2001), fiduciary fraud (e.g., Rosoff/Pontell/Tillman 2014), bank fraud (e.g., Subramanian 2014), investment fraud (Naylor 2007), brokerage fraud (e.g., Stoneman/Schulz 2002), and insurance fraud (e.g., Viaene/Dedene 2004). To bring some degree of order into this terminological muddle, a conceptual distinction is made here between three types of financial fraud. These will be referred to as

- financial statement fraud

- investment scams

- fraudulent financial mis-selling.

In the next three sections, I will discuss these types one by one, beginning with a brief description of each type of fraud. Then I discuss its general modus operandi and its illegal character and identify a number of themes that play a prominent role in the literature dealing with that type of fraud. Subsequently, the empirical character of the specific fraudulent acts that are subsumed under it will be described in more detail. I will describe how these acts are executed, identify the actors and financial instruments involved, present some estimations on the prevalence of these frauds and the social and economic costs and consequences they incur, explain the market structures and dynamics that facilitate these fraudulent conducts, and refer to some cases that have been discussed in the literature. The final section summarizes the general findings that have emerged from this literature review and suggests possible directions for future research. 


\section{Financial statement fraud}

In the context of this report, I use the term financial statement fraud to group together a variety of behaviors in which financial market participants make false statements about the true nature or financial health of an investment outlet - i.e., a company, fund, borrower, or investment product. Notwithstanding the deceptive element, misrepresentations that constitute financial statement fraud pertain to otherwise legitimate enterprises, actors, or products. This distinguishes them from investment scams, which are designed as con games from the start. Financial statement fraud is also distinct from fraudulent mis-selling practices in that it disseminates plain lies and untrue facts, rather than merely creating misleading impressions.

At a general level, financial statement fraud exploits the information asymmetry that exists between different parties in a financial transaction. By combining the illusion of disclosure with false information, financial statement fraud increases this information asymmetry while appearing to minimize it (Black 2006: 247-248). Several scholars have emphasized the future-oriented nature of this form of deception (Langevoort 1997: 110; Lomnicka 2008; Velikonja 2013: 1892). Parties in financial transactions, they argue, merely exchange intangible rights, the present and future value of which is dependent entirely on the status and future performance of the issuer of those rights (Lomnicka 2008). By communicating false information to the market, those perpetrating financial statement fraud distort construals of the future prospects of these rights.

\subsection{General characteristics}

\section{Modus operandi}

Misrepresentations that result in the establishment of financial statement fraud can pertain to all sorts of relevant information used by market participants to assess the financial health and future prospects of an investment. In most cases, fraudulent financial statements concern misrepresentations made by representatives of an organizational entity - e.g., a company or investment fund - in the disclosure of information to investors, regulators, and other market players about the financial health and future prospects of that company or fund. Such misrepresentations are usually communicated through presentations, prospectuses, financial reports, or financial statements. Although at times this involves misrepresentations of the non-financial characteristics of the company - e.g., the credentials or ownership interests of executive management most often these misrepresentations pertain to the financial health of a company or one of its subunits, as documented in the accounts. Hence, many authors speak of financial statement fraud in organizations more specifically in terms of accounting fraud. 
As Leap (2007: 63-64) points out, accounting fraud may have either one of two objectives. First, fraudulent accounting techniques may be used to cover up the misappropriation or misapplication of funds. Company insiders who embezzle funds from the company may alter accounting ledgers and supporting documentation to conceal their deeds. Second, fraudulent financial statements may be issued by managers to mislead investors or regulators about the profitability and future prospects of an enterprise. ${ }^{4}$ Probably the most well-known example of the latter has been the web of accounting fraud perpetrated by the management of the American energy firm Enron. A look at accounting fraud in more detail reveals that, in carrying out their schemes, perpetrators resort to an enormous variety of fraudulent accounting techniques. A review of the literature, ${ }^{5}$ however, shows that this myriad of techniques can be broken down into five broad categories. The first two of these, revenue-based schemes and expense-based schemes, aim at artificially boosting a firm's current profitability as reported on the income statement. The third and fourth categories, asset-based schemes and liability-based schemes, involve the fraudulent strengthening of the balance sheet through misrepresentations of asset values and risk exposures, in order to increase a company's financial health and perceived future earnings power. ${ }^{6}$ The final category, other financial statement schemes, represents a residual one.

Although in the literature the terms financial statement fraud and accounting fraud are generally reserved for financial misrepresentations in the context of corporations, investment funds, and other sorts of organizational entities, here the term is used in a broader sense and also refers to similar kinds of misrepresentations related to other kinds of entities. Like organizational entities, individuals who engage in financial contracts may also misrepresent their financial affairs in an attempt to ensure better terms for the contract. For example, loan applicants may make false statements about their

4 Arguably a third objective of financial statement fraud consists of the use of fraudulent accounting techniques to facilitate other forms of financial crime, such as money laundering operations or the execution of elaborate tax evasion schemes. The role of accounting fraud in the facilitation of these crimes will be discussed later.

5 For example, Zack (2013) distinguishes between revenue-based schemes, asset-based schemes, expense and liability-based schemes, and other financial reporting schemes, a residual category including improper disclosure as well as financial statement fraud used to conceal other forms of financial crime. Similar categories have been suggested by Mulford and Comiskey (2002) and Jones (2011). Practitioners have employed likewise similar categories. The Association of Certified Fraud Examiners, for example, distinguishes between fictitious revenues, asset valuations, concealed liabilities, improper disclosure, and timing differences (Goldmann 2010: 82).

6 Many of the techniques used in revenue- and expense-based schemes indirectly affect assets and liabilities reported on the balance sheet as well. After all, accounting involves two sides to every transaction. For example, both aggressive capitalization of expenses and the lengthening of depreciation periods increase the value of assets reported on the balance sheet. However, under the categories of asset- and liability-based schemes, I exclude schemes that aim primarily at increasing profits and focus instead on those schemes that aim at improving the asset base to boost a firm's future earnings power. 
income, assets, or liabilities in order to induce a lending institution to make a loan it would have otherwise refused. Alternatively, parties seeking insurance may misrepresent a true state of affairs in order to negotiate better terms for an insurance policy.

\section{The illegality of financial statement fraud}

Financial statement fraud is addressed by a country's general fraud laws, its securities law regime, and its disclosure and transparency rules. Establishing the illegality of financial statement fraud, and especially those misrepresentations that pertain to an organization's accounts - i.e., accounting fraud - is a challenging legal issue. Identifying the point at which creative accounting practices become fraudulent has been said to be "more art than science" (Mulford/Comiskey 2002: 42), and in the literature scholars take different stances on this point. Some scholars (e.g., Perols/Lougee 2011:40) draw the line between legal, albeit manipulative, accounting practices and fraudulent ones at the point where manipulation of financial statements becomes more aggressive and occurs outside of the boundaries set by the accounting standards established by financial industry's selfregulatory bodies. ${ }^{7}$ For other scholars (e.g., Jones 2011; Mulford/Comiskey 2002), creative accounting practices become accounting fraud only after they have proven to be so by a court of law or regulatory authority. Seeking to avoid the term fraud altogether, the accounting literature has historically divided financial statement misstatements into two categories. On the one hand, accounting errors are defined to be accidental inaccuracies. Accounting irregularities, on the other hand, are defined to be inaccuracies that are deliberate and open up the possibility of liability (Young 2006: 2-5).

\section{Characterizing the literature on financial statement fraud}

From all the different bodies of literature reviewed in this report, the one dealing with the phenomenon of accounting fraud is probably the most developed one. The literature on financial statement fraud covers a wide variety of disciplinary fields, including (corporate) law, economics, business and organization studies, accounting, financial economics, sociology, and criminology. It is also characterized by a variety of research traditions. First, descriptive studies ${ }^{8}$ provide illustrative examples and use anecdotal evidence - often obtained from journalistic work or reports issued by investigative commission and regulatory agencies - to identify recurring themes and find commonalities between different scandals. Second, sociologists, corporate law scholars, and criminolo-

$7 \quad$ The most widely used accounting standards are the Generally Accepted Accounting Principles (GAAP), which are currently used in the United States, and the International Financial Reporting Standards (IFRS), which are issued by the International Accounting Standards Board (IASB) and are used in Europe and many other countries throughout the world.

8 For broad descriptive studies on accounting fraud, I refer to Jones (2011), who analyzes 58 cases of accounting scandals in 12 countries, and Henselmann and Hofmann (2010), who analyze 44 cases of accounting fraud in the US, Europe, and Asia. 
gists have produced a large number of interpretative studies. Mostly qualitative in nature, these studies discuss and analyze market structures and corporate governance systems and the extent to which these can be criminogenic, in the sense that they structurally facilitate or promote financial statement fraud. Third, statistical studies, which are mostly found in the accounting and financial economics literature, analyze large data sets to search for aggregate evidence of fraudulent financial statements, estimate the costs and consequences of such practices, and look for fraud-risk indicators, also known as red flags - meaning, the common characteristics of firms involved in financial statement fraud. Although the variety of disciplinary fields and the diversity in research traditions makes for a heterogeneous body of literature dealing with financial statement fraud, it is possible to discern some general themes that permeate much of the literature.

Structures of competition and compensation and the proliferation of conflicts of interest

One theme that runs through much of the literature revolves around structures of competition and compensation. In explaining the occurrence of financial statement fraud, scholars have repeatedly discussed the way in which structures of competition and compensation created perverse incentives and gave rise to fundamental conflicts of interest, both of which proved to be fertile breeding grounds for financial statement fraud. The presence of conflicts of interest in financial markets is not a new phenomenon. However, much of the literature suggests that the emergence of a "new economy" (Tillman/Indergaard 2005) and the neoliberal deregulatory policies that came with it have allowed for new fundamental conflicts of interest to develop in the financial services industry. Scholars have, for example, elaborately debated the implications of new conflicts of interest that have emerged with the rise of so-called "multipurpose financial service firms"9 (Walter 2004; Bolton/Freixas/Shapiro 2007; Mehran/Stulz 2007; Dorn 2011). Of specific concern in this regard has been the development in the 1990s of a symbiotic relation between business analysts and investment banking (e.g., Swedberg 2005). More recent literature has revealed how fundamental conflicts of interest developed in the US mortgage industry during the early 2000 s as a consequence of deregulatory policies and a reconfiguration of the structures of competition and compensation in that segment of the financial services industry (Goldmann 2010; Barnett 2011; Ferguson 2012; Fligstein/Roehrkasse 2013).

Contributing to the proliferation of conflicts of interest is the use of performance-based compensation that financial firms have for their employees. Widely discussed in this respect are attempts undertaken during the 1990s to align the interests of executives and owners through stock-option-based compensation packages (Burns/Kedia 2006;

9 Multipurpose financial service firms, or "one-stop banks," are large financial conglomerates that combine a range of financial services, including insurance, commercial, and investment banking activities, under one roof. 
Benmelech/Kandel/Veronesi 2007; Friedrichs 2009; Kat/Lakeman 2010). Most of the literature concludes that these attempts have largely failed. Instead of aligning interests, performance-based compensation created perverse incentives for managers to misreport the financial performance of firms. But the problem goes beyond the level of management. Performance-based compensation penetrates all levels of employment in the financial services industry (Wawoe 2010), and the perverse incentives resulting from compensation structures for lower level employees has been said to have played a major role in a number of large "rogue trader" scandals (Krawiec 2000) as well as the financial frauds perpetrated in the US mortgage industry (Fligstein/Roehrkasse 2013).

\section{The failures of control}

A second and highly related theme concerns the failure of corporate governance and market mechanisms designed to prevent financial statement fraud. At the level of the firm, scholars have pointed to a failure of managers to supervise subordinates. Managerial failures to control are generally explained as a consequence of perverse incentive structures, under which fraudulent behavior by subordinates results in large bonuses for managers, and managers' inability to fully comprehend their subordinates' activities (Instefjord/Jackson/Perraudin 1998; Hudson 1998; Partnoy 2002). At the industry level, scholars have scrutinized the facilitating roles played by boards of directors, external auditors, attorneys, and credit rating agencies in many financial statement frauds. It is argued that these "gatekeepers" (Coffee 2002, 2004) or "reputational intermediaries" (Tillman/Indergaard 2005; Tillman 2009) failed in their tasks of certifying the soundness of financial information provided by corporate insiders to investors; instead they are said to have colluded with those they were supposed to control. An especially prominent and long-standing concern in this regard has been the lack of independence and accountability for external auditors (Coffee 2002, 2004; Young 2006; Soltani 2014). Although the wave of corporate accounting fraud related to the dot.com crash triggered a regulatory response that addressed some of the concerns raised in the academic debate following these scandals, problems surrounding auditors' independence and accountability are lingering issues in the literature (e.g., Lakeman in Kat/Lakeman 2010; Geis 2013; Economist 2014). Another lingering point of concern in the literature is the business model and lack of accountability for credit rating agencies (Johansson 2010; Maas 2011; Cane/Shamir/Jodar 2012; Lehmann 2014; Ryder 2014: 58-71).

Financial innovation and increased complexity in financial bookkeeping

A third theme that figures prominently in the literature concerns the rapid development of new financial instruments and innovative accounting techniques. Financial innovation, it is explained, not only facilitated companies in creatively, albeit legally, circumventing the regulatory net through practices of "regulatory arbitrage" (Shah 1997), it also enabled the emergence of a new generation of illegal financial statement fraud. 
Characterized by a new vigilance, this generation of fraud has been said to engage in increasingly complex, "hyperreal" (Friedrichs 2007) financing arrangements and "fancy financing" techniques (Goldmann 2010). One of these techniques concerns the use of sophisticated off-balance-sheet accounting arrangements, and the reliance on special purpose vehicles (SPVs) therein. Although generally considered a legitimate practice when used for legitimate financing purposes, off-balance-sheet accounting can become fraudulent when it is used deceptively to camouflage debt, as was the case in the Enron scandal (Giroux 2008: 1215-1217). More recent literature has described how off-balance-sheet accounting combined with the financial practice of securitization to facilitate financial statement fraud in the mortgage industry (Barnett 2013; Nesvetailova/Palan 2013; Nesvetailova/Sandu 2015). Another issue concerns the move towards mark-tomarket accounting, or fair value accounting (Benston 2006; Giroux 2008: 1213-1215; Zack 2013). Mark-to-market accounting is generally believed to be an appropriate technique when it concerns financial instruments for which a liquid market exists. However, when markets are illiquid or nonexistent, the technique becomes sensitive to manipulation and fraud (Benston/Hartgraves 2002; Giroux 2014).

\subsection{Financial statement fraud in the context of publicly listed corporations}

The accounting fraud that has been discussed most extensively in the literature is the kind that occurs in the context of publicly listed corporations. Accounting fraud in publicly listed corporations became increasingly widespread during the 1990s (Giroux 2014: 89-92). The burst of the dot.com bubble that had dominated the market for most of that decade revealed that the spectacular growth trajectories of many firms - including major publicly listed corporations such as Enron, WorldCom, Adelphia, Tyco, Xerox, Ahold, and many others - had largely relied on fraudulent accounting practices. In other cases it was revealed that fraudulent accounting techniques had been used to cover up the embezzlement of corporate funds by firms' top management. In the case of the Parmalat scandal, for example, $\$ 17.4$ billion in assets had mysteriously vanished from the company's balance sheet. The fraud was revealed after a $\$ 3.9$ billion account with Bank of America proved to be fictitious (Coffee 2005: 205-206).

Less than a decade later, the collapse of the subprime mortgage market in 2007-2008 revealed yet another wave of financial statement fraud in publicly listed corporations. Contrary to the accounting fraud that had occurred during the dot.com bubble, these more recent cases were perpetrated primarily by the management of financial firms and pertained to these firms' activities in the previously buoyant market for credit derivatives - usually structured finance products derived from subprime mortgages, an area that had long been neglected by financial regulation scholars (Dorn 2010: 9). This time, rather than acting merely as facilitators, established financial institutions, including major Wall Street investment banks and insurance companies, saw themselves being accused of misstating earnings and fraudulently hiding from investors their exposure to 
the collapsing subprime mortgage market (Goldmann 2010: 168-180; Ferguson 2012: 194-195; Rosoff/Pontell/Tillman 2014: 317-318, 357-361; Ryder 2014: 100-102). More recently, major accounting scandals have also begun to surface in the capital markets of emerging markets (Economist 2014).

\section{Prevalence, costs, and consequences}

Notwithstanding the passage of regulatory initiatives intended to curb fraudulent financial statements issued by publicly listed corporations both in Europe and the United States ${ }^{10}$ the phenomenon has not disappeared from the financial landscape. Still today, such fraudulent statements are said to occur on a regular basis and are believed to be one of the most common forms of securities fraud (Snider 2008: 48; Velikonja 2013: 1907, 1911). A recent article featured in The Economist even suggested that corporate accounting scandals occur so frequently that they have become routine (Economist 2014: 24). This view finds empirical support in the literature. Frequently cited studies conducted by the US General Accountability Office and its predecessor, the General Accounting Office (GAO 2002, 2006), for example, have indicated that in 2002 nearly 10 percent, and in 2006 nearly 16 percent of all companies listed in the United States had announced at least one restatement of their financial statements issued with the regulator. More recently, this number found resonance in the work of a group of financial economics scholars, who estimated that, in any given year, 14.5 percent of large publicly traded companies in the United States engage in financial statement fraud, resulting in a loss of almost 3 percent of total enterprise value in any given year (Dyck/Morse/ Zingales 2013).

The costs and consequences of accounting fraud in publicly listed companies have been conceived of in various ways. Initial studies on the costs and consequences of corporate accounting fraud focused on the direct adverse effects on the shareholders' wealth through share price reaction (Gerety/Lehn 1997; Palmrose/Richardson/Scholz 2004; Gande/Lewis 2009; Dyck/Morse/Zingales 2013). However, some scholars (e.g., Rose 2010: 2179-2181; Velikonja 2013) have argued that, as alarming as the estimates of the declines in shareholders' wealth yielded by such estimates might seem to be, they overstate the true losses of accounting fraud to investors. In fact, they argue, for welldiversified investors, gains and losses from secondary market securities fraud net out over time: "For every shareholder who overpaid, there is an equally innocent share-

10 In 2002, the US Congress passed the Public Company Accounting Reform and Investor Protection Act, a watershed piece of legislation. Better known as the Sarbanes-Oxley Act (SOX), the act expanded requirements for the managers and boards of directors of public companies, as well as their external auditors, to protect shareholders and the general public from fraudulent financial statements and to improve the accuracy of corporate disclosures. For a detailed discussion of the content of SOX, see Young (2006), especially chapter 3. 
holder who sold at an inflated price. Investors with diversified portfolios are as likely to be sellers as to be buyers of fraudulent stock, so, on average, investors' expected costs of fraud over time approximate zero, assuming no insider trading" (Velikonja 2013: 1901).

Other studies have emphasized that the costs and consequences of accounting fraud go beyond the direct effect on shareholders' wealth and have concentrated on the effects of accounting fraud on the real activities of the firm. These costs have been measured in terms of "reputational losses," i.e., lower sales and higher financing costs (Karpoff/Lee/ Martin 2008), costs inflicted by the disguising of poor management (Rose 2010: 2173; Kedia/Philippon 2009), enforcement costs (Velikonja 2013: 1903-1904), and legal costs to the firm (Karpoff/Lee/Martin 2008). Still other scholars have argued that the abovementioned "injured-shareholder-centric" understandings of the costs and consequences of accounting fraud miss a large part of the story (Velikonja 2013). Fraudulent financial reporting, Velikonja argues, generates significant negative externalities to non-shareholders - employees, creditors, suppliers, non-fraudulent firms, and the government that by far exceed the direct and indirect losses suffered by defrauded shareholders.

\section{Perpetrators, motivations, and opportunities}

The main figures in accounting frauds perpetrated in the context of publicly listed corporations are companies' own executive managers (CEOs and CFOs). In the literature it has been documented how corporate executives saw their opportunities for creative accounting increase drastically from the early 1990s onwards. Most importantly, financial innovations, including but not limited to off-balance-sheet accounting techniques and derivatives and the approval by regulators of the use of mark-to-market accounting techniques ${ }^{11}$, made new ways available to managers of manipulating and misrepresenting the profitability and financial health of their firms (Shah 1997; Tillman/Indergaard 2007: 477-479; MacLean 2008: 39-42; Giroux 2008: 1213-1217; Shover/Hochstetler/ Alalehto 2012: 3). Already at the end of the 1990s, one observer noted that accounting regulation could be rendered largely ineffective considering the resources that managers had at their disposal (Shah 1997).

11 "Mark-to-market" or "fair value" accounting techniques book assets not at their historical value - the original cost of the asset when acquired - but rather at their current market value, defined as the price for which an asset could be exchanged between knowledgeable, willing parties in an arm's-length transaction (Zack 2013: 117). Mark-to-market accounting has been said to grant managers significant leeway in using their own "judgment" in determining the value of assets - especially when assets are traded in illiquid or non-transparent markets and public market values do not exist - making them susceptible to manipulation and fraud (Giroux 2014: 102103; Zack 2013: 117). For a more detailed account of fair value accounting techniques and their susceptibility to manipulation and fraud, see Zack (2013: chapter 8: Fair Value Accounting). 
The involvement of senior executives in accounting scandals has typically been explained in either one of two ways. The first explanation provided in the literature stresses how ill-designed equity-based managerial compensation schemes - and especially the use of stock options therein - give dishonest corporate executives an incentive to inflate stock prices through fraudulent accounting practices, exercise their stock options, and pocket millions of dollars. Financial economists have indeed found a strong statistical correlation between equity-based compensation schemes and the incidence of accounting fraud ${ }^{12}$ (Burns/Kedia 2006; Efendi/Srivastava/Swanson 2007; Harris/Bromiley 2007; Johnson/Ryan/Tian 2009: 141). Related to this, the literature also looks at fraudulent financial statements in the form of illegally backdated stock options, a practice that was especially widespread during the 1990s and early 2000s. Other scholars (e.g., Young 2006; Dechow et al. 2011; Velikonja 2013), however, suggest that greed represents the primary motivation for accounting fraud in only a smaller subset of cases. For a much larger number of the cases, they suggest that the answer to the question why executives resort to financial statement fraud should be sought in the pressure on corporate executives to meet both internal and Wall Street's performance expectations. These pressures are believed to put fundamentally honest people under pressure to do fundamentally dishonest things (Young 2006: 5). Explanations based on performance expectations emphasize that in most cases accounting fraud is motivated by a perceived need to cover up worsening firm performance (Dechow et al. 2011: 77; Velikonja 2013: 1908). This need is especially pertinent when a bullish stock market combines with a weak economy, pressuring managers to be creative in meeting the high expectations coming from financial markets (Kat/Lakeman 2010). In support of such a reading of accounting fraud, scholars have suggested that the earnings management practices of firms commonly operate within the boundaries set by the law until the firms are faced with decreased earnings management flexibility once their economic performance slows down, which thereby prompts them to turn to illegal accounting fraud (Young 2006; Perols/ Lougee 2011; Jones 2011: 32).

Corporate executives are not the only actors involved in accounting fraud in publicly listed corporations. To a significant extent, the major cases of accounting fraud since the late 1990s have been based on fundamental conflicts of interest that had evolved within collusive networks of financial intermediaries (Tillman/Indergaard 2005; Tillman 2009; Friedrichs 2004). The investigation by journalists and academics into the Enron debacle and other corporate scandals related to the implosion of the tech bubble, as well as those conducted in the aftermath of the more recent financial crisis, all pointed to the facili-

12 It needs to be mentioned that reference to the use of stock options in executive compensation schemes is less meaningful when it comes to explaining the occurrence of accounting fraud in European companies. Compared to the American dispersed ownership regimes, Coffee (2005) points out that European concentrated ownership regimes are less vulnerable to executive accounting frauds that aim at inflating stock prices by fraudulent reporting on the income statement. European companies, however, are more vulnerable to accounting fraud in the form of asset-based misappropriations and other sorts of fraudulent reporting with regard to the balance sheet. But stock options do not play a direct role in such fraud. 


\section{Financial statement fraud by hedge fund managers}

The literature also reports on financial statement fraud perpetrated in the context of hedge funds. Most of the literature that touches upon the phenomenon of such fraud in this context looks at a number of isolated cases that have surfaced in recent years (e.g., Muhtaseb/Yang 2008; Gough 2013). Generally, this involves major fraud schemes in which fund managers had been running their funds' operational activates in a blatantly fraudulent manner. Frequently discussed examples of such cases are the Ponzi scheme run by Bernard Madoff and the collapse of the Bayou hedge fund group. Such schemes, I would argue, are best characterized as investment scams and will be discussed below. Much less attention is given in the literature to cases in which fund managers running otherwise legitimately operating funds misreport the profitability of their portfolios. However, a study by Bollen and Pool (2009) found that approximately 10 percent of returns in the database they used were distorted, suggesting that such practices are widespread.

Essentially, misreporting by hedge fund managers is similar to misreporting by executives in publicly listed corporations and revolves around issues of revenue recognition and mark-tomarket asset valuation. Like CFOs and CEOs in publicly traded companies, hedge fund managers have strong incentives to report superior performance (Bollen/Pool 2009: 2262). In fact, for hedge fund managers these incentives are even more pronounced. Standard compensation structures for hedge fund managers include incentive fees equal to 20 percent of fund profits plus a so-called management fee, which consists of a certain percentage - usually 1 or 2 - of the assets under management. Managers thus benefit from misreporting returns in two ways. It increases their incentive fees and attracts and maintains their investor base, the size of which has a direct impact on their management fees (Bollen/Pool 2012: 2674).

Financial statement fraud by hedge fund managers is greatly facilitated by the lack of regulatory oversight and the mystique surrounding these funds. Because they are not publicly traded entities, hedge funds are exempted from regulatory disclosure and reporting requirements (Shapiro 2013: 131). Moreover, hedge fund managers firmly control the flow of information to the fund's investors and ensure these flows contain only limited information. As Shapiro explains, the maintenance of information asymmetries between fund managers and investors is legitimized by the perpetual quest for "alpha returns," i.e., the attempt to beat the market. Managers "demand secrecy to protect proprietary information regarding trade secrets, trading positions, trading algorithms, risks assumed, related party transactions, and so forth" (Shapiro 2013: 134). Giving away this information would open up opportunities for free riders and render supposedly superior investment strategies less effective. This lack of transparency in hedge funds, it has been suggested, "provides a cover for managers to give false information to their investors about the value of their funds" (Gough 2013: 152).

The cost of financial statement fraud in hedge funds comes primarily in the form of oversized fees for fund managers. Bollen and Pool (2009) estimate that overpayment in the United States totaled between $\$ 1$ billion and \$2 billion between the years 1994 and 2005 .

tating, if not accessory, role played in those scandals by auditors (Coffee 2002, 2005; Geis 2013; Economist 2014; Kat/Lakeman 2010), board directors (Young 2006), investment banks and their security analysts (Sale 2004; Coffee 2002; Swedberg 2005), and lawyers (Rhode/Paton 2002; Coffee 2003). In this literature, the failure of these "gatekeepers"13 (Coffee 2002, 2005) is usually explained as a consequence of the neoliberal deregulatory policies that started to govern the markets from the 1990s onwards. This neoliberal

13 Coffee uses the term "gatekeepers" to refer to "reputational intermediaries who provide verification and certification services to investors" (Coffee 2002: 1405). 


\section{The illegal backdating of stock option grants}

Stock option grants are a form of executive compensation in which managers are granted the right to buy company shares against a fixed price, usually the market price at the time of granting the option, at a certain time in the future. For a variety of reasons, ${ }^{a}$ stock options had become a widely used instrument for executive compensation during the 1990s and early 2000s, especially in the United States. It has been estimated that there stock options had come to constitute one-half to two-thirds of CEO pay packages in the early 2000s (Dash 2008, cited in Shichor/Pontell/Geis 2011).

In the mid-2000s, it was revealed that corporate managers had long found a way to manipulate the benefits they could reap from stock option grants. Building on earlier research by corporate finance scholars, Lie (2005) found in his seminal paper that stock returns were abnormally high immediately after and abnormally low immediately before executive stock option grants. This prompted Lie to conclude that "unless executives have an informational advantage that allows them to develop superior forecasts regarding the future market movements that drive these predicted returns, the results suggest that the official grant date must have been set retroactively" (Lie 2005: 811). Corporate executives, Lie suggested, had been maximizing their gains by altering ex post, i.e., with the benefit of hindsight and after the initial terms of the stock options had been disclosed to the company's shareholders, the date of stock option grants to a point in the past at which the stock price had traded at a low price. Through such "backdating" of stock option grants, managers grant themselves the possibility to buy company stocks at a future date against a price that is significantly lower than the price established in the initial stock option grant as disclosed to shareholders. ${ }^{b}$

Subsequent research conducted by Lie (Heron/Lie 2007) suggested that almost 30 percent of US companies had used backdated options and that 13.6 percent of all options granted to top executives from 1996 to 2005 had been backdated or otherwise manipulated. Although the backdating of stock option grants is not necessarily illegal, managers might become liable to fraud claims by shareholders if the backdating is not fully and timely disclosed to shareholders, or when it does not comply with rules set out in the company charter. As subsequent research and court proceedings revealed, much of the backdating of stock options was indeed illegal.

It becomes clear from the literature that the illegal backdating of stock options might pose real costs to shareholders. One study found that, when illegal backdating was discovered and became public knowledge, the stock prices of the accused firms declined by 20 to 50 percent (Shichor/Pontell/Geis 2011: 136). Moreover, Oppenheimer (2011) points out that the practice of backdated stock options dilutes earnings per share more than would have been the case had the stock option not been manipulated. In addition, he explains that by selling its stock at a discount of market value, the firm leaves money on the table, representing an opportunity cost to the firm and its shareholders. Finally, backdating of stock options may affect the tax treatment of both the option recipient and the issuing corporation, and failure to report the backdating to tax authorities can possibly result in charges of tax fraud.

Although the regulatory stance towards stock option backdating initially was one of laissezfaire, the public outrage following the publication of a Pulitzer Prize-winning article in the Wall Street Journal (Forelle/Bandler 2006) that brought the research conducted by Lie and his colleagues to the attention of the wider public served as a wakeup call for regulatory agencies (Oppenheimer 2011: 66). Apart from triggering regulatory and legal investigations, the media attention also brought the role of external auditors and the independency of boards of directors into question. The US federal government, through the SEC and the Internal Revenue Service (IRS), responded to the episode by enacting several security and tax laws that, although not making the practice illegal by definition, were intended to make it more difficult for corporate managers to manipulate stock option dates without facing tax implications or being subjected to close scrutiny by their shareholders (Oppenheimer 2011).

a Several reasons for the popularity of stock options as a form of executive compensation are frequently mentioned in the literature (e.g., Heron/Lie/Perry 2007; Oppenheimer 2011; Shichor/Pontell/Geis 2011). First, by presumably linking managers' self-interest to the long-term development of the company's 
stock price, stock options were believed to align the interests of managers with those of shareholders. The practice was especially encouraged by institutional investors. Second, in the United States, stock options became an attractive instrument for executive compensation as a consequence of a 1993 change in the tax code that capped the deductibility of non-performance-based compensation for top management of publicly traded companies at \$1 million. As performance-based compensation, stock options were explicitly exempted from this. In addition, remunerating corporate executives with stock option does not require the company to make immediate cash outflows.

b Some other stock-option-related practices that have been lumped into the illegal backdating vocabulary are "spring loading" and "bullet dodging," in which stock options are granted just before good news and just after bad news about the company, respectively, is shared with the wider public. I believe, however, that spring loading and bullet dodging are more accurately conceived of as form of insider trading and will therefore not discuss them in this paper.

move, it has been argued, allowed fundamental conflicts of interest to develop in large multipurpose financial service firms and simultaneously reduced intermediaries' liability for fraud committed by their clients (Tillman/Indergaard 2005; Coffee 2005; Walter 2004). The problem of compromised intermediaries has been further exacerbated by an increasing involvement since the 1990s of retail investors in the stock markets. With retail investors, it has been suggested, information asymmetries are magnified and the reliance on reputational intermediaries increases (Mehran/Stulz 2007; Harrington 2012).

\section{Cases discussed in the literature}

The corporate scandals related to the burst of the dot.com bubble triggered a public outcry that resulted in a large body of scholarly and investigative literature studying the structural factors that could explain the wave of accounting scandals as well as the kind of actors involved in them (e.g., Partnoy 2002; O’Brien 2003). High profile cases discussed in this body of literature include WorldCom, Qwest, Tyco, Xerox, Parmalat, and Royal Ahold. ${ }^{14}$ The majority of this literature, however, centered on one specifically devious case, that of the American energy firm Enron (e.g., Benston/Hartgraves 2002; Thomas 2002; Coffee 2002; Swartz/Watkins 2003; Giroux 2008). Over a period of more than a decade, the firm's top management had constructed a devious web of accounting structures used to design favorable financial statements. This involved over 3,000 special purpose entities, more than 800 of which were registered in well-known off-shore jurisdictions, including 600 using the same post office in the Cayman Islands (Nesvetailova/Palan 2013). Its management also used dubious fair-value accounting valuations (Benston 2006). Ultimately, the firm's management caused investors to lose billions as the firm's stock price plummeted when the fraud was revealed. What makes the case interesting still today is that Enron's management pioneered fraudulent accounting practices that have proven to be prominent in many scandals ever since, including the use of off-balance sheet, derivatives, and fair-value maneuvering (Giroux 2014: 99-106).

14 For descriptive case-study overviews of these scandals, see Henselmann and Hofmann (2010), Kat (2010), and Jones (2011). 
Many of the fraudulent accounting practices used by Enron seem to have re-appeared in the more recent accounting scandals that were related to the boom and bust of the subprime mortgage bubble (Giroux, 208). These scandals involved, amongst others, the insurance giant AIG (Leap 2007: 63; Goldmann 2010: 190-195; Rosoff/Pontell/Tillman 2014: 317-318), the US government-sponsored enterprises Fannie Mae and Freddie Mac (Rosoff/Pontell/Tillman 2014: 315-317), the American mortgage lender New Century (Ryder 2014: 102), the investment bank Citigroup (Goldmann 2010: 172; Fligstein/ Roehrkasse 2013: 30; Ryder 2014: 100-101), and the now defunct Lehman Brothers (Goldmann 2010: 173-175; Jeffers 2011; Norton/Jones 2011: 440-445). However, with legal processes still pending, a substantial literature on these more recent episodes of accounting fraud has yet to emerge.

\subsection{Rogue traders: Accounting fraud at the proprietary trading desks of financial firms}

Another context in which corporate accounting fraud has repeatedly surfaced over past decades is at the proprietary trading desks of securities firms and investment banks. Securities traders working for these trading desks have repeatedly been found to have engaged in unauthorized purchases or sales of securities, commodities, or derivatives and to have subsequently manipulated accounts and internal control systems to make their trading activities look either more profitable or less risky than they actually were or both. Although such "rogue traders" are in no sense a new phenomenon, the 1990s witnessed a remarkable number of consecutive high-profile cases in which financial firms lost billions of dollars. The increasing availability of derivatives at that time not only enabled traders to take trading positions of a size that had previously been unheard of, it also undermined the capacity - or willingness - of senior managers to supervise traders' trading activities (Hudson 1998; Krawiec 2000; Partnoy 2002). Although arguably such traders never truly disappeared from the stage, ${ }^{15}$ a decade later, in the aftermath of the financial crisis of 2007-2008, one observer acclaimed "the return of the rogue" (Krawiec 2009).

Typically, rogue trader scandals begin with traders executing unauthorized trades that result in trading positions that exceed risk limits, loss limits, or even both limits set by the firms they work for (Krawiec 2000; Wexler 2010; Fisher 2015). Rather than unwinding their deteriorating positions and accepting losses when they find the market moving against them, rogue traders often extend their unauthorized positions in an attempt to "double down" on their losses. In doing so they accumulate risks and losses up to a point where they find themselves forced to cover up their activities through fraudulent accounting, forged documentation, and active circumvention of internal control systems. In some cases, rogue traders managed to hide their losses over extended periods

15 A look at footnote 16, listing the rogue trading cases I managed to identify in the literature, reveals that cases of rogue trading have continued to occur ever since the early 1990 s. 
of time by creatively misrepresenting their true trading activities and deceiving their colleagues. Toshide Iguchi, for example, managed to hide his losses from his employer - Daiwa Bank - for nearly eleven years (Wexler 2010: 5).

\section{Prevalence, costs, and consequences}

Rogue trading scandals have been described as "low frequency, high impact events" (Krawiec 2009). The number of detected cases of traders gone rogue is relatively few, especially when compared to the number of accounting fraud cases perpetrated by the executive management of public companies. In the literature I could identify only sixteen cases that have occurred over the last three decades. ${ }^{16}$ However, the costs and consequences of rogue-trading schemes can be enormous. A review of the literature reveals that banks victimized by rogue traders found themselves forced to readjust their financial statements, correcting for losses associated with these scandals ranging from $\$ 118$ million up to $\$ 7.2$ billion. At times, rogue trading scandals may even constitute a direct threat to the stability and existence of established financial institutions (Krawiec 2009). For example, the British investment bank Barings, which had been in business for more than 200 years, was instantly brought down when the rogue trading activities of one of its derivatives traders at the bank's Tokyo branch, Nick Leeson, were uncovered, resulting in losses of over a \$1 billion (Instefjord/Jackson/Perraudin 1998; Friedrichs 2010: 172).

\section{Perpetrators, motivations, and opportunities}

Proprietary traders have been described as "a subtype of well-reimbursed knowledge workers who interpret a vast, continuous stream of technical data to assess the uncertain futures of bonds, derivatives, commodities, and other trading products in increasingly global markets" (Wexler 2010: 3). In trying to understand what drives some of them to cross the boundaries of what is permissible, scholarly research has focused on a number of themes. One theme that is discussed in the literature concerns the "psychological picture" of traders (Laffort/Cargnello-Charles 2014). In general, these individu-

16 The cases I could identify in the literature are those of Yukihusa Fujita (1992, Show Shell Sekiyu K.K., FX trading, \$1.1 billion), Joseph Jett (1994, Kidder Peabody, US Treasury Bonds, \$74.6 million), Juan Pablo Davilla (1994, Codelco, copper, $\$ 218$ million), Nick Leeson (1995, Barings Bank, Nikkei index futures, $\$ 1.3$ billion), Toshide Iguchi (1995, Daiwa Bank, US Treasury bonds, $\mathfrak{E} 557$ million), Yasue Hamanaka (1996, Sumitomo Corporation, copper, $\$ 2.6$ billion), Peter Young (1996, Morgan Grenfell, bonds, $£ 220$ million), John Rusnak (2002, Allied Irish Bank, foreign exchange options, \$691 million), Luke Duffy et al. (2004, National Australia Bank, FX options, AUS $\$ 360$ million), Chen Jiulin (2005, China Aviation Oil, jet fuel futures, $\$ 550$ million), Brian Hunter (2006, Amaranth Auditors, natural gas, \$6.6 billion), Jerome Kerviel (2007, Société Générale, EU stock index futures, \$7.2 billion), Matthew Taylor (2007, Goldman Sachs, S\&P 500 e-mini futures, \$118 million), Boris Picano-Nacci (2008, Groupe Caisse d'Epargne, equity derivatives, $\$ 1$ billion), Kweku Adoboli (2011, UBS, ETFs $\$ 2.3$ billion), Bruno Iksil a.k.a. "the London Whale" (2012, JP Morgan, credit default swaps, $\$ 6.2$ billion). 
als are described as risk-seekers who are "motivated by the rewards, both intrinsic and extrinsic, of pushing outward into the danger zone where others do not have the skills to operate" (Wexler 2010: 4). They do not see their activities as rooted in a casino-like notion of chance but insist that they have special skills that allow them to beat the odds and stay in control in the midst of growing uncertainty, disorder, and chaos (Wexler 2010: 8-9). When things go wrong, their strong ego triggers an ego-defense, which can lead to fraud (Laffort/Cargnello-Charles 2014).

Apart from the psychological depiction of proprietary traders, another central theme in the literature concerns the working environment and incentive structures in which these actors operate. The stereotypical image of the rogue trader is that of a deviant actor, an undersocialized member of an occupational community where most members do not cross the line (Wexler 2010: 7). In the scholarly literature, however, the image of the rogue trader as a "bad apple" has repeatedly been challenged (Krawiec 2000, 2009; Wexler 2010; Laffort/Cargnello-Charles 2014). In fact, it is suggested that the securities industry induces proprietary traders to cross the line. It has been emphasized that proprietary traders are not only in charge of enormous sums of corporate funds, enabling them to make profits for the firm, they are also encouraged to use these funds to maximize their own wealth in the form of year-end bonuses (Krawiec 2000: 309). Moreover, proprietary traders are also strongly driven by a pursuit of esteem and status (Krawiec 2000; Wexler 2010). Both in terms of remuneration and status, traders are evaluated and evaluate themselves relative to their peers, especially the most successful ones. The trading floors on which proprietary traders operate have frequently been described as "superstar environments," where a disproportionate share of benefits is accrued by the superstar. These benefits not only come in the form of higher bonuses and intrinsic rewards. Perhaps equally important, a firm's management confers benefits on the superstar trader in the form of more accommodating risk and loss limits and less scrutiny in terms of oversight, giving him the added benefit of increasing the ease with which he can maintain his superstar status (Krawiec 2000: 311; Wexler 2010: 5). Traders thus feel quite invited by their employees to cross the line (Wexler 2010: 9).

A third theme that figures prominently in the literature on rogue traders concerns the lack of controls to prevent traders from perpetrating their harmful schemes (Hudson 1998; Instefjord/Jackson/Perraudin 1998). The securities industry generally explains the failure to detect rogue trading activities as a consequence of the fact that rogue traders rely on insider knowledge which allows them to draw up sophisticated cover-up schemes and cleverly bypass internal controls. Jerome Kerviel, for example, was said to have relied on his intimate knowledge of back-office operations, which he had acquired while working there, to perpetrate his scheme. The academic literature, however, rather emphasizes a culture of noncompliance that presumably prevails in many security firms. It is indeed striking to see how the literature is rife with examples of management's failures to see, or at least act upon, obvious red flags (Instefjord/Jackson/Perraudin 1998; Krawiec 2000, 2009). For example, a major warning sign ignored by Société Général was that Jerome Kerviel's earnings grew sixfold between 2006 and 2007, instantly amount- 
ing to a substantial percentage of total desk (59 percent) and division (27 percent) earnings (Krawiec 2009: 169). Another example of an often-ignored warning sign is the reluctance of traders to take vacations - presumably for fear that their fraud will be detected. In one extreme case, Toshide Iguchi of Daiwa Bank refused to take a single day off during his eleven-year tenure at the bank (Krawiec 2009: 169). Moreover, even when traders are questioned by back-office staff, the former often ward off the inquiries by maintaining that the latter simply do not understand how the transactions work (Krawiec 2009; Laffort/Cargnello-Charles 2014). The literature seems to suggest that managers refrain from questioning their star traders for two reasons. First, proprietary trading has the potential to bring enormous profits to the company, resulting in large bonuses not only for traders, but also for their superiors (Instefjord/Jackson/Perraudin 1998: 592; Krawiec 2000; Weber 2011). Nick Leeson, whose name has become almost synonymous with the term "rogue trader," would himself say that the biggest crime he was guilty of was trying to protect people and ensure that the bonuses they expected were paid (Leeson 1996). Second, because of the increasing complexity of proprietary trading activities, managers are said to not fully comprehend their subordinates' activities (Instefjord/Jackson/Perraudin 1998; Hudson 1998; Partnoy 2002).

\section{Cases discussed in the literature}

The figure of the rogue trader captured public attention especially during the 1990s. The major consecutive scandals during that era generated an almost pop culture fascination with such events (Krawiec 2000: 303). The case that has probably received most public and scholarly attention is that of Nick Leeson, a young derivatives trader working at the Tokyo desk of the British investment bank Barings who lost over a $\$ 1$ billion for the firm in an elaborate scheme that he built up over three years. ${ }^{17}$ The scandal, which ultimately led to the fall of the 230-year-old investment bank, provided the material for a great number of books and even a film. ${ }^{18}$ Leeson began his career at Barings in 1989, settling trades in the bank's back office. After being transferred to the Baring's Singapore office, Leeson was soon promoted to become a speculative trader dealing in futures contracts. From his promotion in 1992 until early 1995, Leeson reported increasingly large profits on apparently riskless arbitrage trading. The large profits he made for the bank soon granted him the status of star trader and motivated management to subject him to less stringent trading limits and less oversight. Leeson was even permitted to settle his own trades, a highly unusual and questionable combination of roles. As it later turned out, however, Leeson had started to experience losses not long after he commenced trading for the bank. Hoping that he could trade out of trouble, Leeson speculatively increased

17 The discussion of the Leeson case in this section is based on information extracted from Leeson (1996), Instefjord/Jackson/Perraudin (1998), Kane/DeTrask (1999), Krawiec (2000), Friedrichs (2010), and Fisher (2015).

18 In his 1997 book Rogue Trader, Nick Leeson provided an autobiographical account of his role in the events that eventually led to the collapse of Barings Bank. Two years after its publication, in 1999, the book was made into a major film with the same title as the book. 
his positions in futures contracts in the hope that the market would turn and revert to an upward trend. Meanwhile, he used an error account - superstitiously numbered 88888 - to conceal his deteriorating trading positions. Leeson persuaded a back office programmer to alter the Barings account system so that information about the account would not be reported to the head office in London. Investigations conducted after the scandals revealed that, on multiple occasions, management at Barings had received warnings from auditors, competitors, and SIMEX, the exchange on which Leeson was trading. However, given the large profits reported by Leeson, management choose not to act on those warnings, effectively joining Leeson in his gamble that the market would move in favor of his trading positions. Leeson was eventually sentenced to several years in prison. After his release from prison, Leeson began to make a living giving speeches in which he warned bankers of their vulnerability to rogue traders such as himself.

Other notorious cases that have been frequently discussed in the literature include the fraudulent accounting by Joseph Jett at the New York investment bank Kidder Peabody (Instefjord/Jackson/Perraudin 1998), Toshide Iguchi at the Japanese Bank Daiwa (Instefjord/Jackson/Perraudin 1998; Kane/DeTrask 1999), and Jerome Kerviel, who caused his employer Société Générale to lose $\$ 7.2$ billion, the largest recorded loss caused by a rogue trader so far (Krawiec 2009). Finally, some cases that have made the headlines more recently include, Kweku Adoboli at UBS (Fisher 2015), and Bruno Iksil of JP Morgan - also known as "the London Whale" (McConnell 2014; Zeissler/Bennett/Metrick 2014).

\subsection{Mortgage origination fraud: Financial statement fraud in the context of loan applications}

In the housing bubble that preceded the financial crisis of 2007-2008, a significant undercurrent of financial crime existed in the form of mortgage fraud (Bitner 2008; Nguyen/Pontell 2010; Patterson/Koller 2011; Barnett 2011, 2013; Fligstein/Roehrkasse 2013). Analytically the mortgage industry can be thought of as consisting of two distinct segments. In the "primary mortgage market," mortgage originators, ${ }^{19}$ with the interference of brokers, escrow agents, and appraisers, originate and provide loans to borrowers. In the "secondary mortgage market," investment banks, government-sponsored enterprises, and credit rating agencies engage in the business enterprise of securitizing and managing loans originated in the primary mortgage market (Nguyen/Pontell 2010: 597; Collins/Nigro 2010: 634). As will be revealed below, fraud has been rampant in both segments of the mortgage industry.

19 Mortgage originators may be mortgage companies, S\&L banks, commercial banks, or other retail lenders (Fligstein/Roehrkasse 2013: 22). 
In the literature, fraudulent behavior in the primary mortgage market is generally discussed under the heading of mortgage fraud, (e.g., Carswell/Bachtel 2009; Barnett 2011, 2013; Baumer/Arnio/Wolff 2013) or mortgage origination fraud (e.g., Collins/Nigro 2010; Nguyen/Pontell 2010). Mortgage origination fraud has been defined as "the material misstatement, misrepresentation, or omission by an applicant or other interested parties, relied upon by an underwriter or lender to fund, purchase or insure a loan" (FBI, 2007, cited in Nguyen/Pontell 2010: 592). Mortgage fraud consists of a great variety of behavior ${ }^{20}$ (Smith 2010: 473; Carswell/Bachtel 2009). A common thread running through all such behavior is that the purpose is to induce a lending institution to make a loan it would have otherwise refused (Gans 2011: 146). Following government authorities and industry organizations, researchers usually group these different types of behavior under two broad categories: ${ }^{21}$ fraud for housing and fraud for profit (Carswell/ Bachtel 2009: 349; Nguyen/Pontell 2010: 595; Barnett 2013: 111; Baumer/Arnio/Wolff 2013: 303; Fligstein/Roehrkasse 2013: 23).

Fraud-for-housing schemes are relatively straightforward. They involve loan applicants who make minor misrepresentations, usually on a single loan, about their financial health and future prospects; in other words, they overstate income, misreport their employment status, or conceal outstanding liabilities. This is done in the hope that a lender will fund the loan or will provide a better rate on a loan for a property of primary residence. Ultimately, however, the borrower intends to repay the loan. Fraud-for-profit schemes are often more complex. They typically involve multiple loans and elaborate schemes designed to gain illicit proceeds from property sales and real estate transactions. They are usually perpetrated by a variety of cooperating parties, which may include mortgage brokers, home appraisers, and so-called "straw borrowers," who make gross misrepresentations concerning appraisals, loan documents, and even the identity of the borrower. Of the two, fraud-for-profit schemes are of greater concern to law enforcement and the mortgage industry (Nguyen/Pontell 2010: 595). Table 1, adopted from Carswell and Bachtel (2009), lists some common fraud-for-profit schemes. ${ }^{22}$

Mortgage origination fraud is believed to have been a major contributor to the collapse of the subprime mortgage market in the United States and the subsequent global financial crisis of 2007-2008 (Nguyen/Pontell 2010; Baumer/Arnio/Wolff 2013; Ryder 2014).

20 These schemes include but are not limited to making financial misrepresentations, forging loan documentation, obtaining loans through "straw buyers," inflation of appraisals, and "flipping." For a description of the different schemes, see Carswell and Bachtel (2009).

21 Another type of fraudulent behavior involved in the mortgage origination process is predatory lending. Although it is related to mortgage fraud, in the literature, predatory lending is often treated as analytically distinct from mortgage origination fraud. Accordingly, and following the conceptual approach adopted here, I will treat predatory lending as a form of fraudulent misselling.

22 In the context of this paper, it is important to point out that some fraud-for-profit schemes could also be grouped under the category of investment scams. This is especially the case for schemes that involve straw borrowers and those in which perpetrators assume someone else's identity through identity theft. 
Table 1 Common fraud-for-profit schemes (adopted from Carswell/Bachtel 2009)

\begin{tabular}{ll}
\hline Fraud offenses & Description \\
\hline Illegal flipping & Seller inflates the value of the property using an illegitimate appraisal. Once the \\
mortgage is delivered, the home is then sold with the mortgage taken over by \\
another buyer, who unwittingly believes that the house is of higher quality than \\
it truly is. Ultimately, the buyer is left to repay a high mortgage on a property \\
whose mortgage value exceeds the market value, a situation which usually \\
results in default.
\end{tabular}

Real estate title fraud Through identity theft, a mortgage fraud perpetrator is able to secure a mortgage loan using an assumed identity and presumably an untarnished credit file and history.

Straw buyer Similar to the title fraud offense, a straw buyer is someone who has knowingly given credit information to an interested party for a fee, usually totaling several thousand dollars. Months after the mortgage fraud has been committed, the straw buyer is left with the outstanding mortgage, much to his or her surprise.

Silent second mortgages Buyer of the property borrows the down payment through an undisclosed second mortgage (usually through the seller). If the second mortgage is not recorded, this can allow the seller to inflate the actual value of the house, beyond its market value.

Foreclosure rescue/ equity skimming

This situation occurs when a financially-strapped homeowner is urged to sign over the deed of the property to a "specialist" who can help sell the house quickly, sometimes with an up-front fee involved. The rescue buyer may collect rents on the property without making any mortgage payments. This forces the lender to foreclose on the property, holding the original owner and mortgage holder liable in the process

Air loans

The property in question is either misrepresented, does not exist, or is not what the loan says it is. The dishonest broker fabricates borrowers and properties, creates accounts for payments, and maintains custodial accounts for escrows.

Double sales scam

This form of fraud occurs in areas where the recording of the transactions takes several weeks to several months. In essence, the owner of the house (who may operate under the guise of a shell company) takes advantage of this delay in deed recording to sell the home more than once. When the ruse is uncovered, actual title to the property becomes cloudy as a result.

a The original table in Carswel and Bachtel (2009) states: "Ultimately, the buyer is left to repay a high mortgage on a property whose market value exceeds the mortgage value, a situation which usually results in default." In my understanding, this should be: "Ultimately, the buyer is left to repay a high mortgage on a property whose mortgage value exceeds the market value, a situation which usually results in default." The lender then ends up with a nonperforming loan on its books.

Investigations into the causes of these events revealed that fraud was rampant throughout the entire industry, especially the subprime sector, during the pre-crisis boom in the US housing market. In fact, the FBI had already identified the threat to the financial system posed by increasing levels of mortgage origination fraud in 2004 (Ryder 2014: 53). However, since the Bush administration had prioritized the tackling of terrorism over that of white-collar crime, both the agency and the Department of Justice lacked the resources to respond because all resources were being devoted to the war on terror (Ryder 2014: 89-95). Although these priorities were reversed after the collapse of the subprime mortgage market in 2007 and the start of the Obama administration in January 2009 (Ryder 2014: 94), rates of mortgage fraud have not really declined. Perpetrators have simply adapted to the changed market conditions by developing new schemes and modifying older ones. In fact, it has been suggested that "the distress in the US housing sales market has proven to be fertile ground for mortgage fraud" (Smith 2010: 
473-474). Also, since the collapse of the subprime mortgage market, the locus of many fraud-for-profit schemes has moved from subprime loans to prime loans (Smith 2010: 474). As a result, even in the post-crisis period, mortgage fraud has been said to be "the number one white collar crime in the United States" (Smith 2010: 473).

\section{Prevalence, costs, and consequences}

There is wide agreement in the literature that the period from the late 1990s until today has witnessed an explosion of mortgage fraud, especially in the United States ${ }^{23}$ (e.g., Smith 2010; Ryder 2014). The most frequently used indicator for the prevalence of mortgage (origination) fraud in the United States is the number of mortgage-related Suspicious Activity Reports (SARs) filed with the US Treasury Department's Federal Financial Crimes Enforcement Network (FinCEN). ${ }^{24}$ In a 2006 report, FinCEN reported that this number has increased by approximately 1,400 percent over the period between 1997 and 2006 (FinCEN 2006, cited in Nguyen/Pontell 2010: 593; Patterson/ Koller 2011: 32). This number has continued to rise since the collapse of the subprime mortgage market. In 2011, FinCEN received 92,028 SARs, up from 37,313 for the period 2006-2007 (Ryder 2014: 55-56). The continuing pervasiveness of mortgage origination frauds also becomes clear if one considers law enforcement actions. Already in 2006, the FBI warned that mortgage fraud was "pervasive and growing" (FBI 2006, cited in Barnett 2013: 110). The subsequent years witnessed a 400-percent increase in the number of mortgage fraud-related investigations undertaken by the FBI (Ryder 2014: 57). In 2008, the FBI reported that it was investigating 14 corporations as part of its Subprime Mortgage Industry Fraud Initiative (Nguyen/Pontell 2010: 592). In that same year, "Operation Malicious Mortgage," a multi-agency enforcement action, identified more than 400 defendants associated with $\$ 1$ billion in losses. Two years later, the Financial Fraud Enforcement Task Force completed its enforcement action called "Operation Stolen Dreams," which involved 1,517 criminal arrests, resulting in 525 indictments that represented estimated losses of over $\$ 3$ billion (Barak 2012: 14).

23 Because of its centrality to the recent financial crisis, the vast majority of the literature on mortgage fraud is concerned with the US mortgage market. Nevertheless, mortgage fraud is a problem that is not unique to the United States. It has been said to be a serious criminal threat in countries such as the United Kingdom (Ryder 2014: 57-58) and the Netherlands (Van Gestel 2010) as well.

24 It needs to be emphasized that SAR filings do not reveal the full extent of mortgage fraud. Not only does much fraud go undetected or unreported, institutions that are not federally insured, such as independent mortgage lenders and mortgage brokers, are not required to file SARs (Smith 2010: 480, Gans 2011: 149). Nevertheless, it is believed that mortgage-related SAR data provide a useful source for examining trends and patterns in suspected mortgage fraud (Gans 2011: 148). 
Estimates of the monetary costs of mortgage origination fraud fall within a wide range and are difficult to compare. For example, while the US Mortgage Bankers Association has estimated that fraud cost the mortgage industry between $\$ 946$ million and $\$ 4.2$ billion in 2006 (Mortgage Bankers Association 2007, cited in Nguyen/Pontell 2010: 593), the Mortgage Asset Research Institute estimated 2008 losses at between \$15 and \$25 billion. However, even though it is difficult, if not impossible to determine the exact monetary cost of mortgage origination fraud (Ryder 2014: 54), the literature identifies at least three groups of actors for whom mortgage (origination) fraud has serious economic consequences. First, mortgage origination fraud results in direct losses to lenders and investors through higher default rates on loan portfolios (Nguyen/Pontell 2010). For example, Piskorski et al. (2013) found that loans with a misrepresented borrower occupancy status or misreported second lien have a significantly higher likelihood to default when compared with otherwise similar loans. Because these higher risks are hidden, the authors emphasize, they are not compensated for in terms of higher yields. Second, mortgage fraud poses adverse economic consequences for tax payers (Gans 2011). Through securitization and derivatives trades, the hidden risks associated with mortgage origination fraud are spread throughout the financial system. Ultimately, these systemic risks are borne by taxpayers who pay for bailouts. Third, mortgage (origination) fraud has significant consequences for homeowners and communities (Nguyen/Pontell 2011; Piskorski/Seru/Witkin 2013; Baumer/Arnio/Wolff 2013). High levels of mortgage fraud in a given geographical area have been found to be a significant predictor of foreclosures in that area as well as in bordering areas ${ }^{25}$ (Baumer/Arnio/Wolff 2013). In this process, minority and elderly populations are said to have been disproportionally impacted (Wright 2008; Nguyen/Pontell 2011).

\section{Perpetrators, motivations, and opportunities}

The primary perpetrators of mortgage origination fraud can be divided into two groups. First, loan applicants themselves are often involved. According to a 2008 analysis by FinCEN, about 60 percent of all reported mortgage fraud involved the willing participation of borrowers (FinCEN 2008, discussed in Gans 2011: 148). However, it is important here to distinguish between fraud-for-housing and fraud-for-profit schemes. In the case of the former, the involvement of loan applicants is obvious. In order to secure a loan, genuine applicants misrepresent their financial health or employment status. In fraud-for-profit schemes the situation is different. These schemes often involve "straw borrowers" - persons who have knowingly conveyed their identity and credit information to other perpetrators of the scheme for a fee, usually totaling several thousand dollars - or perpetrators who, through identity theft, assume someone else's identity and untarnished credit file and history (Carswell/Bachtel 2009: 350).

25 Especially high levels of fraud-for-profit schemes appear to be a consequential predictor of subsequent foreclosure rates in a given geographical area (Baumer/Arnio/Wolff 2013: 315). 
The second group of primary perpetrators are mortgage industry intermediaries. According to the FBI, 80 percent of all reported mortgage fraud losses involve collaboration or collusion by industry insiders (FBI, 2007, cited in Smith, 2010: 479). This includes corrupt mortgage brokers, real estate appraisers, escrow agents, title officers, builders, and land developers (Collins/Nigro 2010; Nguyen/Pontell 2010; Smith 2010; Gans 2011). Especially mortgage brokers, who assume a crucial position in the overall mortgage origination process (Nguyen/Pontell 2010: 597), are said to play a major role in mortgage origination fraud (Nguyen/Pontell 2010; Gans 2011). With almost no standards in place for licensing and oversight up until the crisis, the mortgage brokerage industry attracted a large number of "less-than-reputable characters," including many individuals with serious criminal records (Gans 2011: 149-150). In the crime facilitative environment that constituted the mortgage industry (Smith 2010; Gans 2011), mortgage brokers widely engaged in mortgage origination fraud both as facilitative intermediaries - by intentionally refraining from verifying information submitted on borrowers' fraudulent loan applications - and as coordinating parties in far more devious fraud-for-profit schemes - by realizing fraudulent real estate transactions and then absconding with fraudulent fees and inflated loans.

To understand the massive involvement of mortgage brokers and other unscrupulous individuals in mortgage fraud, scholars have generally pointed out that mortgage fraud schemes constitute a "low-risk and high-return activity" (Gans 2011: 150). Especially prior to the collapse of the US housing market, there was much to gain and little to lose for those involved in mortgage fraud. Before it collapsed in 2006, the mortgage industry, and especially the subprime part of it, represented an enormous and growing industry, ${ }^{26}$ making it a tempting target for fraudsters. At the same time, perpetrators had little to fear, neither from law enforcement agencies - sentences were light and the chance of getting caught was low ${ }^{27}$ (Smith 2010: 475) - nor from the lending institutions that they seemingly victimized with their devious schemes. In fact, as will be discussed below, these lending institutions facilitated mortgage fraud very much.

Despite the fact that the primary perpetrators of mortgage origination fraud were located outside of the financial industry, the financial industry itself has been highly complicit in the proliferation of this fraud. In the literature it is emphasized that the fraudulent character of loan applications was not unknown either to the lending institutions who originated the loans or to the Wall Street institutions that bought these loans and securitized them into tradable securities. In his book Confessions of a Subprime Lender, Richard Bitner, a former president of the subprime mortgage lender Kellner Mortgage

26 According to Barnett (2013: 108), the subprime mortgage market grew by 324 percent from $\$ 190$ billion in 2001 to $\$ 615$ billion in 2006 .

27 It has been suggested by several observers that one important explanation for the low levels of law enforcement is that, despite warnings by the FBI that mortgage fraud was endemic and that a major crisis was pending, the Bush administration decided to focus attention on the War on Terror. As a consequence, the FBI saw the staffing of its white-collar crime unit reduced by 36 percent in 2001 (Ferguson 2012: 59). 
Investments, states that he was well aware of the fraudulent nature of loan applications coming from mortgage brokers. At some point, he says, 70 percent of submissions from brokers to the company were deceptive, half of the property values related to loans were over-edged by up to 10 percent, a quarter had property prices exaggerated by 11 to 20 percent, and the rest were "so overvalued, they defied all logic" (Bitner 2008: 97).

An obvious question that arises, then, is why the mortgage lending institutions did not detect and act upon these misrepresentations? In the literature, the reluctance by mortgage lenders to report and act upon fraudulent behavior in the mortgage origination process has generally been explained as a function of the structure of competition and compensation in the mortgage industry (e.g., Smith 2010; Barnett 2011; Patterson/Koller 2011; Fligstein/Roehrkasse 2013). Under a so-called "originate to distribute" (OTD) model, lending institutions passed most of the risks associated with the mortgages they originated along to securitizers, who in turn passed the risks on to bullish and often naïve investors. Under the OTD model, originators generated their revenues from fees rather than returns on investment. Hence, lending institutions were principally concerned with volume, rather than quality: "firms were driven to originate, service, and securitize as many loans as possible, but did not have a direct financial interest in whether or not they were well documented or likely to be repaid. This led them to contract predatory and foolhardy loans, to document them poorly or falsely, and to mislead investors about these facts" (Fligstein/Roehrkasse 2013: 18). Moreover, the structure of individual incentives in the mortgage industry mirrored the motivations of firms to deal deceptively in high quantities of low-quality debt. For mortgage brokers and loan officers, compensation was generally tied to the volume, rather than quality, of mortgages that were originated (Fligstein/Roehrkasse 2013).

\section{Cases discussed in the literature}

Detailed case studies of mortgage fraud are hard to come by. In what is an exception in this regard, Barnett $(2011,2013)$ describes the case of an elderly African-American couple who were victimized in a fraud-for-profit scheme. Henderson Hall and Mary Hawthorne had purchased a home in the North Lawndale neighborhood of Chicago in 1993. After Mr. Hall left his job for medical reasons, the couple lived on social security and disability payments. They fell behind on their mortgage payments and were threatened with foreclosure. A solicitation from Unity Management and Development Corporation (hereafter Unity) seemed to offer a way out. Unity promised to "stall" the foreclosure proceedings, buy and hold the property, and lease it back to the couple. In addition, Unity promised to improve their credit score so they could be refinanced back into their home after 12 to 18 months. Under the mistaken belief that this was some form of refinancing, Hall and Hawthorne signed several papers, including a contract to sell the property for $\$ 235,000$, a sale-leaseback contract, as well as a promissory (mortgage) note for $\$ 100,000$, of which the couple was not aware and the sum of which they never received from Unity. What in fact happened was that the property was sold to 
Charlotte Delaney, Unity's office manager. Delaney had financed the purchase with nomoney-down, stated income loans from the larger subprime lender Mortgage Investment Lending Association (MILA) totaling \$235,000. In the loan application, Delany misrepresented herself as owner-occupant rather than as an investor. Moreover, the details of the case reveal that at MILA the loan file was altered in order to have the Delaney loan approved. Delaney used the loans to pay off Hall and Hawthorne's mortgage, but in what amounted to an equity skimming scheme, the roughly $\$ 82,000$ of equity the couple had in the home was kept by various participants in the scheme. The final settlement disclosure statement lists not only Hall and Hawthorne's actual mortgage, but also a fictional $\$ 70,472.54$ mortgage lien to be paid off at closing. As Barnett points out, it is evident that this phantom lien was entered to help account for the $\$ 82,000$ in equity stolen from Hall and Hawthorne. Delany never made any payments on the mortgage and after a few months the property was in foreclosure. The case not only reveals the modus operandi of the fraudsters, but also the fraudulent failure of MILA loan officers to spot and act upon the fraud. According to Barnett, even "a cursory examination of the Delaney file by a knowledgeable underwriter would have revealed the fraudulent nature of the loan and the transaction" (Barnett 2013: 113).

\subsection{Mortgage securitization fraud: Financial statement fraud in the context of structured finance investments}

A review of the literature reveals that the mortgage origination fraud discussed in the previous section was only the beginning of a chain of lies that ran through the entire mortgage industry (see Figure 1). In the secondary mortgage market, investment banks, acting as underwriters for securities issued by structured investment vehicles, have been accused of making false statements to investors and other market participants about the quality and character of those securities (Goldmann 2010: 168-171; Ferguson 2012: 191-192; Barnett 2013; Fligstein/Roehrkasse 2013: 27; Ryder 2014: 95-103; Piskorski/ Seru/Witkin 2015). Structured investment vehicles are contractual entities that pool portfolios of loans - residential mortgages, student loans, car loans, etc. - and then issue bond-like securities for which the principal and interests paid on those portfolios of loans serve as collateral. The process of issuing these structured finance products - primarily residential mortgage-backed securities (RMBSs), asset-backed securities (ABSs) and collateralized debt obligations (CDOs) - usually involves, besides the issuer, the service of an underwriter. ${ }^{28}$ The job of the underwriter, most often an investment bank, is to raise capital from investors who are willing to invest in the security issued by the structured investment vehicle (Fligstein/Roehrkasse 2013: 27). It has been found

28 In fact, the roles of issuer and underwriter are often fulfilled by the same party (Fligstein/Roehrkasse 2013: 27). The Structured Investment Vehicle that issues the security is often owned by the firm - usually an investment bank - that does the underwriting. 
Figure 1 Chain of lies in the mortgage industry

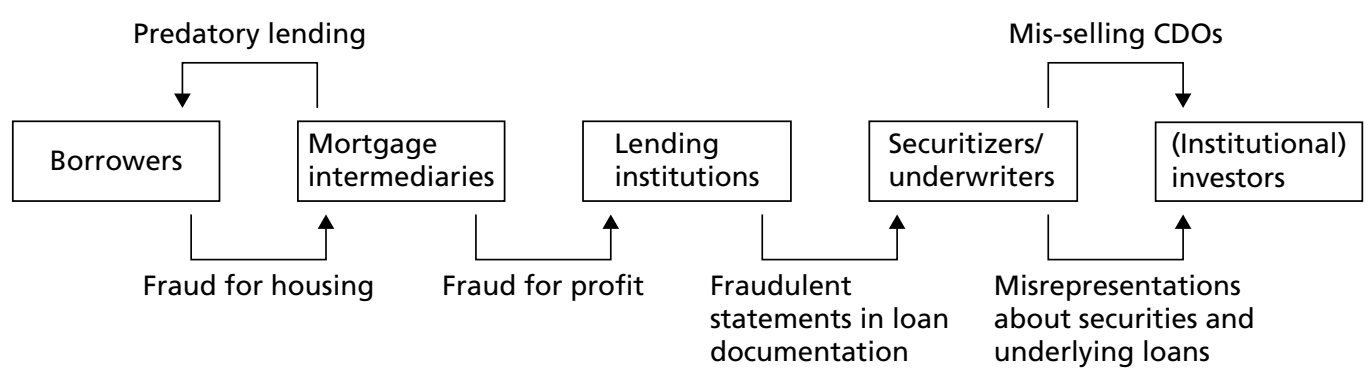

that, during the pre-crisis boom, many underwriters misrepresented the characteristics of these securities and the quality of the loans underlying them to investors and sellers of insurance on those securities - issuers of so-called credit default swaps (CDSs).

These misrepresentations occurred in at least two distinct ways (Fligstein/Roehrkasse 2013: 27-28). First, underwriters either intentionally misrepresented or failed to perform sufficient due diligence on the loans they received from mortgage originators. As a consequence, the prospectuses of RMBSs, ABSs, and CDOs included misrepresentations about the quality of the loans in the portfolios that provide collateral for these securities - e.g., fraudulent property appraisals, misrepresented loan-to-value ratios, misstatements about the sort of loans underlying the security, and misrepresentations about the delinquency status of the loans in the portfolio - or misrepresentations about the credit rating on them. Second, underwriters did not explicitly misrepresent but nevertheless marketized and sold to investors investments they knew to be poor ones. Although empirically these two forms of misrepresentation often occurred in concordance, the latter form of fraud is discussed below under fraudulent financial mis-selling.

\section{Prevalence, costs, and consequences}

Financial statement fraud in the context of structured finance investments are believed to have been especially widespread in the United States, the epicenter of the subprime mortgage boom. According to one observer, "almost all the prospectuses and sales material on mortgage-backed bonds sold from 2005 through 2007 were a compound of falsehoods" in the United States (Ferguson 2012: 191). Recent legal developments seem to support such allegations. It has been reported that the top ten underwriting firms, which together represented 74.1 percent of the market share, have all been implicated in securities fraud cases. Eight of them have settled with regulators or investors over underwriting-related fraud allegations (Fligstein/Roehrkasse 2013: 28). However, given the complexity of structured investments traded both domestically and globally, precise estimates of the prevalence of financial statement fraud in the underwriting of structured finance products are hard to come by (Patterson/Koller 2011: 26). Nevertheless, a rare attempt to quantify the prevalence of fraud in the securitization process indeed 
suggests that misrepresentations in the underwriting of RMBSs, ABSs, and CDOs were widespread. In their study, Piskorski et al. (2013) found that about one out of every ten loans in their dataset involved some sort of misrepresentation. ${ }^{29}$ Moreover, these misrepresentations existed across all underwriters involved in the sale of mortgages. However, as the authors of the study emphasize, these results are complicated by the fact that it is difficult to determine where exactly in the supply chain of credit - be it at the level of the borrower, the lender, or the underwriter - the misrepresentation took place (Piskorski/Seru/Witkin 2013: 32). Theoretically at least, it is possible that underwriters were unable to detect misrepresentations that had occurred at the level of the loan origination process, despite their genuine efforts to perform due diligence.

The ultimate victims of the fraudulent misrepresentations by underwriters were unsuspecting investors in structured finance products and counterparties - midsized European banks, public pension funds, and hedge funds - who bought the ABSs and CDOs (Ferguson 2012: 92; Nesvetailova/Sandu 2015: 39). Although in their defense banks have maintained the opposite, in the literature it is generally assumed that these buyers were not as "sophisticated" as the investment banks who sold these products, giving the latter an informational advantage in the transaction (Piskorski/Seru/Witkin 2013:2). In their earlier mentioned study, Piskorski et al. found that misrepresentations by underwriters had significant economic consequences for these investors. The delinquencies of misrepresented loans were 60 to 70 percent higher than the delinquency rate of otherwise similar loans, potentially impacting MBSs with a combined outstanding balance of up to $\$ 160$ billion (Piskorski/Seru/Witkin 2013: 5). Moreover, it has also been noted that poor underwriting standards and practices in the mortgage securitization industry have been major contributors to fraud in the mortgage origination process, which will be discussed below (Nguyen/Pontell 2011).

\section{Perpetrators, motivations, and opportunities}

The primary perpetrators of mortgage securitization fraud were, of course, the broker-dealers who worked for the investment banks and brokerage firms that underwrite, marketize, and sell these complex investment products to institutional investors. As underwriters, investment banks have a legal obligation to perform due diligence on the loans they receive from originators before selling them on to investor. In fact, the prospectus of a structured finance security such as a RMBS or CDO typically assures investors that the underwriting firm would conduct a review of the seller of the loans - its credit risk, its senior-level management, its mortgage loan origination processes,

29 Piskorski et al. (2013) use two measures of misrepresentation, the first being misreported occupancy status of the borrower and the second being misreported second liens. Because the study uses only two out of a wide variety of possible measures of misrepresentation, it is important to note that the findings are likely to constitute a conservative, lower-bound estimate of the fraction of misrepresented loans (Piskorski et al. 2013: 3). 
historical loan level loss experiences, etc. - prior to acquiring the loans (Barnett 2011: 79). As we now know, they often failed to do so. ${ }^{30}$ In the literature, the failure of investment bankers to perform due diligence in fraudulent underwriting has generally been explained - similar to the involvement of mortgage brokers and originators - as a result of the structure of competition and compensation under the OTD model. Investment banks were enmeshed in a competitive race for new mortgages to securitize and sell. In this race, the legal obligation to perform due diligence appears to have become no more than an afterthought (Barnett 2011: 81). The compensation structure for the individual dealers who engineered and marketed these products mirrored their firms' motivations to deal deceptively in low-quality debt and emphasize quantity over quality (Barnett 2011; Fligstein/Roehrkasse 2013). Moreover, civil lawsuits have already provided evidence that at least in some cases the executive management of banks had knowledge of or were directly involved in securitization frauds (Ferguson 2012: 193).

Notwithstanding the fact that legal liability for misrepresentations in the context of structured finance investments rests primarily with the banks that securitized and underwrote these products, actors from outside the banks have been involved in these schemes as well. Ever since the contours of the mechanisms that caused the financial crisis began to emerge, observers have especially pointed to the role played by the credit rating agencies (CRAs) in mortgage securitization frauds (Bussani 2010; Dorn 2011; Maas 2011; Barak 2012; Ferguson 2012: 106-108; Taibbi 2013; Ryder 2014: 58-71). In February 2013, the US Department of Justice filed civil charges against Standard \& Poor's (S\&P) for allegedly engaging in a scheme to defraud investors in RMBSs and CDOs. ${ }^{31}$ Civil fraud claims against the CRAs have also been filed by private litigants. In general, most of these claims allege that the agencies fraudulently inflated their ratings of structured finance investment products, and that the CRAs lied to investors about their independence and objectivity in the construction of those ratings. ${ }^{32}$ Despite the fact that

30 Exemplary of the failure to meet this obligation by many underwriters is a case discussed by Barnett (2011) in which the investment bank Goldman Sachs failed to provide documentation to establish that it had performed the due diligence that it promised in its prospectus, after being subpoenaed to provide such evidence.

31 The charges, which are seeking $\$ 5$ billion in losses, allege that "by knowingly issuing inflated credit ratings for CDOs - which misrepresented their creditworthiness and understated their risks - S\&P misled investors. ... In addition, [the DoJ alleges] that S\&P falsely claimed that its ratings were independent, objective, and not influenced by the company's relationship with the issuer who hired S\&P to rate the securities in question - when, in reality, the ratings were affected by significant conflicts of interest, and S\&P was driven by its desire to increase its profits and market share to favor the interests of issuers over investors" (US Department of Justice, cited in Ryder 2014: 69).

32 Incriminating evidence of CRAs fraudulently inflating their ratings has been presented in civil lawsuits in the United States. In a June 2013 article in Rolling Stone Magazine, reporter Matt Taibbi exposed how executives and analysts at the CRAs have been caught admitting their business model was crooked: "'Lord help our fucking scam ... this has to be the stupidest place I have worked at' writes one Standard \& Poors executive. ... 'Lets hope we are all wealthy and retired by the time this house of cards falters,' ruminates one more” (Taibbi 2013). 
the CRAs have generally responded to such accusations by stating that, at all times, their ratings reflected their current best judgement about the RMBSs and CDOs in question, it is interesting to note that they continue to settle such claims (Ryder 2014: 71).

The academic literature on the involvement of CRAs in securitization fraud is primarily concerned with the absence of proper accountability, both civil and criminal, for the CRAs (Bussani 2010; Johansson 2010; Maas 2011; Cane/Shamir/Jodar 2012; Lehmann 2014). CRAs have generally equated their ratings to mere opinions and recalled the right of free speech, making them immune from civil liability. In order for plaintiffs to successfully sue a CRA, they would have to prove that it did not trust or accept its own ratings at the time these were provided (Ryder 2014: 71; Bussani 2010: 6; Maas 2011: 1015; Cane/Shamir/Jodar 2012: 1102-1111). The necessity of proving intent is also said to be the most significant barrier to a criminal conviction of the CRAs (Maas 2011). Although the legal and regulatory framework in both the United States and European Union has been reviewed in the post-crisis period, these changes have been said to be insufficient, and there seems to be at least a certain level of agreement that an improved liability regime for the CRAs is highly desirable.

\section{Cases discussed in the literature}

As the fraudulent underwriting practices of major securities firms and investment banks have come to light in the wake of the financial crisis of 2007-2008, lawsuits have resulted involving virtually all major underwriters in the subprime mortgage industry (Fligstein/Roehrkasse 2013: 28-30). Cases that have been mentioned in the literature include Credit Suisse (Fligstein/Roehrkasse 2013: 28), Deutsche Bank (Fligstein/Roehrkasse 2013: 28), Bank of America (Fligstein/Roehrkasse 2013: 29), JP Morgan: (Fligstein/Roehrkasse 2013: 30; Ryder 2014: 98), Mizuho Financial Group (Ryder 2014: 100), and Citigroup (Fligstein/Roehrkasse 2013: 29-30; Ryder 2014: 99). However, scholarly studies providing more in-depth analyses of these cases have not yet appeared.

\section{Financial scams, cons, and swindles}

Financial scams, cons, and swindles are deceptive and fully fraudulent schemes in which fraudsters, often assuming a false identity or exhibiting a misplaced aura of trustworthiness, convince, mislead, or induce people to voluntarily interact with the fraudster and, ultimately, to willingly hand over money or sensitive information related to their personal finances. Financial scams are different from financial statement frauds in that, unlike the latter, they are designed from the beginning as con games or larceny schemes ${ }^{33}$

33 In reality, the distinction between fundamentally legitimate business ventures and outright scams is often difficult to make. Businesses have been said to range along a continuum extend- 
(Shapiro 1984: 21-22). Financial scams are also different from fraudulent mis-selling practices in that they go beyond misleading and suggestive communications. Financial scams are built on blatant lies and completely fabricated facts.

\subsection{General characteristics}

\section{The modus operandi of financial scams}

Two major groups of financial scams are discussed in the literature. One group of scams is designed in a way that allows for the scam artist to directly fleece investors of their money by inducing them to invest in a sham enterprise, be it a company, an investment fund, a real estate project, or an insurance policy. The second group of financial scams involves an intermediating step. Initially, the operator of the scam induces the victim to reveal to the operator of the scam information about that person's or company's financial identity, such as credit card and account numbers, security codes, passwords. Subsequently, the operators of the scam use the obtained information to fleece investors of their money. Here I will use the term investment scams to refer to the first group of financial scams and the term financial identity scams for the latter.

Both forms of financial scams typically proceed according to a well-delineated pattern (Langenderfer/Shimp 2001). First, the potential victims - the "marks" - must be approached and their interest piqued. The perpetrators of financial scams - the "operators" - may do this in a variety of ways. In some cases, operators work with lists that contain telephone numbers or e-mail addresses of individuals, usually people with high disposable incomes or individuals who have been successfully defrauded before ${ }^{34}$ (Policastro/Payne 2014; Shover/Coffey/Sanders 2004: 64). Such "lead lists" or "mooch lists" can be easily purchased on the internet for a relatively small price. In other cases, scam artists take advantage of affinities and social networks, which quickly generate interest in the scam by word of mouth ${ }^{35}$ (Baker/Faulkner 2003; Nash/Bouchard/Malm 2013). The mark's attention may be caught by offering high returns at low risks or by threatening that the mark's bank account will be shut off if the mark does not cooperate. Affinity relationships between the scammers and their victims may also play an important role in the second step, in which operators try to garner trust. Besides appealing to affinity relationships, scam artists may also hijack trusted brand names and misrepresent themselves as being representatives of legitimate companies. Finally, the marks must be

ing from wholly legal and ethical on one end to the blatantly criminal and unscrupulous at the other, with a good many enterprises falling somewhere in between (Naylor 2007: 89; Friedrichs 2010: 202).

34 Financial scams that establish contact with their marks in this manner are often referred to as "telemarketing frauds" (e.g., Shover/Coffey/Sanders 2004; Policastro/Payne 2014).

35 Scholars often use the term "affinity frauds" to describe financial scams relying on this method (e.g., Blois 2013; Perri/Brody 2012). 
enticed to participate, that is, to either part with their money or to reveal identifying information. To undercut the marks' perceived need for due diligence, operators appeal to trust and visceral triggers (Perri/Brody 2012; Button et al. 2014). They may, for example, appeal to the marks' greed or distressed financial situation by promising high returns and stressing the need to make the decision urgently.

Financial scams do not simply victimize their targets by exploiting existing information asymmetries that could impossibly have been bridged by the victims. In most cases, vigilant investors or cautious marks could have easily known or found out that the opportunity or invitation was a scam (Pressman 1998). Therefore, the skill of the con artist lies in the ability to induce the mark to make a leap of faith. It is this aspect that makes a financial scam a true confidence game. ${ }^{36}$

\section{The illegality of financial scams}

In comparison with other types of financial fraud, the illegality of financial scams is often rather obvious. Once discovered, the falsehoods on which financial scams are built are relatively easy to litigate or prosecute using general fraud laws and a variety of legal statutes (e.g., securities regimes).

\section{Characterizing the literature on financial scams}

Most of the scholarly research on financial scams as conceptualized here can be found in two rather distinct bodies of literature. The first is found at the crossroads of sociology, criminology, and psychology. Using terms such as "investment frauds," "Ponzi schemes," "personal frauds," "consumer scams," and "telemarketing frauds," this literature is primarily concerned with investment scams. Despite its richness of theoretical and conceptual approaches, it has until now largely refrained from engaging with the relatively new and rapidly spreading financial identity scams. ${ }^{37}$ Scholarly work on financial identity scams can instead be found in a second body of literature. The proliferation of identity-related crimes, which are frequently perpetrated on the internet, has brought together computer scientists, security engineers, economists, lawyers, and psychologists in the rapidly evolving field of "cybercrime"/"online crime," and "identity

36 Connoting the confidence-game nature of investment scams, the perpetrators are also frequently referred to as "scam artists," "hustlers," "swindlers," or "con men." These people are often said to be charismatic individuals with charming and convincing personalities (Pressman 1998).

37 Discussing the rise of identity-related fraud, Henry Pontell and Gilbert Geis, two prominent scholars in the discipline, state that "mainstream criminology has by and large missed the major transformation in the nature of crime in the 21st century, or, at a minimum, is lagging in taking up such issues as measured by work published in major journals or presented at professional meetings" (Pontell/Geis 2007: 53). 
theft" research (see Cheney 2003; Anderson/Moore 2006; Chryssikos/Passas/Ram 2008; Moore/Clayton/Anderson 2009). In this body of literature, scholars refer to financial scams as "technocrime," "cybercrime," "computer crime," and "internet scams."

Although these two bodies of literature have to date been very disconnected from each other, empirically this distinction is hard to justify. Indeed, "many of the behaviors now termed 'identity theft' are age-old scams, swindles, and confidence games perpetrated on a massive scale using computers and new electronic technology" (Pontell/Geis 2007: 47). Perhaps, it thus comes as no surprise that a key question dominating both bodies of literature is "what factors lead people to make the apparently irrational decision to participate in a scam?" Much of this research agitates against neoclassical economic explanations of financial scams and suggests that the notion of asymmetric information really does little to explain financial scams (Pressman 1998: 411). To better understand such fraudulent activity, scholars have studied the psychology and sociology of the victimization process. Their findings suggest that financial scams "arise not because of asymmetric information, but because of the psychological disposition of human beings and the fact that human decision making involves employing some heuristics or focal points in the face of uncertainty regarding future events" (Pressman 1998: 417). More specifically, research in those fields has pointed to the different ways in which financial scams appeal to trust and trigger visceral influences and perception biases in order to overcome the mark's skepticism and suspend his suspiciousness (e.g., Button et al. 2014: 6; Stajano/Wilson 2011; Frankel 2012).

The role of trust and authority in the victimization process

The successful execution of any financial scam ultimately relies on the willingness of the marks to make a leap of faith and participate in the scheme. To do so, the mark often needs a certain level of trust. Operators of financial scams apply a variety of methods to create trust. A review of the literature reveals four methods that are frequently used by con artists. First, words and behaviors can be used to signal trust. Con artists typically wrap their scams in detailed and convincing stories meant to signal trustworthiness through the use of a vocabulary with a specific legal or professional meaning; however, in the specific context of the scam, such words are actually empty and meaningless (Frankel 2012: 29-32). Moreover, con artists often generate trust through their behavior. For example, they exhibit lavish lifestyles and generously support charities in order to make themselves appear as trustworthy and successful businessmen (Frankel 2012; Lewis 2012). Second, scam artists often exploit the implicit trust that exists among the members of a social group. The exploitation of group trust has been said to be an extremely powerful way of overcoming people's skepticism, enabling the victimization of both unsophisticated and seemingly sophisticated victims (Comet 2011; Perri/Brody 2012: 306). Third, con artists exploit their marks' respect for authority. In investment markets, investors often demonstrate extensive trust in individuals whose reputations are so great that they are recognized to be stars (Blois 2013). This is perhaps best exem- 
plified by the Ponzi scheme perpetrated by Bernard Madoff. In financial identity scams, operators often assume a professional façade and refer to well-known, legitimate companies to dissipate authority (Button et al. 2014: 10-11). Finally, con artists may signal trust through actions. Operators who have skin in the game, make timely payments, and fulfill promises do so in an effort to establish a reputation of trustworthiness (Frankel 2012: 39-41; Lewis 2012: 303).

The role of visceral influences and psychological dispositions in the victimization process

Apart from garnering trust so as to induce the mark to participate in the scheme, con artists also frequently exploit human psychology. At one level, con artists have been said to rely on a myriad of persuasion techniques that appeal to visceral influences (Langefelder/Shimp 2001). Well-crafted scam propositions, much like persuasion techniques adopted by legally operating advertisers, appeal to desires and emotions such as need, greed, fear, etc. (Schaper/Weber 2012: 345-346). Such techniques distract the victims from protecting themselves and prevent them from asking the appropriate questions (Stajano/Wilson 2011: 71-72). At another level, scholars have pointed to the reliance of con artists on psychological dispositions and projection biases involved in human decision-making in the face of uncertainty (Pressman 1998; Perri/Brody 2012). For example, people are said to be psychologically predisposed to be optimistic with regard to the true intention of another person whenever they have no bad past experiences; this makes it relatively easy for a con artist to induce a mark with no such experiences to participate in a scam (Pressman 1998: 414; Perri/Brody 2012:312-313). Also, projection biases - a human tendency to believe that people who share with us a certain affiliation such as race, faith, or ethnic background, also share similar values and beliefs - have been said to play a role in the victimization process (Perri/Brody 2012: 311-312).

\subsection{Investment scams: Sham business ventures and Ponzi schemes}

The first major group of financial scams is referred to here as investment scams. Investment scams are fraudulent schemes that try to deceive investors into investing their money in a specific investment opportunity - a company, investment fund, real estate project, or insurance policy - that, in fact, is non-existent or that will not live up to expectations. The investment opportunities provided by investment scams may consist of shares, equity stakes, or debt issued by fake or dubious companies and purportedly backed by a hot new product, technology, or business opportunity (Blanton 2012: 5). Precious-metals mining operations have been said to be especially suitable for investment scams (Naylor 2007: 89; Friedrichs 2010: 204-207). Alternatively, the opportunity offered by an investment scam might be in the form of participation in a unique investment strategy pursued by an investment fund. For example, Bernard Madoff, who per- 
petrated what has been said to be the biggest Ponzi scheme in history, told investors he pursued a so-called "split-strike conversion" investment strategy, which had presumably yielded an 11-percent annual return over the last 15 years, with only 13 losing months (Frankel 2012: 19). Other forms of investments that have been involved in such scams are real estate projects (Friedrichs 2010: 210) and insurance plans (Tillman 2002; Rosoff/Pontell/Tillman 2014: 350-354).

For the outside observer, investment scams are often difficult to distinguish from legitimate investments. Scholars frequently point out that operators of investment scams do not behave very differently from legitimate entrepreneurs. They are creative and optimistic - sometimes overly optimistic - and their offerings are usually unique (Frankel 2012: 101). However, contrary to legitimate enterprises, investment scams do not benefit society by providing incentives to finance productive and creative projects; instead they deceive investors about the true nature of the enterprise (Frankel 2012: 103).

Investment scams can be designed in either one of two ways. In what I will refer to as sham business ventures, the operators of the scam simply collect the money and then disappear. Investment scams designed as sham business ventures frequently make use of shell companies registered in secrecy jurisdictions. The anonymity provided by these jurisdictions enables the operators to collect the money and then disappear without leaving any traces for duped investors to recover their losses. In most cases, however, investment scams are designed to live a longer life and take the form of a Ponzi scheme. Ponzi schemes are often characterized as investment scams wherein investors' returns are generated by capital coming in from new investors rather than the success of the underlying business ventures ${ }^{38}$ (Nolasco/Vaughn/del Carmen 2013: 378). A somewhat more nuanced understanding of Ponzi schemes, however, recognizes that the rollover of investments made by new investors is not the only mechanism that helps to keep the scheme going. Indeed, "if new investors constituted the only source of additional

38 In accounting terms, Ponzi schemes are business enterprises that are technically insolvent from the first day of operation (Lewis 2012: 295). In their structure, Ponzi schemes are somewhat similar to so-called pyramid schemes. In a pyramid scheme, "victims are invited to recruit salespersons to sell products that are not in fact sellable. The buyers of the privilege to sell pay those who recruited them. Each recruit pays for sales materials and the permission to sell the product. The recruit then seeks to sell this right to another recruit, and be paid by the latter. In reality, what is being sold is the right to sell a product that is rarely or never sold. New recruits pay to the parties that recruited them. Each of the recruiters keeps part of the money received from the new recruit and pays the rest of the money to the persons who recruited them. Thus, the top of the pyramid collects from a seller below; the amount of the collection falls with the position of the person in the pyramid. Those at the lower level pay people at the higher level a percentage of the amounts their new recruits pay and receive payment from those below. At some point, the number of the potential buyers of the privilege to sell is exhausted, and the scheme comes to an end" (Frankel 2012: 6). Despite their similar structure, Ponzi schemes have been said to differ markedly from pyramid schemes in that they do not reveal to investors the true method of financial gain, which is to recruit new investors, rather than gain from investments in high yield vehicles (Furman/DeJoy 2009: 64; Lewis 2012: 307). 
capital, the number of investors needed to keep the scheme going would be astronomical" (Lewis 2012: 295). Often, operators provide earlier investors with fictitious paper earnings ${ }^{39}$ that are then re-invested in another investment cycle (Frankel 2012; Lewis 2012). In any case, what makes Ponzi schemes distinct from sham business ventures is that, in the case of the former, the returns promised to investors do in fact materialize initially, at least on paper. However, even though the seeming realization of returns enables Ponzi schemes to last over longer periods of time without being discovered, in the long run they are doomed to collapse as a result of their structure (Trahan/Marquart/ Mullings 2005: 603). The circular nature of Ponzi schemes requires that new investors keep coming in and earlier investors stay invested; as soon as new investors stop joining or earlier investors want to redeem their investments, the scheme starts to collapse (Trahan/Marquart/Mullings 2005: 603).

To lure victims into participating, investment scams appeal to a variety of needs and emotions such as greed, ego, the fear of losing opportunities for financial security, and the urge to increase wealth and status (Will 2013: 46). Typically, they draw the marks' attention with promises of steady returns, often above the market rate, at low risk (Nolasco/Vaughn/del Carmen 2013). The exact rates of return vary widely between schemes. There are examples in the literature in which con artists offered returns of up to 40 percent within six to eight weeks, or 100 percent within a month (Frankel 2012: 22-23). On the other hand, the scheme perpetrated by Bernard Madoff, supposedly the largest Ponzi scheme ever, offered investors modest but steady returns of 10 to 12 percent per year, regardless of market conditions (Nolasco/Vaughn/del Carmen 2013: 376). Perpetrators of investment scams go to great length to create the appearance that the company they are touting is real (Blanton 2012: 5). They cover the fraudulent nature of their schemes with creative stories that "explain" the sources of the high returns. These stories may vary widely from scheme to scheme and are only limited by imagination.

Apart from the promise of lucrative returns and a convincing story to "explain" these returns, the profitability and longevity of investment scams also depends on an effective diffusion system. This is especially pertinent in the case of Ponzi schemes, which need a constantly expanding investor base to survive. A review of the literature (Baker/ Faulkner 2003; Shover/Coffey/Hobbs 2003; Shover/Coffey/Sanders 2004; Frankel 2012; Lewis 2012) reveals two different ways in which the investment opportunity is made known among investors.

First, the scam can be disseminated through impersonal methods. Operators of investment scams may use paid sales forces to promote the scam. They may, for example, recruit telemarketing teams to run through mooch lists or salesmen to go from door to door to sell a certain "investment opportunity" (see Baker/Faulkner 2003; Shover/Coffey/Hobbs 2003; Shover/Coffey/Sanders 2004). Also, con artists may recruit registered

39 Paper earnings are earnings that are not actually paid out to investors but that accumulate within in the scheme (Lewis 2012: 295). 
broker-dealers who advertise the fund with their clients. Ponzi schemes operating on a larger scale may even recruit so-called "feeder funds": investment advisers and money managers, backed by prominent financial institutions, who direct their clients' funds directly towards the Ponzi fund (Lewis 2012: 304). For example, established financial institutions throughout the world had been known to accept payments from Madoff for recruiting investors (Frankel 2012: 80-81). In all of the above cases, those who recruit new investors are attracted by generous commissions and are often not completely aware of the fraudulent nature of the investment opportunity they are selling to clients (Frankel 2012: 80).

Second, the scam might be promoted to investors through social networks (Baker/ Faulkner 2003; Comet 2011; Perri/Brody 2012; Blois 2013; Nash/Bouchard/Malm 2013). Frequently, such scams take the form of "affinity fraud" ${ }^{40}$ (Perri/Brody 2012; Blois 2013), in which operators take advantage of a shared affinity with the victims, be it as part of a religious organization (e.g., Bernard Madoff), an immigrant community (e.g., Charles Ponzi), exclusive clubs, or simply a group of family or friends. In affinity frauds, the diffusion of the investment opportunity occurs through word of mouth amongst members of the social group. Often a fortunate group of early investors become the "songbirds" that sing the praises of the scam to others (Frankel 2012; Lewis 2012). To provide credibility and induce the songbirds to bring friends, family members, or business colleagues into the scam, operators make regular dividend payments to those early investors, giving the scam an appearance of profitability and legitimacy. The entrance of new investors is further facilitated by the fact that the affinity creates a sense of kinship and community-based trust that "is so powerful in overcoming people's skepticism that both the financially unsophisticated and the seemingly sophisticated fall victim to these scams" (Perri/Brody 2012: 306).

\section{Prevalence, victims, costs and consequences}

Investment scams are by no means the low-frequency, high-impact events that some people might believe them to be. What probably first comes to mind for most people when thinking about investment scams and Ponzi schemes are those high-profile cases that have been extensively scrutinized in the press. The best examples of such cases are probably the multibillion dollar schemes perpetrated by Bernard Madoff and Allan Stanford. However, the scholarly literature on investment scams is rife with examples of smaller and less well-known albeit, at least for the victims, equally destructive investment scams. One scholar specializing in the phenomenon has even suggested that "Ponzi schemes and investment frauds seem to have reached the proportion of an epidemic"

40 According to Perri and Brody, affinity fraud "refers to investment scams that prey upon members of identifiable groups, such as racial, religious and ethnic communities, the elderly, professional groups, or other identifiable groups" (Perri/Brody 2012: 306). 
(Frankel 2012: 9). In the years 2008 and 2009 alone, 190 Ponzi schemes collapsed in the United States (Anderson 2009, cited in Lewis 2012: 294), and a 2007 study conducted by the Canadian Securities Administration noted that about one in twenty Canadians had been victimized by investment fraud (CSA 2007, cited in Lokanan 2014: 226).

Although precise figures on the monetary costs associated with investment scams are scarce, they are generally believed to be significant (Frankel 2012: 7). For example, the costs associated with global investment fraud in the year 2001 have been estimated to be around $\$ 35$ billion (Frankel 2012: 9). The majority of these costs fall on those who invested their money in the scheme. However, the actors injured by investment schemes are not limited to the investors. Victims of Ponzi schemes also include financial institutions that have unwittingly - at least so they say - facilitated the scheme. For example, feeder funds that directed their clients to the scheme, brokerage firms that executed transactions for the Ponzi fund, and banks that offered - sometimes secretive - accounts to the operator, etc. These institutions might be affected in their daily operations and often suffer from tainted reputations (Frankel 2012: 9). Finally, the victims of investment scams sometimes also include the operators themselves. When the scheme collapses, the con artists have to pay for their deeds, both in monetary terms and in terms of an often intolerable loss of self-esteem. It is not uncommon that, upon discovery, operators of Ponzi schemes commit suicide.

\section{Perpetrators, motivations, and opportunities}

Operators of investment scams frequently exhibit certain character traits. On the one hand, they are said to be charming, captivating and presentable, normally good dressers, good listeners, and great flatteners that frequently exhibit considerable generosity (Lewis 2012: 303). On the other hand, con artists are said to frequently have a narcissistic character and lack any concern or empathy for their victims. They feel superior to other people, especially their victims, deny responsibility for their wrongdoings, and sometimes even blame the victims (Frankel 2012: 110-121). Their motivation is intrinsic and comes from more than greed alone. Con artists may have grandiose dreams of making a fortune but also of gaining recognition and respect (Frankel 2012: 103). In pursuing their dream, they behave very much like legitimate entrepreneurs (Frankel 2012: 101-106). They view and present their activities as true "businesses." Like entrepreneurs, they are optimistic and often truly believe in their scheme: "when con artists speak of their enterprise enthusiastically, they talk the truth - their truth, as they see it and feel it and want it to be" (Frankel 2012: 104). This not only makes them believable in the eyes of investors, it also explains a tendency amongst operators of investment scams not to want to see certain things, such as the unsustainable structure of the scheme (Naylor 2007: 90). In some cases, investment scams might actually begin as a legitimate enterprise. Entrepreneurs may be truthful when they launch the business, but then, as the business develops and begins to falter, turn to fraudulent solutions to keep 
the business running instead of declaring bankruptcy (Frankel 2012: 92-97). They are often driven towards the slippery slope of fraud by the unwillingness to admit to failure or an addiction to lavish lifestyles or even both (Frankel 2012: 108).

Building on Robert K. Merton's theory of the anomic society, some scholars have pointed to the American dream as a factor driving perpetrators of investment scams (e.g., Trahan/Marquart/Mullings 2005; Young 2013). Most importantly, the American dream emphasizes the importance of success and de-emphasizes the methods of acquisition. Trahan et al. (2005) argue that the same theoretical contentions can be used to explain what enables fraudsters to victimize investors. The American dream, they argue, acts as a catalyst that makes people vulnerable to fraud victimization. At a more general level, these scholars contend that contemporary investment scams must be understood in the context of the values and practices of present-day finance capital and that the sociopolitical context in which fraud occurs is highly conducive to the necessities of these crimes (Trahan/Marquart/Mullings 2005: 618; Young 2013).

Scholars have also indicated the way in which investment scams take advantage of the institutional arrangements governing financial markets. In a financial world where the mystique of the alpha manager and alpha returns reign supreme, the justified use of secrecy is said to be of especially great help to fraudsters perpetrating investment scams (Blois 2013: 194; Shapiro 2013: 130; Frankel 2012: 36-37, 41-44). In the hedge fund and private equity fund industry, trading models are generally described without rigorous detail for fear that competitors will imitate them and to prevent free riders. Perpetrators of investment scams take advantage of this "justified secrecy," using it primarily to keep investors at bay and avoid detection.

It has also been suggested that technological advancements have given fraudsters a greater range of vehicles and opportunities to perpetrate investment scams. Especially the internet has reduced the need to finance a large sales force, and the anonymity it provides shields con artists from detection (Frankel 2012: 78). Moreover, it has been maintained that the impersonal character of internet-based relationships has an emotional benefit for con artists as well. The possibility to perpetrate investment scams without the necessity of personal contact may produce more con artists today than there were in the past (Frankel 2012: 78).

Finally, the success of investment scams has also been said to depend on a lack of independent and objective oversight. At one level, scholars have pointed to the lack of serious scrutiny by supposedly independent auditors (Geis 2013; Shapiro 2013: 138). With audits frequently failing to achieve their purpose - because they are deficient or sometimes even fictitious - the perennial issue of "who guards the guardians?" remains. At another level, observers have emphasized the failure of regulatory authorities to police the market and detect, at an early stage, large-scale investment scams such as those perpetrated by Bernard Madoff and Allen Stanford (Markopolos 2010; Shapiro 2013: 132). One interesting point in this regard is that regulatory investigations are usually theory-driven, 
that is, investigators do not approach a case with an open mind but with a hypothesis in mind. This may direct their attention away from what they should be looking for. In the Madoff case, for example, the SEC had been tipped off by a hedge fund but was blinded by the idea that Madoff was engaged in insider trading (Lewis 2012: 298).

\section{Cases discussed in the literature}

Not surprisingly perhaps, one case that has been frequently discussed in the literature is the scam perpetrated at the turn of the twentieth century by Charles Ponzi, an Italian immigrant in the United States whose name would be used from then on to describe a certain type of investment fraud, the Ponzi scheme. Charles Ponzi has been described as a man with a dream and an unshakable faith that he would be inspired by a magical idea that he could make come true (Frankel 2012: 104). He thought he had found this idea in the cross-border trading of postal stamps. These stamps were redeemable by the issuing governments in their own currencies. Ponzi believed that trading on the difference between the value of the currencies in which these stamps were issued could produce enormous profits (Frankel 2012: 15). He began advertising his plan, which was effectively an arbitrage trade, promising to pay a 50-percent return in 45 days. Soon he was collecting millions of dollars (Furman/DeJoy 2009: 65). When his business soon failed to meet expectations, Ponzi hoped to invest the money in a legitimate enterprise, while gradually lowering the promised returns. In the meantime, he used the money raised from new investors to pay the promised return to earlier investors and finance a lavish lifestyle (Frankel 2012: 17).

\section{High yield investment programs (HYIPs)}

So-called high yield investment programs (HYIPs), labeled by some as "the post-modern Ponzi scheme" (Moore/Han/Clayton 2012), are online investment schemes that promise outrageous levels of interest, wherein payments to existing investors are made using money from new investors. What remains of the money paid in by new investors is siphoned off by the operator of the scheme. Although the financial structure of these schemes is identical to that of a traditional Ponzi scheme, their modus operandi is somewhat different. First of all, they are perpetrated online and are facilitated by an extensive online fraud ecosystem (Neisius/Clayton 2014). Second, the eventual collapse of HYIPs works somewhat differently from that of a real-world Ponzi scheme because there will be no bankruptcy and no liquidators checking to see if there is any value left in the enterprise that can be used to pay off the victims. HYIPs collapse as soon the operator concludes that paying the next round of interest payments is less lucrative than shutting the scheme down and absconding (Moore/Han/Clayton 2012: 46). Third, it is believed that many investors are well aware of the fraudulent nature of the scheme. They hope that by investing at an early stage, and withdrawing their money before the scheme collapses, they will be able to make a profit at the expense of less savvy investors (Moore/Han/Clayton 2012: 41). Researchers have said that a considerable amount of HYIP websites are active at any given time and have estimated that HYIPs attract at least $\$ 6$ million per month in revenue. Computer science scholars doing research on HYIPs point out that many HYIPs have begun to embrace Bitcoin and thus discuss several other Bitcoin-related scams (Vasek/Moore 2015). 
In recent years, the case that has attracted by far the most intense media attention and academic scrutiny is the multibillion Ponzi scheme perpetrated by Bernard Madoff. ${ }^{41}$ Although exact figures vary from source to source, Madoff allegedly cheated about 4,000 to 10,000 investors in his scheme of somewhere between $\$ 15$ billion and $\$ 65$ billion (Geis 2013: 89). In the scheme, which lasted over an extended period of approximately 40 years, Madoff offered his clients - initially exclusively members of the Jewish community in New York, but over time a truly global clientele that included large and established financial institutions - an unfluctuating return of 10-12 percent per year regardless of market activity (Nolasco/Vaughn/del Carmen 2013: 376). Madoff explained these returns as being the result of a complex "split-strike conversion" investment strategy. Madoff enjoyed a high level of credibility amongst his clients, both because he belonged to the Jewish community and because of his star status on Wall Street. ${ }^{42}$ Moreover, Madoff created a myth of exclusivity around his enterprise, giving his victims the impression that they belonged to a select group of people with access to his fund (Frankel 2012: 20; Straney 2011: 95-96). Madoff sent regular statements to his investors in which he detailed their holdings and their illusory high levels of profits (Geis 2013: 90). What in hindsight might come as a surprise is that his clients apparently never exercised any due diligence that involved checking the person or organization responsible for auditing the company's books. Madoff had his enterprise audited by Friehling \& Horowitz, a little-known three-person accounting firm with only one certified accountant on its payroll. This firm had been auditing Madoff's books since 1991 (Lewis 2012: 297; Geis 2013: 90). Not only investors took Madoff on trust, so too did regulators. Over the years, investigators conducted several investigations into Madoff's enterprise but failed to cross-check trades with supposed counterparties and to check the stock records against the central securities depository. Had such steps been taken, they would almost certainly have revealed the scam Madoff was operating (Lewis 2012: 297).

Another high-profile Ponzi scheme was perpetrated by Robert Allen Stanford, a Texas billionaire and head of Stanford International Bank. ${ }^{43}$ Stanford deceived his clients into believing that their investments were earning extraordinary rates of return from opportunities available offshore, while in fact he was diverting their funds for his personal use (Shapiro 2013: 139). He had his firm audited by a 72-year-old man who had been examining the company's books for at least a decade (Geis 2013: 91) and had officials in his pocket in the offshore jurisdictions where his bank was operating (Gough 2013: 71-85). Contrary to the Madoff case, regulators did actually have suspicions that the Stanford operation was a Ponzi scheme. However, it has been suggested that senior

41 For in-depth accounts of the Madoff affair, see Oppenheimer (2009), Sander (2009), Strober and Strober (2009), and Markopolos (2010).

42 In his earlier career, Madoff had been active in the National Association of Securities Dealers (NASD) and served as chairman of the board of directors of NASDAQ.

43 For an in-depth account of the investment scam perpetrated by Allen Stanford, I refer to Gough (2013: 71-85). 
management at the SEC had discouraged pursuing the case because they were under pressure to increase the number of successful prosecutions, and they believed the Stanford case would be difficult to prosecute because the Stanford bank was based offshore.

\subsection{Financial identity scams: Phishing, pharming, and payment scams}

I use the term financial identity scams ${ }^{44}$ here to refer to fraudulent schemes that try to induce potential victims to reveal personal identifying information related to their financial accounts to the operator of the scheme. Once the operator has succeeded in inducing the mark to surrender the information - which may include account numbers, credit card details, passwords, user IDs, etc. - the operator then uses this information to perform fraudulent money transfers. Thus understood, the term financial identity fraud refers to both the obtaining of the victim's financial identifying information, often through scam-like schemes, and the subsequent fraudulent use of that information for financial gain. ${ }^{45}$

In obtaining the identifying information, operators of financial identity frauds resort to different techniques. In the literature, a conceptual distinction has been made between technical subterfuge schemes and social engineering schemes (Vittal 2005; Button et al.

44 Financial identity scams as conceptualized above belong to a wider family of "identity abuses" - a generic term used here to refer to a wide variety of illegal activities in which individuals misuse people's identifying information. The literature on identity abuses, which overlaps with the literature on "computer crime" and "online crime" and which transcends multiple disciplines including law, criminology, computer sciences, and finance, is a rapidly evolving one. However, despite the abundance of research conducted on the phenomenon, probably the most striking feature of this emerging literature is the persistence of definitional vagueness. Terms like "identity crime," "identity theft," "identity fraud," "credit card fraud," and "payment fraud" have been used with varying meanings attached to them. Some have attributed this definitional vagueness to the multifaceted nature of identity abuses. Identity abuses may involve both plain theft (e.g., stealing cards and personal identifying information from someone's wallet, rummaging through trash, hacking into databases of banks and credit card companies, or "skimming," that is, copying information directly from the credit card when processing the card) and deceit in the form of scams, swindles, and confidence games. Moreover, identity abuses usually are a means to an end. Identity abuses are not necessarily economically motivated, and even when they are, the ways in which perpetrators use the obtained identities vary significantly. For example, Pontell and Geis (2007) distinguish between financial identity theft, which entails the use of personal identifying information to establish credit lines in the name of the victim; criminal identity theft, which involves a criminal giving another person's identifying information to law enforcement; and identity cloning, whereby imposters, illegal immigrants, or wanted felons use the victim's personal information to establish a new life. However, in the majority of cases, identity crimes are used to perpetrate economic fraud (McNulty 2008).

45 Some scholars treat the illegal obtaining of financial identities and the subsequent fraudulent use of that information as separate crimes. In making this distinction, the obtaining of the identifying information is considered an identity abuse, while the fraudulent use of that information is considered to be a more general form of economic fraud (e.g., Ram 2008). 
2014). Social engineering schemes contact their marks with "spoofed" e-mails - e-mails with forged sender-addresses - that prompt recipients to visit counterfeit websites designed to trick them into divulging their financial identity voluntarily (Vittal 2005). The most common social engineering scheme technique is what is called phishing (see Jagatic et al. 2007; Lynch 2005; Vittal 2005; Brody/Mulig/Kimball 2007). In a typical phishing attack, a scam artist pretending to be an agent from a bank or credit card company ${ }^{46}$ sends out e-mails to customers in which the operator prompts them to click on a hyperlink that brings them to a website, controlled by the phisher, where they will be asked to further process their account details (Vittal 2005: 28; Geeta 2011: 235). To appear credible and to trick the recipient's into participating in the scheme, the scam artist's e-mails contain company logos and use scare tactics - such as threats of account closure - and urgency cues that short-circuit victims' elaboration on clues that could reveal the deceptive nature of the invitation (Lynch 2005: 259; Vishwanath et al. 2011).

Technical subterfuge schemes, in comparison, are more technical in nature and rely much less on persuasion to entice victims into the scheme, which enables a much wider victim base. For example, in what is generally referred to as pharming (see Vittal 2005; Brody/ Mulig/Kimball 2007), fraudsters send out e-mails which, when opened, plant malware malicious software - in the victims' personal computers. The malware then directs traffic from those PCs that is destined for a legitimate website, say, a bank, to the pharmer's bogus website, which looks just like the real one. Without the victim's knowledge or consent, all the information the victim thinks is being sent to the bank's website is sent directly to the pharmer. Another possible mode of operation for pharmers is to alter a website's internet protocol (IP) address in the domain name server (DNS). In so doing, pharmers redirect all users who type in the URL (the web address) of, say, a bank to the illegitimate website controlled by the pharmer.

After having obtained the victim's financial credentials, operators of financial identity scams then fraudulently use this information to realize financial gain. ${ }^{47}$ Here, again, operators choose from a menu of different techniques, which can be thought of as falling along a continuum (Cheney 2003; Anderson/Moore 2006; Anderson/Durbin/Salinger 2008). At the least sophisticated and low-cost end of the spectrum are traditional payment frauds, or credit card frauds, whereby perpetrators make unauthorized use of one or several of the victim's existing bank and credit card accounts by withdrawing cash or buying merchandise. These kinds of frauds are generally detected at an early stage by victims or by financial services providers' fraud detection systems and hence are generally limited to a few transactions. The relatively rapid identification - often within one week - allows for prompt remedial action, such as the cancelling of the card, to prevent

46 The financial services industry is the primary target of financial identity scams such as phishing and pharming. Scholars estimated that between 84.5 and 92 percent of all attacks in 2005 were targeted at banks and other financial institutions (Brody/Mulig/Kimball 2007).

47 Identity abuses have also been linked to financial crimes such as money laundering and terrorist financing (Acoca 2008: 77; Ozaki 2008: 12-14). The use of identity abuses in these kinds of crimes will be discussed below. 
further losses. At the other end of the spectrum are fraud schemes that are much more sophisticated, take longer to be detected, and, accordingly, involve much larger costs to the victims. Here, fraudsters not only make unauthorized use of the victim's existing accounts, but open up and deplete new credit accounts and credit lines using the victim's identity, without the victim being aware of it. In perpetrating such schemes, fraudsters tend to follow a typical pattern ${ }^{48}$ (Cheney 2003). Between those ends of the continuum are "account takeover frauds," whereby fraudsters establish complete control over an existing account in order to extract the entire balance in a deposit account or to access the full credit line of a credit account, and "fictitious identity frauds," in which pieces of real data from one or more consumers are combined with made-up information to fabricate an identity and establish a credit line that does not belong to any real person ${ }^{49}$ (Cheney 2005).

\section{Prevalence, victims, costs, and consequences}

There is widespread agreement in the literature that financial identity scams and identity abuses in general constitute a serious and growing threat for contemporary economic systems (e.g., Pontell/Geis 2007: 54). Identity abuses have been said to form the number one and fastest growing economic crime in a range of countries as diverse as the United States (Brody/Mulig/Kimball 2007; Pontell/Geis 2007), China (Bai/Chen 2013), and India (Geeta 2011). In the United States, losses from financial identity scams have been estimated to be as high as $\$ 49.3$ billion for the year 2006 (Javelin 2007, cited in Epstein/ Brown 2008). In the United Kingdom, estimated losses caused by identity-related crime have been calculated around $\mathfrak{E} 1.3$ billion per year; for Australia estimates vary from 1 to 3 billion US dollars (Pontell/Geis 2007: 53; Ozaki 2008: 9).

It needs mentioning, however, that the reliability of quantifications regarding the prevalence and financial costs associated with financial identity scams is frequently questioned in the literature. It has been suggested that quantifying financial identity frauds is problematic for several reasons. First, the lack of definitional clarity with regard to

48 First, the fraudster establishes an address that is different from the one used by the victim. To test the usability of the fraudulently obtained identity and to establish a credit bureau file tied to the new address, the fraudster then establishes a small account that can be opened without the physical presence of a card and that involves a low probability of detection - typically a cellular phone account. In the next step, the fraudster establishes a bank account with a small amount in order to deepen the credit file with positive data. Subsequently the fraudster starts applying for new credit cards, credit lines, and bank loans. Having done all of the preparatory work, the fraudster then capitalizes on his preparatory work by fully utilizing the newly established credit accounts and then abandons them, leaving the victim, merchants, and the credit providers with the loss and the task of re-establishing the victims' credit standing and sorting out associated liabilities.

49 Because of the fictitious nature of the identity, there are no consumer-victims involved in this type of fraud. The primary victims are the financial service providers that extend the credit lines. 
identity abuses makes categorization for the purpose of counting crimes and offenders in official statistics problematic (Cheney 2005: 16-17; Smith 2010: 286). Second, because of the very nature of the crime, many financial identity scams might go unnoticed until months after the fact (Newman/McNally 2005: 13). Third, victims might be unwilling to publicly acknowledge and describe the details of their less than cautious conduct in sharing sensitive information related to their private finances (Smith 2010: 287; Newman/McNally 2005: 7-18). Finally, quantifying the costs associated with financial identity scams can be problematic because a great deal of those costs are indirect and intangible, involving emotional distress and loss of customer trust or confidence (Newman/McNally 2005: 32; Ram 2008: 58).

A review of the literature ${ }^{50}$ reveals that the adverse consequences of financial identity scams may involve three separate groups of victims who suffer from both direct and indirect costs as a result of financial identity scams. The first group of victims consists of the consumers and businesses whose financial identities are fraudulently obtained and then misused by the swindlers. This group of victims experiences negative consequences that may include having to spend time and money in sorting out the fraud and re-establishing the victim's identity and credit standing, a loss of access to credit due to credit score deteriorations, and psychological and emotional consequences. A second group consists of the merchants and credit providers ${ }^{51}$ who have been tricked by the operators of financial identity scams into delivering money or goods based on fraudulent payments. These companies generally suffer from direct and quantifiable fraud losses; costs resulting from investments in fraud detection technologies; and the forgoing of additional potential revenue due to the refusal to accept valid transactions because they look suspicious and due to growing consumer reluctance to engage in e-commerce. The third group of victims consists of the banks, credit card companies, and e-retailers whose brand names are hijacked by phishing schemes. These companies may suffer from costs associated with deactivating scam sites. resetting passwords, and other such protective steps; costs associated with increased surveillance and prevention; and the negative effects on stock prices and trading volume. Finally, financial identity scams have also been said to incur costs for society at large in the form of a loss of trust in banking, finance, and commercial structures, especially e-commerce.

50 The overview of victims and consequences provided in this section is extracted from Newman and McNally (2005: 30-38), Vittal (2005: 28), Brody et al. (2007: 50-52), Anderson et al. (2008: 176-182), Ram (2008: 58), Ozaki (2008: 9), Geeta (2011: 237-239), Bose and Leung (2014).

51 The policies of credit card companies usually dictate that fraud losses be charged back to the merchant's account, unless the merchant has implemented verified transactions (Cheney 2003: 13). 


\section{Perpetrators, motivations, and opportunities}

It has been frequently emphasized in the literature that identity-related crime is in itself not a new phenomenon. Phishing, for example, is an old-fashioned scam that used to target people through fliers or through the regular mail (Blanton 2012). What is said to be new, however, is the industrial scale on which these crimes are being perpetrated and the strictly financial motivation behind the majority of them. This proliferation of financially motivated identity scams is usually attributed to technological advances and the emergence of new financial and organizational arrangements, which are said to have increased both the incentives to commit such crimes and the opportunities available to do so. Information and communication technologies, most notably the networked computer, are said to have created new channels through which financial identities can be fraudulently obtained. Especially the proliferation of electronic means for personal banking and the rise of e-commerce are believed to have opened up new ways of perpetrating financial identity scams and allowed these scams to be perpetrated on an industrial scale (Pontell/Geis 2007: 45; Smith 2010: 281-283). Parallel to this, the economic value of identifying information has significantly increased as well. In this regard, scholars have pointed to the specific nature of modern payment systems, and specifically to the increased reliance on identification in those systems: "In the modern economy, sellers are willing to offer goods and services to strangers in exchange for a promise to pay, provided the promise is backed up by data that link the buyer to a specific account or credit history" (Anderson/Durbin/Salinger 2008: 171). This increased reliance on identification has made modern societies vulnerable to identity abuses (Ozaki 2008: 9). Criminals, especially organized crime groups, increasingly look at identifying information as a profitable business opportunity (Smith 2010: 276). Thus, it has been maintained that another important reason for the proliferation and professionalization of online identity fraud is the increased involvement of organized crime groups, which has greatly increased the financing available to hackers and other scam artists (Brody/ Mulig/Kimball 2007: 50).

The picture of the social organization of contemporary financial identity scams that emerges from the literature is one of a highly sophisticated industry in which identifying information is being traded as a commodity. ${ }^{52}$ According to Moore et al. (2009: 3-4), online financial crime took off as a serious industry about a decade ago. Before that time, typical payment card fraudsters ran a vertically-integrated small business, in which the scammer himself would perpetrate the scam in order to obtain password data that he would then use to realize a financial gain. Today, financial identity scam operations are organized as highly professionalized, global criminal networks. These networks involve a wide variety of criminal entrepreneurs and exhibit a highly developed division of labor (Lovet 2006; Brody/Mulig/Kimball 2007; Pontell/Geis 2007; Moore/ Clayton/Anderson 2009). For example, at the front end of the value chain, where the

52 What reveals the developing sophistication of the industry most strikingly is perhaps the fact that an intermediating system of guarantors and escrow agents has developed (Schipka 2007). 


\section{Advance fee frauds and letter of credit scams}

In advance fee frauds, victims are promised a large sum of money if they provide upfront an initial financial payment to the scammer (Schaper/Weber 2012: 339). These payments are usually presented to the victim as funds needed to cover initial costs, such as delivery charges, levies, bribes, or taxes. Unforeseen problems always arise, and the victim is lured into an endless cycle of fees that will continue until they run out of money or they come to their senses (Durkin/Brinkman 2009: 272). Needless to say, the promised sum of money is never delivered. The most well-known advance fee fraud is the so-called "Nigerian advance fee scam" or "419 scam," named after the section of the Nigerian penal code that prohibits the activity (see Glickman 2005; Durkin/Brinkman 2009; Schaffer 2012). In a typical 419 scam, the victim receives an unsolicited e-mail requesting his cooperation in transferring a large sum of money out of some African country. Frequently this involves a dormant bank account belonging to a deceased business man with no next of kin. In return for his cooperation, the recipient is promised a fair share of the money. To ostensibly facilitate the eventual transfer of the money, the victim is asked to provide the sender with some money. The scam became popular in Nigeria after the collapse the country's oil market in the 1980s, but over time it spread across the globe. Nigerian syndicates, hiding behind anonymous e-mail services and proxy servers, have been said to run cells in different countries, including the United States, Canada, Great Britain, India, and South Africa (Durkin/Brinkman 2009: 272). Losses associated with 419 scams are significant. For example, for 2005, global losses caused by such scams have been estimated at $\$ 3.1$ billion (Durkin/Brinkman 2009: 273). Letter of Credit scams (see Polat 2012; Zhang 2012, 2014) are somewhat similar to advance fee frauds. Letters of Credit (L/Cs) are widely used instruments of payment in international trade, in which an independent, recognized bank acts as a guarantor of the buyer in a specific transaction. The promise to pay under a L/C are thus only worth as much as the bank issuing them is worth (Polat 2012: 221). Fraudulent buyers set up sham banking institutions for the sole purpose of defrauding sellers through L/Cs. They use the sham banking institution as a guarantee in international trades in which they themselves act as buyers. The sellers mistakenly accept the sham bank as a guarantor of payment. The goods are shipped but the payment for the goods is never made.

collection of identifying information takes place, phishermen - criminal actors that operate a copy of a genuine bank website - hire spammers to drive customers of the bank to their fake websites. In contacting customers, spammers use the services of botnet herders, people who manage large collections of virus-infected personal computers that can be controlled remotely under a common command and control infrastructure. ${ }^{53}$ Spammers, phishermen, and botnet herders all make use of malware that has been developed by malware developers. Once the identifying information has been obtained, the fraudsters may obtain the service of information specialists who fill in the gaps when identity data are incomplete. One step further down the line in the "production chain," the fraudulently obtained information might be used in several ways. In the case of traditional payment card frauds, runners use the information for online purchases of expensive goods, which are then delivered at the address of a drop, someone who allows delivery of items at their home. The drop then forwards the goods to the runner who finally sells them to complicit retailers for a price below market value. In other cases, the information obtained by the phishermen is sold to cashiers, who use the information

53 For more on the role of botnets and botnet herders in online crime, see Ianelli and Hackworth (2007). 
to transfer money from the victim's account to an account controlled by a money mule. The money mule fulfills a role similar to that of a drop; he receives and subsequently forwards the money, usually through irrevocable payment services such as Western Union. Both money mules and drops are often duped into cooperating in the scheme. They are recruited via job ads sent in spam e-mails or on websites, where they have been offered opportunities to work from home as "transaction processor" or "sales executives." After the fraud is discovered, they often become personally liable for the buying and laundering of stolen goods and money.

\section{Cases discussed in the literature}

There is a notable lack of in-depth case studies on financial identity scams in the literature.

\section{$4 \quad$ Fraudulent financial mis-selling}

The term fraudulent financial mis-selling ${ }^{54}$ is used here to refer to the deceptive and manipulative marketing, selling, or advising of a financial product or service to an end user, in the knowledge that the product or service is unsuitable for that specific end user's needs. Contrary to financial statement fraud and financial scams, mis-selling cases do not necessarily involve false representations of facts. At the heart of fraudulent financial mis-selling are deceptive sales practices in which the seller of a financial product or service or the financial adviser advising on it makes misleading and highly speculative statements with regard to the future performance of the products or service or fails to communicate in a "fair and balanced manner" the suitability of the financial product or service for the specific end user. All too often both deceptive practices occur.

Similar to the other forms of fraud discussed here, the heart of any fraudulent mis-selling practice is an illegal exploitation of an information asymmetry that exists between transacting parties. In the case of mis-selling, however, an additional dimension comes into play with regard to this information asymmetry. It involves not only an asymmetry in access to financial facts relevant to the transaction, but also an asymmetry of more general financial expertise, that is, the capability of interpreting the available information and extracting meaning from that information with regard to the future performance of a financial product.

54 According to one observer, what the industry euphemistically calls "mis-selling" in fact involves "institutionally endorsed manipulation, deception and sometimes fraud" (Ericson/Doyle 2006: 994). 


\subsection{General characteristics}

\section{The modus operandi of mis-selling practices}

Fraudulent mis-selling practices are generally perpetrated by agents who fulfill a double role as sales agent and adviser in financial transactions. In its most innocent form, misselling involves cases in which such agents - direct salesmen, brokers, financial advisers, broker-dealers - provide their clients with unsuitable advice because they lack the advisory competence required by regulations. A more devious and fraudulent form of mis-selling, and of primary concern in this section, involves cases in which sales agents and financial advisers abuse their role by deceptively inducing clients to engage in financial contracts that, given full information and devoid of behavioral and cognitive biases, they would not have engaged in. Especially in the retail financial market, the relative ignorance and lack of financial literacy of most consumers puts the sales agents at a considerable informational advantage. Mis-selling agents exploit this informational advantage by providing their clients with biased advice or utilizing aggressive and manipulative marketing strategies. Such strategies might involve hidden costs and unrealistic projections of the future performance of financial products and frequently rely on complex and unusual contract structures (Paterson/Brody 2014: 2).

Often, mis-selling practices involve financial products that have a relatively far-off horizon and therefore are associated with high levels of uncertainty. In many cases these are financial products that provide insurance against possible life- or market-events in a relatively distant future. Examples of such products are pension saving plans, life insurance plans, interest rate swaps, or foreign exchange swaps. Because the benefits of such products for the consumer only become clear long after the transaction has taken place, determining whether a certain product is beneficial for the consumer involves a lot of guesswork and speculation. Using misleading promotional materials, high pressure sales techniques, and inaccurate or suggestive statements, mis-sellers overemphasize beneficial scenarios, while underemphasizing those that are less beneficial to the buyer. In doing so, they misleadingly provide potential buyers with a "veneer of certainty" (Ericson/Doyle 2006) with regard to the benefits of the products.

Although mis-sellers typically target relatively "unsophisticated" investors ${ }^{55}$ - most often retail consumers or small and medium enterprises buying loans and insurance policies - at times mis-selling practices have targeted more sophisticated market players as

55 In the US, as well as in most other countries with developed financial markets, regulators employ a two-track regulatory system in which they distinguish between "sophisticated" and "non-sophisticated" or "unsophisticated" investors. Under such a regulatory regime, sophisticated investors (mostly institutional investors and big corporations) are largely exempted from protective regulation, allowing them to engage in tailored contracts that help them to fulfill needs stemming from their specific investment strategies (see Markham 1995). Unsophisticated investors (mostly retail consumers and small and medium enterprises), are protected against exploitative practices by a relatively paternalistic regulatory regime that relies on legal concepts 
well. As will be revealed towards the end of this section, derivatives have proven to be especially useful instruments for investment bankers attempting to "out-mathematize and sweet-talk" (Goldmann 2010: 195) supposedly sophisticated clients into deals they really don't understand.

\section{The illegality of fraudulent mis-selling practices}

It is a fine line between aggressive but legal sales practices and fraudulent mis-selling. In many cases, determining whether aggressive sales practices have reached the level of illegality hinges on the relationship between the transacting parties. By prohibiting market participants from making misrepresentations, general fraud laws criminalize some of the behaviors involved in fraudulent mis-selling practices, such as sales agents' failure to disclose certain fees or commissions. However, apart from the general fraud laws, the law in most jurisdictions provides several legal concepts addressing those dimensions of mis-selling that deal with misleading speculations and the creation of false impressions.

First, legal and regulatory frameworks usually pose a variety of fair dealing requirements and ethical business conduct standards on actors active in specific industries. ${ }^{56}$ Second, depending on the nature of this relationship, regulatory frameworks may subject the sales agent or adviser to so-called suitability requirements. Suitability requirements, which are used by regulatory frameworks in different countries and across different sectors ${ }^{57}$ such as securities, commodities, insurance, banking, dictate that the seller or adviser of a financial product has a responsibility to guarantee that the product is suitable for the specific end user. For the seller, this responsibility implies the obligation both to know the specific risk profile of his client and to make suitable recommendations based on this profile. Third, regulatory frameworks might subject sales agents and financial advisers to a fiduciary duty in their dealings with their clients. Under a fiduciary duty, which is a higher standard compared to the suitability requirement, the selling or advising agent has to act in the best interest of the client. As is the case with the suitability requirement, a fiduciary duty implies an obligation for the sales agent or adviser to actively inquire about the specific risk profile of the client before making any recommendations or conducting any transactions with the client.

such as fiduciary standards and suitability requirements.

56 For example, through the Dodd-Frank Wall Street Reform and Consumer Protection Act of 2010, the US Congress directed the Commodities Futures Trading Commission (CFTC) and the Securities and Exchange Commission (SEC) to promulgate rules requiring certain large financial institutions to "act fairly" with their counterparties in the context of OTC derivatives transactions (see Scopino 2014).

57 For a discussion of the suitability doctrine in financial regulation in different jurisdictions and across different sectors, see the report of the Basel Committee on Banking Supervision Joint Forum (Joint Forum 2008). For the specific case of the US, see Mundheim (1965), Engel and McCoy (2002: 1318-1334), and Gibson (1998). 
Whether the abovementioned legal concepts apply in a certain transaction often depends on the extent to which the different parties in the transaction are considered to be sophisticated investors ${ }^{58}$ and whether the party that acts as a seller or broker has discretionary authority or gives advice or recommendations concerning the purchase of the product or does both. If no discretionary authority is involved and if no advice is given, that is, if the broker or sales agents merely serves as an order clerk executing a certain transaction on behalf of the client or acts as a counterparty in an arms-length transaction, then the broker or seller is usually not subjected to seller liability under a fiduciary duty or suitability rules (see Mundheim 1965; Stoneman/Schulz 2002: 67-81). It might come as no surprise, then, that those who are accused of mis-selling practices often deny responsibility by invoking caveat emptor, ${ }^{59}$ that is, a defense in which blame is attributed to the victim (Ericson/Doyle 2006: 996).

\section{Characterizing the literature on fraudulent mis-selling practices}

A review of the literature reveals that fraudulent mis-selling practices are widespread in the financial services industry and can pertain to wide variety of financial products or services. According to one observer, product mis-selling is the "stand-out systemic problems in the UK retail financial markets" (Ferran 2012: 249). However, given the persistence of mis-selling in the financial service industry, it is indeed surprising that to date this kind of behavior has been subject to scholarly scrutiny so seldom (Ashton/ Hudson 2013: 9). Only a few mis-selling episodes have been thoroughly investigated, and a coherent academic literature on fraudulent mis-selling in the financial industry has not yet materialized. Instead, accounts of fraudulent mis-selling practices as conceived in the context of this paper are spread over many different literatures, the most relevant of which are probably the financial economics literature on financial advice ${ }^{60}$ (e.g., Inderst/Ottaviani 2009; Ackermann 2011; Mullainathan/Noeth/Schoar 2012; Hackethal/Haliassos/Jappelli 2012; Mitchell/Smetters 2013), the business literature on marketing ethics (e.g., Falconer 2005; MacLean 2008; Taek Yi/Dubinsky/Un Lim 2012; Ashton 2015; Mulki 2015), and the legal literature on consumer protection and consumer financial literacy (e.g., White/Mansfield 2002; Rutledge 2010; Campbell et al. 2011; Paterson/Brody 2014). Despite the lack of a coherent body of literature on the phenomenon, some general themes can be identified.

58 Determining whether certain classes of investors - e.g., local governments, institutional investors, corporations, small and medium enterprises - should be considered sophisticated is often a contentious issue and has been subject of considerable debate amongst legal scholars (e.g., Markham 1995; Roberts 1996; Rosenthal 1996).

59 Caveat emptor is a term derived from Latin meaning "let the buyer beware."

60 The emerging body of literature on financial advice reports on the increasing importance of financial advisors in a changing financial landscape, characterized by the emergence of new distribution channels for financial products and services and the compensation models of sales agents therein. Although this literature scrutinizes practices that could very well be described as misselling, problematizes conflicts of interest that result in biased advice, and ultimately questions the economic value of such advice, most of the work does not ponder the illegality of such practices. 
Increased financial autonomy and lack of financial literacy

One recurring theme in the literature concerns the increased financial autonomy of consumers. It is suggested that, as a consequence of the general trends towards the privatization of social security, consumers have become more and more responsible for taking care of their own financial affairs and increasingly see themselves forced to make a number of highly consequential financial decisions throughout their lifetime ${ }^{61}$ (Campbell et al. 2011; Ericson/Doyle 2006; Erturk et al. 2007; Joint Forum 2008). However, it is noted that consumers typically have no more than limited experience in making such critical financial decisions and that it is difficult to acquire experience (Campbell et al. 2011: 92). This lack of financial literacy has resulted in a pool of vulnerable consumers who can be easily exploited by providers of financial services whose primary aim is profit maximization. A similar development can be observed in the wholesale market. The increasing complexity of financial products, especially derivative products, has undermined the capacity of what are considered to be sophisticated investors, such as institutional investors and (semi-)public entities, to fully understand and appreciate the risks associated with the products they invest in.

Changing distribution channels and biased financial advice

A second recurring theme concerns the changing distribution channels through which financial products are sold to consumers (Black/Nobles 1998; Inderst/Ottaviani 2009; Boot 2011; Jackson 2008). In this regard, scholars have especially underscored the increasing importance of agents acting as intermediaries between buyers and sellers. In many cases, these agents - brokers, sales agents, or advisers - fulfill a double task; they both act as advisers for financially illiterate consumers and prospect for new customers on behalf of the seller of the financial product - either because they are employed or receive side payments from the seller. Scholars have argued that when agents face such a "multitask problem," the risk of biased advice and mis-selling is particularly acute. The steeper the incentives provided to the agents, the more acute the danger of mis-selling (Inderst/Ottaviani 2009; Beyer/de Meza/Reyniers 2013). For financial regulators, these side payments and double roles pose a significant dilemma (Jackson 2008).

Product innovation, product line management, and consumer confusion

Third, different scholars have pointed out the fact that, in handling their financial affairs, consumers - and small and medium enterprises for that matter - encounter an everwidening menu of increasingly complex financial products (Boot 2011; Ashton 2015).

61 For example, the privatization of pension systems, the increase in the number of life insurance plans, and the rise in homeownership have all forced consumers to make long-term and highly consequential financial decisions. 
Product innovations, it has been suggested, might now have a much darker motivation: they might be intended to fool market participants and seek rents through the exploitation of information asymmetries, rather than to fulfill economic goals related to the financial sector's social functions (Bavoso 2015). In addition to questionable product innovations, scholars have also noted the way in which certain product line management practices that are popular amongst financial firms might facilitate mis-selling. Practices such as "tying," "bundling," and "cross-selling," whereby multiple financial services or products are offered in combination, have been said to at times coerce consumers into buying certain products, limit their apprehension of the variety of products on offer, and undermine their ability to compare product providers and make suitable purchase decisions (Renda et al. 2009). "Churning," a product-line management practice whereby financial firms frequently change their product line in order to increase sales, has been said to facilitate mis-selling because it frustrates financial consumers in their attempt to learn about financial products (Ashton 2015: 444). Some scholars have suggested that such product management practices are popular amongst financial service firms exactly because they engender confusion amongst consumers. Obfuscation, they argue, is a deliberate strategy pursued by financial firms with the aim of increasing the proportion of poorly informed consumers from whom rents can be extracted (Carlin/Manso 2011). As will be revealed below, a common denominator in different mis-selling episodes is indeed the presence of an excessive variety of products that share one characteristic: complexity in conjunction with the obscurity of costs (Boot 2011: 169-170).

\subsection{Predatory lending: The mis-selling of (mortgage) loans}

The mis-selling practices that have probably received most attention in the recent literature are those that have been associated with the selling of mortgage loans. Commonly referred to as predatory lending, ${ }^{62}$ the mis-selling of mortgage loans involves a wide range of practices that include charging excessive fees, steering borrowers into bad loans that net higher profits, making unaffordable loans based on the borrower's assets rather than on the borrower's ability to repay, inducing a borrower to repeatedly refinance a loan in order to charge high points and fees each time the loan is refinanced or to induce, convince, or mislead a borrower into signing a loan where income, credit, or assets are misrepresented and the loan is unsustainable (Nguyen/Pontell 2011: 9; Barnett 2013: 110-111). Although predatory lending is extremely hard to define (Delgadillo/ Erickson/Piercy 2008; Ryder 2014: 80), a common trait shared by all of these practices

62 In the literature the term predatory lending has been reserved almost exclusively for the misselling of mortgage loans. However, the term is occasionally also used for the mis-selling of all other sorts of consumer credit. According to Friedrichs (2010: 169-170), financial institutions have a long history of misleading people in solicitations about fees and long-term interest rates they will pay on their loans. It has been said that the credit card industry has also been guilty of engaging in predatory lending practices that arguably reach the level of illegality, but that this has been largely ignored and covered up (Stadler 2011; Issacharoff/Delaney 2006). 
is that they take advantage of disadvantaged borrowers by either extracting excessive fees and costs or by stripping them of their home equity (Nguyen/Pontell 2011: 8; Ryder 2014: $73-74) .{ }^{63}$

Predatory lenders often target potential and current homeowners who are generally not seeking loans (Renuart 2004). In the majority of cases, predatory lenders target subprime borrowers $^{64}$ with little prior experience in the credit market (Engel/McCoy 2002: 1261; Delgadillo/Erickson/Piercy 2008). They capitalize on these borrowers' lack of financial literacy and lack of access to unbiased financial advice (Engel/McCoy 2002). Based on descriptions of the predatory lending process described in the literature (e.g., Renuart 2004; Hill/Kozup 2007), I divide the predatory lending practice into three phases: the solicitation phase, the closing phase, and the exploitation phase. In the solicitation phase, predatory lenders conduct aggressive door-to-door solicitations in target neighborhoods. In this phase they "endear themselves with charm and solicitude that mask their guile. They consciously exude an aura of expertise and success, intimidating customers from questioning the advisability of the loans they are offering" (Engel/McCoy 2002: 1283). During the loan closing that marks the second phase of the predatory lending process, predatory lenders impose on these borrowers exploitative loan conditions that often differ from what the borrowers thought they would get, based on their communications with the lender in the solicitation phase. To induce borrowers to sign their overpriced and overly risky mortgage loan contracts, predatory lenders create excessively complex contracts and make use of consumer psychology (McCoy 2005; Willis 2006). For example, predatory lenders may persuade borrowers to close a deal as soon as possible under the pretext that their opportunity to borrow will soon vanish (Engel/McCoy 2002: 1283). In the final exploitation phase, the "friendly veneer" (Hill/Kozup 2007) with which predatory lenders have initially approached their victims yields to aggressive exploitation of the precarious situation that the loan contract got the borrower into. Often this is where a new round of high pressure solicitations to refinance the loan starts.

63 It is important here to point out that scholars emphasize that not all predatory lending practices are necessarily illegal (Nguyen/Pontell 2010: 595; Ryder 2014: 73). For example, there is no federal legislation that specifically criminalizes predatory lending in the United States, the epicenter of predatory lending in the run-up to the crisis. Moreover, no standard of suitability currently exists for the mortgage lending industry (Engel/McCoy 2002). Nevertheless, the link between predatory lending and fraud has been recognized by the judiciary (Ryder 2014: 75).

64 The mortgage market can be thought of as consisting of three distinct markets (see Engel/McCoy 2002; Renuart 2004). In the prime market, mortgages are extended to borrowers who are deemed to have a high level of creditworthiness and good credit histories. The subprime market, then, refers to that segment of the mortgage market that caters to borrowers who, for one reason or the other, lack the credentials to qualify as prime borrowers. The predatory market has generally been conceived of as constituting a separate and particularly pernicious section of the subprime market and has been said to target "people who, because of historical credit rationing, discrimination, the exodus of banks from inner-city neighborhoods, and other social and economic forces, are disconnected from the credit market and hence are vulnerable to predatory lenders' hard-sell tactics" (Engel/McCoy 2002: 1279). 
Prevalence, costs, and consequences

Estimates of the prevalence of predatory lending, especially those forms that becomereach the level of illegality, are hard, if not impossible, to come by. The diversity of practices subsumed under predatory lending, the different credit markets involved, and the lack of a common definition of predatory lending make it difficult to quantify its prevalence and costs. According to one scholar, "it is impossible to determine how many of the subprime loans issued before the start of the financial crisis fell within the definition of predatory lending" (Ryder 2014: 75-76). There is, however, a shared understanding in the literature that, at least in the United States, predatory lending practices were widespread during the housing boom that preceded the financial crisis of 2007-2008 and that hundreds of thousands of homeowner have been victimized in the past decade (Willis 2006; Fligstein/Roehrkasse 2013; Ryder 2014). Interestingly, a review of the literature on the phenomenon reveals that scholars had already identified the problem of widespread predatory lending practices and their adverse social and economic consequences well before the financial crisis of 2007-2008 (e.g., Engel/McCoy 2002; Renuart 2002; Willis 2006).

As is the case with estimates of its prevalence, quantifications of the monetary costs of predatory lending are hard to find. One estimate for the United States suggests that predatory lending of all kinds - including predatory lending by payday lenders, credit card companies, and the like - costs borrowers $\$ 25$ billion annually. A 2001 report by the Coalition for Responsible Lending estimated that excessive fees and interest rates alone cost those US borrowers who fell victim to predatory lending specifically in the area of mortgage loans around $\$ 9$ billion annually (Stein 2001, cited in Friedrichs 2010: 172). Apart from these direct monetary costs to borrowers, it is generally argued that the ultimate social and economic consequences associated with predatory lending come in the form of increased foreclosure rates because borrowers are tricked into loans they cannot actually afford (Ryder 2014: 74). ${ }^{65}$ Subprime loans with predatory terms are believed to be more likely to end in foreclosure than conventional loans. Moreover, it has been emphasized that this has detrimental effect beyond those who obtain a predatory loan and may affect entire communities and neighborhoods (Engel/McCoy 2002: 1258; Ryder 2014: 74). In this process, the elderly, poor, and minority populations are said to be hit the hardest (Engel/McCoy 2002: 1281; Hill/Kozup 2007: 30; Nguyen/Pontell 2011).

\section{Perpetrators, motivations, and opportunities}

The primary perpetrators of recent predatory lending practices are mortgage brokers and mortgage originators who, driven by fees and enabled by enormous information asymmetries between lenders and borrowers, an abundance of credit, and a lack of

65 Scholars have identified predatory lending practices as one of the primary causes for the "foreclosure crisis" that followed the collapse of the mortgage market (Baumer/Arnio/Wolff 2013). 
regulatory oversight, took advantage of disadvantaged borrowers. The mechanisms that in the literature are believed to have motivated perpetrators of predatory lending in the mortgage industry are similar to those that have been discussed in relation to mortgage origination fraud. The OTD model that prevailed in the mortgage industry operated under a fee structure by which mortgage brokers and originators profited from maximizing the volume of the loans they originated, irrespective of loan quality (Fligstein/ Roehrkasse 2013). Moreover, as Fligstein and Roehrkasse (2013: 27) point out, "when brokers were compensated in terms of yield-spread premiums - the difference between the rate charged and the par rate - brokers had incentives to inflate that rate through deception or discrimination. When mortgage brokers were compensated through fees, they had incentives to conceal add-ons and penalties." Under such a compensation structure, brokers and originators thus have obvious economic incentives to originate as many loans as possible, to refinance them as often as possible, and to originate loans with high interest rates, irrespective of whether this was in the best interest of borrowers, and even worse, irrespective of whether borrowers would be able to carry the burden of their debts over the long run.

Predatory lenders have been greatly facilitated in their egregious practices by two major changes in the mortgage industry that have taken place over the last few decades. These changes, it has been argued, set in motion a process that relieved lenders from a need for credit rationing and simultaneously caused a dramatic increase in information asymmetries between borrowers and lenders (Engel/McCoy 2002, 2007). To begin with, widespread securitization of subprime mortgage loans made possible a constant flow of money to the subprime mortgage market and allowed non-bank lenders to enter that market. This resulted in the rise of thinly capitalized and barely regulated mortgage banks that were not regulated by financial institution regulatory agencies and have relatively little to fear from reputational risk (Engel/McCoy 2002, 2007). Indeed, the majority of cases of predatory lending are said to have occurred among such independent mortgage banks (Delgadillo/Erickson/Piercy 2008: 328; Nguyen/Pontell 2011: 9). ${ }^{66}$ Moreover, for mortgage lenders, the increased availability of funds opened up the possibility to serve a new market segment of "subprime" borrowers who had previously been excluded from the credit market because of credit rationing and discrimination. Most of these borrowers were inexperienced and had low levels of financial literacy, resulting in a substantial information asymmetry between lenders and borrowers in the subprime market (Engel/McCoy 2002). In reaching out to these new borrowers, mortgage lenders, facilitated by the deregulatory policies of the industry's regulators and governmental policies that aimed at increasing homeownership, engendered a proliferation of mortgage products that were difficult for inexperienced and unsophisticated borrowers to understand. This further impaired the decision-making capacity of borrowers (Willis 2006). Ironically, then, the combined result of this "brave new world of

66 In fact, many of these "independent" mortgage banks later became subsidiaries of "respectable" banks that operated as securitizers and underwriters in the secondary mortgage market (Rosoff/ Pontell/Tillman 2014: 48). 
proliferating products, price, and risk" and the lack of financial literacy amongst the new class of borrowers was a further increase in information asymmetries ready to be exploited by unscrupulous mortgage lenders (Engel/McCoy 2002; Willis 2006).

\section{Cases discussed in the literature}

Because of predatory lending practices in the United States, a long list of financial institutions have settled with duped borrowers, local governments, regulators and the US Department of Justice for amounts that run in the hundreds of millions. Among many others, these included Household International ( $\$ 484$ million to the Federal Trade Commission), Ameriquest ( $\$ 325$ million to the Federal Trade Commission), Bank of America ( $\$ 335$ million to the DoJ), Citigroup ( $\$ 70$ million to the Federal Reserve), Wachovia ( $\$ 2$ billion to the State of California), Wells Fargo ( $\$ 175$ million to the DoJ), and EMC Mortgage, a subsidiary of Bear Stearns ( $\$ 28$ million to the Federal Trade Commission) (Fligstein/Roehrkasse 2013: 25-26; Ryder 2014: 78).

Although predatory lending practices and their role in triggering the global financial crisis of 2007-2008 have been discussed extensively in the literature, most of this work is primarily concerned with the structural features of the mortgage industry and the (de)regulatory policies that explain the widespread mis-selling of mortgage loans. Detailed case studies of predatory lending practices are extremely rare. One more detailed account of a real-world example of predatory lending is provided by Goldmann (2010). Paraphrasing from one of many class action law suits brought by victims of predatory lending practices, he describes the case as follows:

In early 2002, Nona Knox, an elderly woman who owned a home in East Palo Alto, CA, responded by telephone to an unsolicited advertisement mailed to her by Ameriquest. The mailing piece was designed to appear to be a ready-to-execute contract. Ameriquest made an appointment with Mrs. Knox and sent two men, Richard Valle and another Ameriquest agent, to the Knox home. Mrs. Knox informed Valle that she and her husband wanted to refinance their home to pay off credit cards and a car loan and to obtain cast to remodel their bathroom.

Mrs. Knox showed Valle their then current mortgage terms and said that she wanted to refinance at a fixed rate. To the best recollection of Mrs. Knox, Valle responded, "We can do better," and asked Mrs. Knox and her husband their ages. Mrs. Knox was 66 at the time; Mr. Knox was 79.

Valle filled out the entire loan application for the Knoxes. He did not have Mr. or Mrs. Knox write down any information. Rather, in response to Valle's questions about the Knoxes' income and assets, Mrs. Knox provided Valle with bank statements, Social Security check stubs, and pension information, which together documented a monthly income of approximately $\$ 4,000$. The loan application, however, lists the Knoxes' monthly income as $\$ 6,800$. This false amount was inserted into the mortgage application without the knowledge of Mr. or Mrs. Knox.

Valle also told the Knoxes that the loan would be at "no cost" to them, and he promised that they would receive $\$ 20,000$ cash back for the bathroom remodeling.

Mrs. Knox asked Valle whether he was offering the best rate. Valle responded, "I'm giving you the lowest possible rate for a person your age." 
Valle and the other Ameriquest agent returned to the Knox home shortly thereafter to complete the signing of the mortgage contract. The loan signing took only about one hour, during which Valle did most of the talking. Valle did not give Mrs. Knox any opportunity to read a single page of the loan contract; instead he flipped through the contract page by page while stating "this is for [purported purpose of the page], sign here." When Mrs. Knox inquired why she and her husband needed to sign blank pages, Valle responded, "you just need to sign these to get things done."

At the signing, the loan contract presented to Mr. and Mrs. Knox by Valle included a Notice of Right to Cancel. This notice was ineffective, however, since Ameriquest failed to fill in both the "signing date" and the "final date to cancel."

Valle did not even leave a copy of the loan contract or any other papers with Mrs. Knox nor did he say anything to her about points, fees, or the insufficiency of income.

Valle did not tell Mr. or Mrs. Knox that the loan contract - which was based on the loan application filled out by Valle - falsely stated the Knoxes' monthly income was \$6,800 and that Mr. Knox was self-employed by the "Knox Music Academy," a fictitious entity purportedly operating at the Knox home address. Mr. and Mrs. Knox did not know that this fictitious income from a fictitious business was included in the loan contract and did not suggest or consent to it. Mr. Knox was not a music teacher of any kind. Indeed, at the time of the loan application and contract signing, Mr. Knox was suffering from terminal cancer and related medical conditions, and was unable to tend to rudimentary activities without the assistance of Mrs. Knox.

Ameriquest did not provide the Knoxes with the final loan documents until after the loan had been approved, at which time Valle returned to the Knox home with a disbursement check. The check was for only $\$ 8,000$ even though Valle had promised the Knoxes that they would receive $\$ 20,000$. Valle explained the discrepancy by stating that the Knoxes needed to "pay off more bills."

Unbeknownst to the Knoxes, the loan was “bought down” from 12.5 percent to 8.25 percent at a cost of $\$ 14,875$, which was added to the loan principal without the knowledge of the Knoxes. The Knoxes also paid \$2,726 in closing costs and \$1,114.80 for the first month's interest. The Knoxes' total settlement charges were $\$ 18,715.80$ - despite having been told initially that the loan would be at "no cost" to them. (Goldmann 2010: 155-157)

Although the case described by Goldmann is probably an extraordinary egregious one, it does show in more detail a number of deceptive sales techniques that are involved in many financial mis-selling practices. In addition to plainly false statements, these include unsolicited advertising, hidden costs, high pressure sales techniques, biased advice, a failure to inquire about the client's risk profile, a failure to properly explain the details of the contract, and the use of complex and unusual contract structures.

\subsection{The mis-selling of life insurance and pension schemes}

One segment of the financial services industry that over the last few decades has been repeatedly plagued by episodes of large-scale mis-selling is the life-insurance and private pensions industry. Widespread mis-selling of life insurance and pension plans resulted in major scandals and regulatory actions in the United States in the 1980s (Fischel/ 
Stillman 1997; Egler/Malak 1999), in the United Kingdom in the $1990 \mathrm{~s}^{67}$ (Black/Nobles 1998; Ryley/Virgo 1999; Schulz 2000; Ward 2000), and in the Netherlands ${ }^{68}$ and India in the 2000s (Anagol/Cole/Sarkar 2013; Halan/Sane/Thomas 2014).

Although academic literature on mis-selling practices in the life insurance industry is scarce, the literature that does exist shows that the abovementioned mis-selling scandals all occurred against the backdrop of a gradual withdrawal of government support for state pension provision and a secular move away from traditional, collective "defined benefit" pensions toward personal "defined contribution" accounts, which essentially are investment products based on the investment performance of an underlying portfolio (Black/Nobles 1998; Ryley/Virgo 1999: 20; Ericson/Doyle 2006: 998; Mitchell/ Smetters 2013: 1). Governments in those countries allowed, through legislation, and encouraged, through tax incentives and advertising, individuals to substitute personal pension plans provided by life insurance companies for collective occupational pension schemes (Black/Nobles 1998: 796-797). To facilitate the provision of personal pensions by private companies, governments coupled the reforms with a deregulation of retail financial services sectors, allowing all sorts of financial institutions to provide an increasingly large menu of pension plans (Black/Nobles 1998: 797). The political rhetoric behind these reforms was one of bigger pension benefits, increased efficiency and flexibility of pension systems, enhanced individual control over life savings, higher returns, and decreased government pension costs (Schulz 2000: 104). In reality, however, the reforms turned out to create the perfect conditions for widespread mis-selling of life insurances and pensions in all of the abovementioned countries.

Although the exact details of the life insurance and pension mis-selling scandals in each of these countries differ, the literature indicates that some general dynamics played a role in all scandals. In all cases, life insurance companies experienced an intensification of competition as government deregulatory policies allowed banks and other financial services providers to enter the life insurance market. The entrance of new competitors

67 More recently, the issue of mis-sold life insurances has resurfaced in both the US and the UK. Driven by presumably faulty and misleading advice, many people in the US over the last decade have rolled-over from $401(\mathrm{k})$ pension plans to so-called individual retirement accounts (IRAs), which give more freedom to individuals to make decisions about their own investments. The deceptive sales practices have resulted in regulatory actions by the Department of Labor and FINRA, the financial industry's self-regulatory authority (Turner/Klein 2014). In February 2015, the news media reported that the Obama administration is responding to the problem by proposing new fiduciary duties for retail financial advisers (Chon/Jopson 2015). In the UK, a new mis-selling scandal is in the making that involves annuities (FCA 2015). In many cases, pensioners in poor health have been mis-sold regular annuities while in fact they were entitled to so-called "enhanced annuities," which provide higher payments to compensate for shorter life expectancies (Hyde/Morley 2014; Dyson 2014; Morley 2015).

68 The mis-selling affair in the Netherlands, in the country itself usually referred to as the "woekerpolisaffaire," involved not only life insurance policies but also mortgage-related payment-protection insurance policies, study saving plans, and other kinds of investment-related insurance plans. 
into the industry promptd life insurance companies to rapidly expand their sales forces and adopt more aggressive sales techniques (Black/Nobles 1998; Egler/Malak 1999: 3). In an attempt to sell as many plans as possible, poorly trained sales agents driven by perverse incentives exploited consumers' ignorance about financial affairs on a massive scale. In many cases, sales agents did not sufficiently inquire about the risk profile of the client, failed to properly explain risks, created overly optimistic projections of the future performance of the plans, or failed to properly disclose charges and commissions. Sales agents particularly exploited the uncertainty stemming from the strong investment component of personal pension plans, which significantly increases the guesswork and speculation involved in establishing the suitability of the plan for the specific consumer (Ericson/Doyle 2006: 998). A widespread practice in the industry, for example, is to have sales agents suggest that, thanks to the investment component of the plan, the product would pay for itself over time (Ericson/Doyle 2006: 997). In reality, however, consumers frequently ended up seeing much of their premiums leak away to hidden costs and fees, subtracting from the amount of capital over which return can be achieved and resulting in investment results that failed to meet expectations.

\section{Prevalence, costs, and consequences}

Although it is has been suggested in the literature that mis-selling in the life insurance industry is widespread (Ericson/Doyle 2006), exact numbers concerning the prevalence and monetary costs of the phenomenon are hard to come by. As Ericson and Doyle (2006: 995) point out and similar to the case of predatory lending practices, it is often difficult to discern when or how often the deceptive behavior of insurance salespeople might violate the law. In many cases, plan holders of mis-sold insurance plans are themselves not even aware that they have been victimized. Nor do regulatory investigations provide much conclusive results with regard to the exact scope of the problem. This is due largely to the fact that only a case-by-case examination can determine whether a product has been fraudulently mis-sold.

However, the scarce estimates that can be found in the literature do indicate that the scale of the problem is considerable, both in terms of the number of victims involved and the costs associated with it. For example, a review of life insurance selling practices in the United Kingdom during the early 1990s, commissioned by the UK securities market regulator at the time, found that 91 percent of a representative sample of files failed to prove substantial compliance (Ryley/Virgo 1999: 24). More specifically, the review found that 61 percent of the files indicated that the adviser did not adequately determine the investor's risk profile, 85 percent of the files showed no evidence of alternative pension arrangement having been considered, and in only 23 percent of the files was there an adequate analysis supporting the recommendation (Black/Nobles 1998: 793). It is generally assumed that around 2 million people were involved in the scandal,

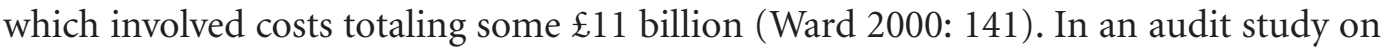
the advice given by financial advisers in the Indian life insurance market, Anagol et 
al. (2013) found that in 60-80 percent of the cases agents provided unsuitable advice. The costs associated with this scandal have been estimated at $\$ 28$ billion (Halan/Sane/ Thomas 2014). However, such estimates focus primarily on the costs associated with fines and customer redress, which are borne by shareholders of mis-selling firms. Excluded from such estimates are the emotional and psychological costs associated with the economic insecurity that plan holders have to cope with as a result of mis-sold life insurance products (Schulz 2000: 104; Tombs 2013: 14).

\section{Perpetrators, motivations, and opportunities}

Scholarly research enumerates a number of factors that have contributed to the "institutionalization of deceptive sales in life insurance" (Ericson/Doyle 2006). With regard to the supply side of the market, scholars have pointed to the remuneration of life insurance agents. The earnings of sales agents are said to be based almost exclusively on commissions, creating a strong incentive to adopt aggressive marketing techniques and to sell the highest commission product rather than the product that is most suitable for the consumer (Black/Nobles 1998: 802-804; Ericson/Doyle 2006: 997) ${ }^{69}$ Another factor that has been highlighted in the literature is the facilitating effects of an aggressive sales culture that prevails in many life insurance companies (Ericson/Doyle 2006; MacLean 2008). Agents, it has been suggested, "face a constant barrage of motivational messages aimed at augmenting their production" (Ericson/Doyle 2006: 1005). Embedded in these messages are a number of beliefs, or interpretive frames (MacLean 2008), that are thought to facilitate, if not encourage, mis-selling among agents. Scholars have, for example, mentioned the way in which customers are depicted by agents as perpetually underinsured (Ericson/Doyle 2006: 1006; MacLean 2008: 9-11) and the way in which compliance regulations are described in formal company documents as empty rituals (MacLean 2008: 11-12). Third, scholars have named vulnerabilities in the recruitment, training, and supervision of sales agents as a source of mis-selling practices (Ericson/ Doyle 2006; Black/Nobles 1998). In what has been referred to as a "revolving doors" policy, insurance firms capitalize on agents' networks of sales prospects and then cut them loose when their networks are exhausted, so that "recruitment is not based on the recruit, but on the prospect list that the recruit can come up with among his family and friends" (Ericson/Doyle 2006: 1003). One consequence of such a policy is that life insurance sales agents generally go through little training, and what little training time they do have is used primarily to focus on sales techniques and the specificities of the firm's in-house products, rather than on life insurances in general or the requirements of regulatory rules and compliance procedures relating to the selling process.

69 It needs to be mentioned here that recently regulators in the UK, Australia, the Netherlands, and Germany have passed legislation that effectively bans commission-based remuneration for life insurance sales agents and investment advisers in general (Mitchell/Smetters 203:2). 


\section{The mis-selling of payment protection insurance}

In connection with their mortgage-lending business, major banks, credit card companies, and other lenders were found guilty of mis-selling credit insurances, also known as payment protection insurances (PPI) in the early 2000s (Ferran 2012; McConnell/Blacker 2012; Ashton/Hudson 2013; Lanchester 2013; Georgosouli 2014). Lending companies pushed PPI plans provided by their affiliated insurance subsidiaries alongside loans and other credit deals with the promise that payments would be covered should borrowers to become unable to make credit repayments themselves for reasons of sickness or loss of income. It was discovered that in many cases bank staff, lending managers, and insurers working for the lending companies simply did not exercise the due diligence necessary to check the suitability of PPI for customers and failed to ensure that clients fully understood the contracts they entered into. This resulted in the misselling of PPI plans to millions of customers in the UK alone (McConnell/Blacker 2012). One observer has suggested that "if there had not been so much other lurid wrongdoing in the world of finance, and if mis-sold payment protection insurance had a sexier name, PPI would stand out as the biggest scandal in the history of British banking" (Lanchester 2013: 3). According to the British newspaper The Guardian (Treanor 2015), as of June 2015, the lending industry in the UK has already incurred $\mathrm{f} 25$ billion in fines and compensations to cover the PPI scandal, the majority of which has been imposed on the big four British banks; Lloyds, RBS, Barclays, and HSBC. It has been claimed that PPIs have also been mis-sold in connection with in relation to unsecured loans to consumers. Paterson and Brody (2014: 5) mention the example of a payday lender in Australia who sold a two-week loan to a consumer with a PPI which only paid out the amounts required to repay her small loan if the consumer lost her job (the person was a disability pensioner) or if the person suffered a catastrophic illness or died during the two-week loan period.

The demand side of the market has also been said to feature certain characteristics that facilitate mis-selling by agents. One issue that continuously comes up in the literature is the public ignorance with regard to life insurance products and the investment value of money. Consumers have been said to have difficulties comparing an ever-widening menu of products, all of which involve different risks, potential benefits, and costs (Black/Nobles 1998; Ericson/Doyle 2006). The assessment of risks and potential benefits for insurance and pension plans involves high levels of uncertainty and is therefore subject to speculation. This speculative element has been compounded by the increasing prevalence of plans that combine insurance with an investment component. It is maintained that life insurance firms and their agents exploit consumers' ignorance by providing them with deceptive projections of the future performance of insurance and pension plans that are based on highly speculative assumptions, by downplaying risks, and by hiding the mechanisms through which fees are charged by the insurance companies (Ericson/Doyle 2006).

Finally, the literature finds that regulatory authorities have done little to ameliorate the problems. Conform to the neoliberal approach to market regulation, regulators have downloaded responsibility with regard to compliance to companies themselves. Regulatory actions have been largely reactive to public complaints, an approach that becomes problematic when the majority of consumers that have been mis-sold life insurance plans are not even aware they have been victimized (Ericson/Doyle 2006: 1007-1008). Even when regulatory institutions did step in, they continued to delegate authority to 
the industry itself. Rather than punishing and excluding offenders, regulators have generally commissioned firms to internally re-evaluate their sales procedures and identify and compensate possible victims. However, in both the United Kingdom and the Netherlands, the failure of firms to properly redress victims and their attempts to reach secretive agreements with select groups of victims in an attempt to minimize legal costs have led to great public controversy.

\section{Cases discussed in the literature}

What little academic literature there is that discusses fraudulent mis-selling practices in the life insurance industry focuses primarily on identifying the structural causes that account for large waves of life insurance and pension mis-selling in certain countries and in certain historical periods. As a result of this focus, no specific cases have been discussed in more detail.

\subsection{The mis-selling of interest rate derivatives}

Because of their complexity and opaqueness, derivatives have proven to be useful devices for mis-selling practices. From the late mid-1990s onwards, derivatives have become the subject of a number of mis-selling claims in the securities industry, in which not only retail consumers but also small and medium enterprises and at times even supposedly sophisticated institutional investors have been victimized. One category of derivative contracts that has repeatedly been involved in allegations of fraudulent mis-selling by financial service firms is the interest-rate hedging product (IRHP). IRHPs, colloquially referred to as interest rate swaps, are derivative contracts that are intended to protect against interest rate risk associated with an underlying loan. The first accusations of IRHP mis-selling began to emerge in the mid-1990s and involved IRHPs that were allegedly mis-sold to a number of large, presumably sophisticated clients of the American investment bank Bankers Trust. A more recent wave of IRHP mis-selling claims emerged in the aftermath of the financial crisis of 2007-2008 (see Zepeda 2013; Marshall 2014; Bavoso 2015). In the run-up to the crisis, banks had been targeting much smaller and definitely less sophisticated clients with their aggressive and manipulative derivative-selling practices. Banks in Belgium, the Netherlands, and the United Kingdom, for example, have been found to have mis-sold large numbers of IRHPs to small and medium enterprises (SMEs) and semi-public entities.

Many SMEs in those countries had obtained business loans that had floating rates attached to them. Floating rates are interest rates that are linked to a certain benchmark rate, for example, the central bank's bank rate or the Libor rate. To hedge against fluctuations in these rates, loan officers at banks and sales agents advised and sometimes even coerced those SMEs to purchase IRHPs in connection with their business loans. In 
some cases, the purchase of an IRHP was made a condition for the loan. In their simplest form, IRHPs set a fixed rate and oblige the parties in the contract - the borrower and the bank - to make payments to each other that offset the variability of the interest rate paid on the underlying loan vis a vis the fixed rate. When the relevant benchmark rate - and thus the interest rate that needs to be paid over the loan - is higher than the fixed rate agreed upon, the bank pays the difference to the SME. When interest rates fall below it, the SME pays the difference to the bank. Often, however, loan applicants were talked into purchasing the more complex and more risky types of IRHPs. In the UK, for example, this frequently involved so-called "structured collars." ${ }^{\text {"70 }}$ A structured collar involves a standard collar, which might, for example, consist of a 5-percent "cap" "71 and a 3-percent "floor," time the bank rate falls below this strike rate, the buyer is obliged to pay to the seller of the structured collar the difference between the strike rate and the bank rate, in addition to the floor rate of 3 percent (Zepeda 2013).

During the initial period when most of the SMEs engaged in these contracts, the bank rates of central banks were relatively stable (Zepeda 2013: 210). However, when postcrisis monetary conditions led central banks to drastically lower interest rates to historic lows, many SMEs were prompted to make large and unexpected payments to the banks or to pay exorbitant exit fees to terminate the IRHPs (Zepeda 2013), causing major financial difficulties for many SMEs. Later, studies into the matter by regulators in different countries revealed that many of the SMEs had been mis-sold the IRHPs by the banks and that large-scale mis-selling had taken place. For example, the FSA, the UK financial regulator at the time, said it had found "serious failings" by several banks in the sale of IRHPs. These concerns related to evidence of inappropriate sales of IRHPs, poor sales practices, poor record-keeping by banks, and sales incentive schemes that were likely to exacerbate the risk of poor sales practices (FSA 2012, referred to by Zepeda 2013). It was found that many IRHPs had been "over-hedged" - meaning that the amounts or the duration of the IRHP, or both, did not match the underlying SME

70 In the Netherlands, the majority of IRHPs that were (mis-)sold to SMEs involved plain vanilla swaps, in which counterparties simply exchange interest rate cash flows, from a fixed to a floating rate or vice versa. In its investigation, the FSMA, the Belgian financial market regulator, focused on the mis-selling of so-called "Bermudan callable swaps," which had been sold to SMEs during the period 2007 to 2009. In the case of a Bermudan callable swap, the buyer pays a fixed interest rate over an initial period of, say, five years. Compared with a plain vanilla swap, this interest rate is somewhat lower in the case of a Bermuda swap, say 3.8 percent instead of 4 percent. The buyer thus receives some sort of a discount. In exchange for this discount, however, the bank gets the option at the end of the initial period to decide whether it wants to continue the 3.8-percent interest rate or to charge instead the bank rate prevailing at the time (Follow the Money 2015).

71 A "cap" of, say, 5 percent can be purchased in relation to a loan with a floating rate and obliges the seller of the cap - usually a bank - to credit the buyer of the cap in case bank rates rise above 5 percent. It thus effectively "caps" the interest rate to be paid on a floating rate loan at 5 percent.

72 A "floor" operates in reverse to a cap. It places a minimum interest rate to be paid by the buyer, even if bank rates fall below that rate. 
loan - and that banks had included excessive break costs - costs to prematurely exit the contract - in the contracts; these costs sometimes exceeded 40 percent of the value of the underlying loan. Moreover, in many cases sales agents had failed to ascertain the customer's understanding of these costs as well as other risks involved in the contract (Zepeda 2013: 211; Marshall 2014). Another key issue identified by the financial conduct authority in the Netherlands was that banks had not made it sufficiently clear to their clients and customers that they were not acting as advisers in the sale of IRHPs, as they usually do in other transactions with their clients, but merely as sales persons (AFM 2013). Clients thus assumed the banks were advising them on IRHPs, while in fact the banks were acting as counterparties in an arms-length transaction, which frees them from their fiduciary duties towards clients. ${ }^{73}$

In addressing the issue, regulators in Belgium, the Netherlands, and the UK all urged or forced banks to come to a suitable solution and offer appropriate redress and compensation on a case-by-case basis. ${ }^{74}$ To the dismay of many, these solutions allowed banks to do settle claims out of court. Thus, claims have been settled privately and away from public scrutiny. ${ }^{75}$ Some have suggested that the watering down of findings in regulatory investigations and the low-profile solutions suggested by regulators have come into being under the pressure of governments and banks, for whom the mis-selling scandals would be "a scandal too far" (Zepeda 2013: 10).

\section{Prevalence, costs, and consequences}

At the time of writing, not much is said in the scarce literature about the extent of misselling of IRHPs. The Dutch regulator has stated that about 17,000 IRHP contracts have been sold to SMEs (FTM 2014a) and in the United Kingdom this number is estimated at about 60,000 SMEs (Khalique 2015b). However, what proportion of these IRHPs has been fraudulently mis-sold is not clear. In Belgium, the government regulatory agency did not reveal the exact extent of the mis-selling of IRHPs but did say the problem had not reached the proportions it has in the Netherlands and the United Kingdom (FTM

73 This practice of financial advisers alternating seamlessly between their legal identities as fiduciary-level advice givers and conflicted salespersons without making this explicitly clear to their clients, has been referred to as "hat switching" (Mitchell/Smetters 2013: 3).

74 In the UK, the FSA reached an agreement with eight banks that had been involved in the scandal - most notably Barclays, HSBC, Lloyds, and RBS - that forced these banks to provide redress and compensation to customers who had been mis-sold IRHPs. As was the case in the UK, the Belgian financial market regulator FSMA used its authority to force banks to re-evaluate their most questionable IRHPS sales to SMEs, i.e., those that involved so-called "Bermudan callable swaps," and provide suitable redress to the SMEs (FTM 2015). The regulator in the Netherlands (the AFM) did not use its authority to force banks to re-evaluate their sales of IRHPs to SMEs but nevertheless said that the advice given by banks to SMEs was often inadequate and urged banks themselves to come up with a suitable solution to the problem (AFM 2014).

75 Nevertheless, some SMEs have filed private and collective suits against the banks that sold them the IRHPs, accusing them of misleading marketing and sales practices in regard to these products. 
The mis-selling of interest rate swaps to "sophisticated" corporate clients

From the late 1980s onwards, several investment banks, most notably the Wall Street giant Bankers Trust, had started to marketize and sell interest rate swaps (IRSs) to some of their institutional clients as a way of hedging against interest rate volatility. At that time IRSs were cutting-edge financial products that were probably not very well understood even by what were considered to be "sophisticated investors," such as local government and big corporations. Initially, the contracts seemed to be beneficial to the end users. However, when interest rates were suddenly cut by the FED in 1991-1992, many holders of IRSs, primarily major corporations and local governments, started to experience substantial losses on their IRS positions. A number of end users filed suits against the banks that had sold them the derivatives, claiming that the banks' dealers had misled them with respect to the risks involved in these products. Two high-profile cases in this episode were that of the American greeting cards company Gibson Greetings (Overdahl/Schachter 1995; Schmedlen 1995: 1459-1462) and the American consumer goods company Procter \& Gamble (Rosenthal 1996: 1250), both of which had been (mis-) sold IRSs by Bankers Trust. A major point of contention in the academic debate that followed was the extent to which the investors that engage in derivative deals should be considered "sophisticated investors" and, following from that, whether they warrant special legal protection in the form of fiduciary duties and suitability requirements when engaging in such deals (see Schmedlen 1995; Roberts 1996; Rosenthal 1996; Geckeler 1996; Gibson 1998).

2015). Nevertheless, an indication of the extent of fraudulent mis-selling that has been offered in the literature refers to a 2012 FSA pilot study. The study, which looked at 173 sales of IRHP to non-sophisticated clients by eight different banks, found that over 90 percent of these sales did not comply with one or more regulatory requirements (FSA 2012, cited in Zepeda 2013: 10).

For individual SMEs, the costs and consequences of mis-sold IRHPs are substantial and have resulted in a great number of bankruptcies. The unprecedented low interest rates in the post-crisis period forced many SMEs to either make large payments to the banks who sold them the IRHP or pay exorbitant exit costs to terminate the contract. These termination costs could amount to 50 percent of the value of the loan, in addition to the value of the loan itself (Bavoso 2015: 7). In some cases, SMEs that were unable to make such payments saw their credit lines with the bank being blocked because the negative value of their IRHP was accounted for by the banks as a claim of the bank on the SMEs. The mis-selling episode has also resulted in significant costs to the firms who sold the IRHPS. In the UK, as of February 2015, banks have already paid out $\mathfrak{E} 1.3$ billion in redress and compensation (Khalique 2015b). However, despite this large number, it has been argued that redress is unlikely to ensure full and fair compensation for all victims. SMEs face major challenges in providing evidence that they are eligible for redress and, even when they manage to do so, are likely to be grateful for whatever redress is proposed by the banks, even though, according to some, this might be "considerably less than what they should receive in the interest of fairness" (Zepeda 2013: 11). 
The mis-selling of IRHPs to local governments and semi-public institutions

Not just SMEs and larger corporate clients have been mis-sold IRHPs by banks. Local governments in the US and semi-public building associations in the Netherlands have become entangled in predatory swap agreements as well (Bavoso 2015). Banks had been selling IRHPs to a great number of municipalities across the US, which had been convinced by these banks that these products would help them offset costs from rising interest rates. As was the case for the SMEs that bought these products, a sudden fall in interest rates during the post-crisis period caused many of these entities to lose their swaps "bet" catastrophically. Many of them saw themselves forced to either continue making payments on their IRHP positions or pay exorbitant termination fees in order to opt-out of the contracts. Perhaps the most notorious case is that of the city of Detroit. The city became entangled in predatory IRS agreements proposed by UBS and Bank of America. The IRHP agreements, amounting to \$1.4 billion, were entered into to hedge the risks of interest rate fluctuations on bonds that had been issued to fund public pensions (Bavoso 2015: 9-10). By 2009, the city was unable to continue payments averaging more than $\$ 4$ million per month to the banks, so UBS and Bank of America extorted control over revenues from Detroit's casinos from the city by threatening it with a $\$ 400$ million termination fee. The regulator in the US - the SEC - did not undertake a formal investigation of the matter, hence the scandal did not give way to mis-selling. This is, however, not the first time that IRHPs have led to public bankruptcies. The mid-1990s witnessed several quite similar episodes. For example, the bankruptcy of Orange County, California, in 1994 was closely tied to IRHPs that had been sold to the county by Merill Lynch. The county's treasurer, who eventually pleaded guilty to six counts of fraud, argued that he was primarily to blame for following the advice of the investment brokers of Wall Street giant Merill Lynch. Although the company denied any wrongdoing, it paid \$400 million to settle claims that it permitted and encouraged the county's treasurer to enter into an investment scheme that the firm knew was wholly inappropriate and unsuitable for the county (Geckeler 1996: 309, footnote 130; Rosoff/Pontell/Tillman 2010: 605-607).

\section{Perpetrators, motivations, and opportunities}

Reports of regulatory authorities and journalists, as well as the scarce academic literature on the topic, suggest that rewards and incentives for sales agents acted as the main motor driving the mis-selling of IRHPs. Loan officers were subjected to perverse incentives in the form of targets and bonuses to sell as many IRHPs as possible and preferably the types of IRHPs most profitable for the bank in connection with the loans they extended to SMEs (FTM 2014b; Bavoso 2015: 7). It has also been suggested that IRHP mis-selling practices were facilitated by the fact that interest rates had been relatively stable throughout the period from 2001 to 2008, the period during which most of the IRHPs were sold. According to one observer, it is possible or perhaps even likely that this stability was used by banks' salespeople to persuade SMEs that the potentially high payment obligations for the knock-in floor strike rate would never be triggered (Zepeda 2013: 210). Rather, loan officers and sales agents emphasized the fact that these more complex and potentially more destructive types of IRHPs could be acquired for free or at least against a much lower premium (price) compared with other, more straightforward IRHPs (Zepeda 2013: 210). 


\section{The mis-selling of FX hedging products}

In the footsteps of the IRHP mis-selling scandal, a new mis-selling scandal is said to be emerging as of very recently. It has been claimed that banks have aggressively sold FX hedging products and seduced unsophisticated clients, such as travel agencies, into entering into some very speculative and complex derivatives that involved triggers and knock-out rates similar to those that were involved in the IRHP mis-selling episode and that are believed to be unsuitable for those clients (Khalique 2015a; Khalique 2015b). The recent spike in currency volatility has had significant adverse economic consequences for many holders of these FX hedging products. To make things worse for the banks' counterparties, the banks had also included excessive cancellations fees in the contracts, just as in the case of IRHP mis-selling. The scandal has not yet been taken up in the academic literature.

\section{Cases discussed in the literature}

Despite wide coverage of the episode in the financial press, little academic literature on the IRHP mis-selling claims brought by SMEs exists, and no cases have been discussed in detail (Khalique 2015b).

\subsection{The mis-selling of synthetic CDOs}

Two other forms of derivatives contracts that have been involved in transactions and could have arguably been fraudulently mis-sold are the so-called "collateralized debt obligation" (CDO) and the "synthetic collateralized debt obligation"76 (synthetic CDO). Journalistic endeavors, ${ }^{77}$ court cases, and Senate subcommittee hearings in the United States have revealed that, in the wake of the credit crunch, broker-dealers in a number of banks had been marketing and selling to some of their institutional clients (synthetic) CDOs which they knew to be defunct and which had in some cases even been designed to fail. This involves cases in which broker-dealers of the banks who acted as underwriters did not necessarily make explicit misrepresentations about their products

76 A synthetic CDO is made out of credit default swaps. A credit default swap is a derivative contract through which one party sells and the other party buys insurance on a reference portfolio of debt instruments - usually asset-backed securities. The reference portfolio can consist of any combination of ABSs. What is important in the case of a synthetic CDO is that the buyer of the insurance does not actually have to own the reference portfolio for which insurance is bought. Effectively, then, through the insurance contract, the seller of the insurance receives a cash flow consisting of periodical payments made by the buyer in exchange for which it exposes itself to the risk of default of the reference portfolio, without actually owning the reference portfolio. Because synthetic CDOs allow parties to buy insurance on assets that they do not actually own, they create a situation in which a buyer of insurance can actually make a profit, rather than merely receive compensation for losses, when a credit event occurs.

77 Perhaps one of the most revealing and influential investigative works on this topic has been Michael Lewis' best-seller The Big Short: Inside the Doomsday Machine (Lewis 2011). 
but nevertheless marketed and sold their clients investments they knew to be poor ones (Fligstein/Roehrkasse 2013: 28). The banks, so it seems, deliberately lured their clients into money-losing deals, while they themselves, in collaboration with some of their other clients, bet against them.

These questionable and arguably fraudulent sales practices first became known to a broader public when the so-called Hudson and Timberwolf synthetic CDOs became the focus of the Levin subcommittee hearings in the US Senate (Ferguson 2012: 192). In both cases, Goldman Sachs, the bank that for many has become the primary example of bubble-era greed (e.g., Taibbi 2009), was accused of marketing and selling to naïve investors (synthetic) CDOs that it had designed in order to rid itself of its worst loans and that it internally believed to be "a piece of shit," as leaks of the firm's internal correspondence revealed (Ferguson 2012: 192). More recently, in April 2010, the SEC leveled a highly publicized enforcement action against the firm that has attracted a lot of scholarly and public attention (e.g., Jeffers/Mogielnicki 2010; Taibbi 2009; Davidoff Solomon/Morrison/Wilhelm 2012; Rosoff/Pontell/Tillman 2014: 260-262; Ryder 2014; Scopino 2014: 76-77; Nesvetailova/Sandu 2015: 141-143). It concerned the so-called ABACUS 2007-AC1 transaction, marketized and underwritten by Goldman Sachs. Although scholars agree that misleading sales practices related to (synthetic) CDOs by major banks were systemic in the wake of the credit crunch, virtually all scholarly attention has focused on this specific case. This section will follow the example set by the literature and primarily discuss this single case.

\section{The ABACUS case}

The ABACUS 2007-AC1 transaction involved a $\$ 2$ billion synthetic CDO that referenced a pool of mortgage-backed securities. Acting as underwriter in the transaction, Goldman Sachs, and especially one of its lead salespeople, Fabrice Tourre - known to refer to himself as the "fabulous Fab" - allegedly tricked investors into investing in the synthetic CDO, even though they knew it to be a bad investment. Not only did Tourre endorse the viability and soundness of the housing market while actually being fully aware of its impending future ${ }^{78}$ (Rosoff/Pontell/Tillman 2014: 261), he also neglected to disclose material information about a significant conflict of interest involved in the construction of the instrument. This conflict of interest was that the reference portfolio had been assembled by hedge fund manager John A. Paulson of Paulson \& Co. Inc., whose firm had subsequently taken a short position on that same CDO. According with his short position, Paulson had carefully selected a portfolio of assets that he knew to

78 The most incriminating evidence for Tourre was an e-mail that surfaced during the SEC investigation that read: "More and more leverage in the system, the whole building is about to collapse anytime now. ... Only potential survivor, the fabulous Fab ... standing in the middle of all these complex, highly leveraged, exotic trades he created without necessarily understanding all of the implications of those monstrosities!!!” (cited in Rosoff/Pontell/Tillman 2014: 261). 
be of poor quality. The deal was closed on April 26, 2007, and by October 24 of that same year, about 83 percent of the loans included in the reference portfolio had downgraded $^{79}$ (Rosoff/Pontell/Tillman 2014: 261), resulting in major losses for the investors in the synthetic CDO - in particular the German bank IKB and the Dutch bank ABN AMRO. Had Tourre told his clients his true opinion on the housing market, and had the role of Paulson in the construction of the portfolio been appropriately disclosed to investors, it is likely that many investors would have refrained from investing in the ABACUS CDO altogether. Goldman Sachs invoked caveat emptor in its defense and maintained no legal wrongdoing (Fligstein/Roehrkasse 2013: 28). The case was eventually settled on the grounds that a "mistake" had been made by Goldman Sachs (Dorn 2011: 162). In the settlement, Goldman Sachs agreed to pay a financial penalty of $\$ 550$ million. Although the penalty was heralded by the SEC as a record fine, critics have suggested that the size of the penalty pales when compared with the $\$ 3.46$ billion Goldman Sachs earned during the first quarter of 2010 and the fact that the firm saw its share price rise by more than 10 percent after announcing its consent to the SEC fine (Ryder 2014: 97-98; MacDonald 2012).

\section{Legal ambiguity}

For legal and finance scholars, the ABACUS case, and its settlement on the basis of a "mistake," left many questions unanswered regarding the meaning of conflicts of interest and the fiduciary duties of banks in their dealing with supposedly sophisticated clients (Dorn 2011). What followed was a body of academic literature contemplating the legal character of the case and the challenges it poses for the legal regime governing such behavior (Buell 2011; Jeffers/Mogielnicki 2010; Davidoff Solomon/Morrison/Wilhelm 2012; Scopino 2014). This body of literature places the question of Goldman Sachs' fiduciary duty towards its clients in the context of rapidly evolving financial markets and structural changes in the banking business. Both journalists and academics reporting on the ABACUS case have pointed to a changing identity of banks with regard to their function as intermediaries between transacting parties (Gandel 2010; Davidoff Solomon/Morrison/Wilhelm 2012). It has been suggested that banks have abandoned their traditional role as reputational intermediaries facilitating transactions through tacit rules and norms of trust and instead increasingly conduct deals that are transactional in nature and executed at arms-length (Davidoff Solomon/Morrison/Wilhelm 2012).

For some, this changing identity is a function of technological changes in the investment banking business (e.g., Davidoff Solomon/Morrison/Wilhelm 2012). Others have explained the changing identity of banks rather as a consequence of a transformation in the banks' business models and the rise in prominence of traders as a specific category of actors within those banks. It has been suggested that two decades of cheap money and the employment of increasingly complex mathematical models have pushed profits

79 By January 2008, this number had risen to 99 percent (Rosoff/Pontell/Tillman 2014: 261). 
in banks' trading activities and increased the importance of profits made by these activities vis a vis profits made by more traditional investment banking activities (Gandel 2010; for more on this trend, see also Partnoy 2002; Luyendijk 2015). Parallel to this, former traders, with their appetite for risk-taking and their mindset of "making money every minute of every day," began to fill more and more positions in the upper echelons of many banks (Gandel 2010) ${ }^{80}$ As a result of these developments, the overall business models of banks have increasingly moved from one focused on nurturing long-term relationships with the economy and the companies in it to one oriented towards making quick profits through trading activities, if necessary at the cost of clients. Also discussed in this literature are the more recent legislative initiatives that tried to establish specific requirements and ethical business conduct standards aimed at preventing swap dealers from taking advantage of certain investors (Scopino 2014).

\section{Other cases in the literature}

Although the ABACUS transaction represents one of the most compelling occurrences of the mis-selling of structured finance products in the wake of the credit crunch (Nesvetailova/Sandu 2015: 141), it is far from being an isolated case. Similar cases have been mentioned in the literature that involve Deutsche Bank (Scopino 2014: 70-71), JP Morgan (Ryder 2014: 98), Merill Lynch (Taibbi 2009), and Citigroup (Ryder 2014: 99). In the latter case, the SEC stated that "securities laws demand that investors receive more care and candor than Citigroup provided to these CDO investors" and that "Citi's alleged conduct arguably [was] more egregious than that in Goldman Sachs' [case]" (SEC, cited in Ryder 2014: 99).

\section{Conclusion}

This paper set out to present a descriptive account of the empirical universe of fraud in the context of financial market activities. It did so by reviewing the literature on financial fraud in a variety of academic disciplines. Specifically, its aim was to describe the different forms of fraudulent behavior financial markets, the prevalence and consequences of such behavior as identified by previous scholarly research, and the economic and market structures that scholars believe facilitate this behavior.

The literature reviewed is found in a wide range of academic disciplines, including law, economics, finance, accounting, business, political economy, sociology, criminology, and psychology. Authors working in these different disciplines generally do not come

80 According to one observer, this development is best exemplified by the career of Goldman Sachs CEO Lloyd Blankfein, who made it from commodities and currency trader - in the 1990s still a side business for most investment banks - to CEO of the firm (Gandel 2010). 
together in a common approach. The notion of financial fraud is viewed differently in different academic disciplines. Whereas legal scholars conceive of fraud as a legal concept that prescribes civil or criminal liability, scholars working in the fields of sociology and criminology think of it as a behavioral category that involves human action and exploitation of social relations of trust. Finance and economics scholars, in turn, see fraud as a form of risk that market participants must factor into their investment portfolios. This paper has tried to bypass these conceptual differences and instead draw a general picture of the empirical universe of financial fraud. What emerged from the literature review is a picture of financial fraud as a complex phenomenon that takes very different forms, depending on the market segments in which they are perpetrated, the financial instruments they pertain to, and the actors involved in them. What all forms of financial fraud have in common, however, is that they illegally exploit information asymmetries by providing market participants with false or misleading information. By looking in more detail at the way in which these information asymmetries are being exploited, I have made a conceptual distinction between three types of financial fraud: financial statement frauds, financial scams, and fraudulent mis-selling.

When recapitulating the literature review presented in this paper, one gets a strong sense not only that financial fraud is widespread throughout the financial industry, but also that the problem of fraud has intensified over the last couple of decades, both in retail and wholesale financial markets. Although financial fraud is not new in any sense, both the frequency with which it occurs and the monetary cost associated with it seem to have increased. It has also been noted here that monetary costs are not the only costs associated with financial fraud. At a general level, six types of cost have been identified in the literature. These are monetary costs to individual victims, emotional and psychological costs to individual victims, monetary costs to firms and shareholders resulting from fines and customer redress, monetary costs to firms and shareholders associated with share price depreciations caused by reputational damage to the firm, societal costs in the form of increased systemic risk as a consequence of bubble forming and potential financial collapses, and wider societal costs in the form of an inefficient allocation of capital.

Some caution, however, is needed in interpreting the quantifications of the prevalence and cost of financial fraud presented in the literature. Given the nature of financial frauds as crimes of concealment, most of these numbers are estimates at best. Little hard data is available on the prevalence of financial fraud, and the data that is available is often subject to definitional biases and related issues of overinclusion or overrestrictedness. All available databases fail to account for the iceberg of undetected fraud, a problem researchers generally address by constructing ad hoc proxies that come with their own methodological deficiencies. Another important point with regard to the prevalence of financial fraud concerns the relationship between financial fraud and financial crises. There is a general consensus in the literature that financial fraud is linked to economic cycles, although there is much less agreement on the character of the causal mechanisms that establish this link (Blanqué 2003; Kindleberger/Aliber 2005; Povel/ Singh/Winton 2007; Sen 2009; Huisman 2011; Gill 2011). Two of the possible causation 
scenarios (Huisman 2011) suggest that the increase in financial fraud observed during the aftermath of financial crises is a consequence not so much of an actual increase in the number of schemes perpetrated by fraudsters, but rather by an increase in the exposure of long-running fraud schemes as a consequence of a decline in the availability of credit, or by the informal and formal criminalization of types of behavior that were previously not considered illegal.

What makes the perceived proliferation of financial fraud especially worrying is the increased involvement of established financial institutions. Captains of industry, including large banks the likes of Goldman Sachs and Deutsche Bank, accountancy firms like Ernst \& Young and Deloitte, and insurance conglomerates such as Lloyds and AIG, have been involved in many of the financial scandals discussed in this paper. Even in those cases where these respected institutions did not play an active role as primary perpetrators, they often played a more facilitating role backstage by turning a blind eye to fraudulent practices from which they could reap profits indirectly. The industry itself has usually responded to revelations of their involvement in financial fraud by suggesting that such fraudulent deals are the work of "a few bad apples" within the organization. The findings of this literature review, however, seem to dismiss the "bad apples" theory and instead lend support to the criminogenic markets hypothesis, which postulates that markets and organizations can be criminogenic in the sense that they structurally facilitate or even promote illegal behavior. Although the market structures and arrangements that have been identified in the literature as being responsible for financial fraud differ between different types of fraud, it is possible to distill from this literature review four recent developments that are believed to have greatly facilitated the occurrence of financial fraud.

First, scholars have repeatedly pointed out the problematic consequences of financial deregulation and the changing structure of competition and compensation. Financial deregulation has intensified competitive dynamics in previously protected industries and allowed new fundamental conflicts of interest and perverse incentive structures to develop in both vertically and horizontally integrated, large financial conglomerates that provide a wide range of financial services to a great diversity of clients. Parallel to this, the institutionalization of incentive-based compensation structures (e.g., stock options, bonuses, commission fees) in financial firms, not only at the top but at all levels, has been said to have created perverse incentives throughout the entire financial value chain. As a result, business models of financial firms have become increasingly oriented towards short-term profit-making and stock-price maximization, irrespective of the legal implications of such business models. Fines and other legal penalties are built into such business models as simply a cost of doing business. ${ }^{81}$ The incentive problem has been further exacerbated by the introduction of new layers of intermediaries (e.g., fund managers, financial advisers, mortgage brokers, insurance agents) in the financial value chain and the new forms of compensation that have come with it.

81 For more on the adverse consequences of incentive-based compensation structures in the financial services sector, see Wawoe (2010). 
Second, over the last few decades financial markets have seen an influx of relatively unsophisticated investors. As a consequence of a general trend towards the privatization of social security and the financialization of Western economies, consumers, small and medium enterprises, local governments, and semi-public institutions in those economies increasingly started to engage in financial market activities. This influx of relatively unsophisticated investors has provided fraudulently predisposed and more financially sophisticated market players with a large pool of vulnerable, easily exploitable investors.

A third development that has repeatedly surfaced throughout the paper is the increasing complexity involved in financial market transactions. Rapid technological, legal, and financial innovation (e.g., derivatives, securitization, special purpose vehicles) and an ever-widening menu of financial products have greatly reduced the transparency and comprehensibility of financial transactions and increased the opportunities available to fraudsters to deceive other market participants. Some scholars have suggested that the increased complexity of financial market transactions should be understood as the result of a deliberate strategy pursued by financial firms. As one observer put it:

The unpalatable reality that very few self-interested industry participants are prepared to admit is that much of what passed for financial innovation was specifically designed to conceal risk, obfuscate investors and reduce transparency. ... The process was entirely deliberate. Efficiency and transparency are not consistent with the high-profit margins that are sought after on Wall Street. Financial products need to be opaque and priced inefficiently to produce excessive profits or economic rents. (Bloomberg News, in Schechter 2010: 20)

Fourth and finally, the veil of secrecy and mystique surrounding many financial market activities further facilitates the occurrence of fraud in financial markets. The increased use of justified secrecy in the form of strict confidentiality rules around banking and legal services and the use of off-balance-sheet constructions and shell companies located in secrecy jurisdictions has been on the rise over recent decades. Financial frauds "thrive in [this] fertile soil of incomplete disclosure and lack of transparency. Secrecy holds investors at bay, making them vulnerable" (Shapiro 2013: 135).

With regard to the general findings of this paper, some additional remarks are in order here. On the one hand, the scope is limited in the sense that a number of relevant dimensions of the literature have not been discussed in detail. For example, theories of financial fraud, historical accounts, ${ }^{82}$ and issues related to the political economy of lawmaking and law enforcement have largely been left out. ${ }^{83}$ Moreover, the list of types of financial fraud discussed is not exhaustive. Other fraudulent acts have been discussed in the literature as well, but I have limited myself to discussing only those acts that have

82 For historical accounts of the phenomenon and legal concept of financial fraud, I refer to Poovey (2009), Taylor $(2007,2012)$, and Wilson $(2006,2014)$.

83 For discussions of the political economy of law-making and law enforcement, especially after the financial crisis, I refer to Tomasic (2011), Barak (2012), Baber (2013), O’Brien (2013), Pontell and Geis (2014), and Pontell et al. (2014). 
received the most attention. On the other hand, some of the findings presented here have relevance beyond the phenomenon of financial fraud. Although I have exclusively focused on financial fraud as a behavioral category, many of the observations and findings pertain to other forms of financial crime as well. Much of the literature covers areas that go beyond financial fraud and discusses such behavior in a broader context also involving other types of financial crime, such as market manipulation, insider trading, bribery, self-dealing, and tax evasion. Finally, the study's focus on English-language literature has had implications for the representativeness of the findings presented, which is skewed heavily towards the Anglo-Saxon world.

The findings of the literature review presented in this paper suggested that fraud has moved from the fringes of financial market activity to become a widespread type of behavior throughout the industry. In much academic work on financial markets, however, financial fraud is still treated as no more than a circumstantial issue with only tangential relevance to a number of mainstream issues. The perceived proliferation of financial fraud turns it into a social phenomenon that deserves to be a mainstream focus in its own right. For academics working on financial markets, there is still much uncovered terrain when it comes to financial fraud. More research is needed, and such future research could focus on a number of themes.

First, more exploratory work can be done to map the empirical universe of financial fraud. Especially the phenomenon of fraudulent financial mis-selling, which has become a prevalent form of fraud over the last decade, has been neglected so far. Scholars could also study in more detail the psychological dimension of illegal decision-making and the particularities of the social settings and cultural environments in which such decision-making takes place. Some journalistic work has suggested that the financial industry represents a very particular working environment that is isolated from the outside world by a strong "code of silence" and in which job security is extremely low (Luyendijk 2015). Earlier work conducted in the field of organizational studies has suggested that corrupt practices can become normalized, that is, embedded in organizations to the point that it is more or less taken for granted and perpetuated (Ashforth/ Anand 2003). An experimental study on business culture and dishonesty in the banking industry published in the journal Nature seemed to indicate that such a culture favoring dishonest behavior might currently prevail in the banking industry as a whole (Cohn/ Fehr/Maréchal 2014). More systematic work on the culture prevailing in the financial industry is called for. Research in this direction could build on earlier work conducted in the field of white-collar crime, where the social and psychological dimensions of illegal decision-making have for long been at the heart of the discipline's research agenda.

At a more systemic level, future research could look at the impact of fraud on the functioning of markets and investigate the way in which financial frauds have an impact on the stability of financial systems. Recent research going in this direction (e.g., Sen 2009; Huisman 2011; Blanqué 2003; Nesvetailova/Palan 2013; Nesvetailova/Sandu 2015) has found meaningful points of departure in the works of Hyman Minsky and Charles 
Kindleberger. More research could also be done on the political and economic structures that facilitate financial fraud. What has been especially lacking so far is comparative research on the nature and character of financial fraud across different political economic systems. How do levels of financialization of national economies and degrees of institutionalization of financial systems affect the occurrence and control of financial fraud? Also, to what extent does the occurrence of financial fraud differ between different legal systems? Such work could build on existing work in the field of comparative political economy and on literature in law and finance (e.g., La Porta et al. 1998; Coffee 2005; Deakin et al. 2015). Another interesting issue for future research concerns the relationship between deregulation and financial fraud. What are the causal mechanisms establishing the observed link between deregulation and financial fraud? Finally, scholars could study the way in which prevailing interest rates affect the occurrence of financial fraud. To what extent do low interest rates encourage excessive risk taking and facilitate Ponzi-like investment schemes? This question is especially relevant when considered against the backdrop of the secular stagnation thesis (Summers 2014), which predicts a sustained period of unusually low interest rates.

It is imperative to recognize the illegal dimension of behavior among financial market participants and to deepen our understanding of such behavior in order to further our understanding of financial market dynamics and to safeguard the integrity and soundness of financial systems in the future.

\section{References}

Ackermann, Thomas, 2011: Consumer Protection and the Role of Advice in the Market for Retail Financial Services. In: Journal of Institutional and Theoretical Economics 167, 22-25.

Acoca, Brigitte, 2008: Online Identity Theft: A Growing Threat to Consumer Confidence in the Digital Economy. In: Demosthenes Chryssikos/Nikos Passas/Christopher D. Ram (eds.), The Evolving Challenge of Identity-related Crime: Addressing Fraud and the Criminal Misuse and Falsification of Identity. Milan: ISPAC (International Scientific and Professional Advisory Council of the United Nations Crime Prevention and Criminal Justice Programme), 71-86.

AFM (Autoriteit Financiële Markten), 2013: AFM rapportage rentederivaten: Dienstverlening aan semipublieke instellingen en het professionele MKB. Amsterdam: Autoriteit Financiële Markten. $<$ www.afm.nl>

_ - 2014: Aanbevelingen rentederivatendienstverlening: Voor een passende dienstverlening aan het niet-professionele MKB. Amsterdam: Autoriteit Financiële Markten. <www.afm.nl>

Anagol, Santosh/Shawn A. Cole/Shayak Sarkar, 2013: Understanding the Advice of Commissions-motivated Agents: Evidence from the Indian Life Insurance Market. Working Paper 12-055. Boston: Harvard Business School. <www.hbs.edu/faculty/pages/download.aspx?name=12-055.pdf $>$ (March 7, 2013)

Anderson, Keith B./Erik Durbin/Michael A. Salinger, 2008: Identity Theft. In: The Journal of Economic Perspectives 22, 171-192.

Anderson, Ross/Tyler Moore, 2006: The Economics of Information Security. In: Science 314, 610-613.

Ashforth, Blake E./Vikas Anand, 2003: The Normalization of Corruption in Organizations. In: Research in Organizational Behavior 25, 1-52. 
Ashton, John K., 2015: The Scale and Scope of Financial Mis-selling. In: Tina Harrison/Hooman Estelami (eds.), The Routledge Companion to Financial Services Marketing. New York, NY: Routledge, 441-455.

Ashton, John K./Robert S. Hudson, 2013: The Mis-selling of Payments Protection Insurance in Mortgage and Unsecured Lending Markets. In: José M. P. Monsálvez/Juan F. de Guevara Radoselovics (eds.), Modern Bank Behaviour. Basingstoke: Palgrave MacMillan, 8-33.

Baber, Graeme, 2013: A Critical Examination of the Legislative Response in Banking and Financial Regulation to Issues Related to Misconduct in the Context of the Crisis of 2007-2009. In: Journal of Financial Crime 20, 237-252.

Baker, Wayne E./Robert R. Faulkner, 2003: Diffusion of Fraud: Intermediate Economic Crime and Investor Dynamics. In: Criminology 41, 1173-1206.

Barak, Gregg, 2012: Theft of a Nation: Wall Street Looting and Federal Regulatory Colluding. Lanham, MD: Rowman \& Littlefield.

, 2011: The Securitization of Mortgage Fraud. In: Mathieu Deflem (ed.), Economic Crisis and Crime. Bingley: Emerald, 65-84.

Barnett, Harold C., 2013: And Some with a Fountain Pen: Mortgage Fraud, Securitization, and the Subprime Bubble. In: Susan Will/Stephen Handelman/David C. Brotherton (eds.), How They Got Away with It: White Collar Criminals and the Financial Meltdown. New York: Columbia University Press, 104-129.

Baumer, Eric P./Ashley N. Arnio/Kevin T. Wolff, 2013: Assessing the Role of Mortgage Fraud, Confluence, and Spillover in the Contemporary Foreclosure Crisis. In: Housing Policy Debate 23, 299-327.

Bavoso, Vincenzo, 2015: Financial Innovation, Derivatives and the UK and US Interest Rate Swap Scandals: Searching for Lessons and Drawing a Way Forward. Draft, March 2015. $<$ http://papers.ssrn.com/sol3/papers.cfm?abstract_id=2467006>

Benmelech, Efraim/Eugene Kandel/Pietro Veronesi, 2007: Stock-based Compensation and CEO (Dis) Incentives. NBER Working Paper 13732. Cambridge, MA: National Bureau of Economic Research. <www.nber.org/papers/w13732.pdf>

Benston, George J., 2006: Fair-value Accounting: A Cautionary Tale from Enron. In: Journal of Accounting and Public Policy 25, 465-484.

Benston, George J./Al L. Hartgraves, 2002: Enron: What Happened and What We Can Learn from It. In: Journal of Accounting and Public Policy 21, 105-127.

Beyer, Max/David de Meza/Diane Reyniers, 2013: Do Financial Advisor Commissions Distort Client Choice? In: Economics Letters 119, 117-119.

Biegelman, Martin T., 2013: Faces of Fraud: Cases and Lessons from a Life Fighting Fraudsters. Hoboken, NJ: Wiley.

Bitner, Richard, 2008: Confessions of a Subprime Lender: An Insider's Tale of Greed, Fraud, and Ignorance. Hoboken, NJ: Wiley.

Black, Julia/Richard Nobles, 1998: Personal Pensions Misselling: The Causes and Lessons of Regulatory Failure. In: The Modern Law Review 61, 789-820.

Blanqué, Pascal, 2003: Crisis and Fraud. In: Journal of Financial Regulation and Compliance 11, 60-70.

Blanton, Kimberly, 2012: The Rise of Financial Fraud. Brief 12-5. Boston: Center for Retirement Research, Boston College. <http://crr.bc.edu/wp-content/uploads/2012/02/IB_12-5-508.pdf>

Blois, Keith, 2013: Affinity Fraud and Trust within Financial Markets. In: Journal of Financial Crime 20, 186-202.

— 2009: Do Hedge Fund Managers Misreport Returns? Evidence from the Pooled Distribution. In: The Journal of Finance 64, 2257-2288.

Bollen, Nicolas P. B./Veronika K. Pool, 2012: Suspicious Patterns in Hedge Fund Returns and the Risk of Fraud. In: Review of Financial Studies 25, 2673-2702.

Bolton, Patrick/Xavier Freixas/Joel Shapiro, 2007: Conflicts of Interest, Information Provision, and Competition in the Financial Services Industry. In: Journal of Financial Economics 85, 297-330.

Boot, Arnoud W. A., 2011: Banking at the Crossroads: How to Deal with Marketability and Complexity? In: Review of Development Finance 1, 167-183. 
Bose, Indranil/Alvin Chung Man Leung, 2014: Do Phishing Alerts Impact Global Corporations? A Firm Value Analysis. In: Decision Support Systems 64, 67-78.

Brody, Richard G./Elizabeth Mulig/Valerie Kimball, 2007: Phishing, Pharming and Identity Theft. In: Academy of Accounting and Financial Studies Journal 11, 43-56.

Buell, Samuel W., 2011: What Is Securities Fraud? In: Duke Law Journal 61, 511-581.

Burns, Natasha/Simi Kedia, 2006: The Impact of Performance-based Compensation on Misreporting. In: Journal of Financial Economics 79, 35-67.

Bussani, Mauro, 2010: Credit Rating Agencies' Accountability: Short Notes on a Global Issue. In: Global Jurist 10, 1-13.

Button, Mark, et al., 2014: Online Frauds: Learning from Victims Why They Fall for These Scams. In: Australian \& New Zealand Journal of Criminology 47, 391-408.

Campbell, John Y., et al., 2011: Consumer Financial Protection. In: The Journal of Economic Perspectives 25, 91-114.

Cane, Marilyn Blumberg/Adam Shamir/Tomas Jodar, 2012: Below Investment Grade and above the Law: A Past, Present and Future Look at the Accountability of Credit Rating Agencies. In: Fordham Journal of Corporate \& Financial Law 17, 1063-1126.

Carlin, Bruce I./Gustavo Manso, 2011: Obfuscation, Learning, and the Evolution of Investor Sophistication. In: Review of Financial Studies 24, 754-785.

Carswell, Andrew T./Douglas C. Bachtel, 2009: Mortgage Fraud: A Risk Factor Analysis of Affected Communities. In: Crime, Law and Social Change 52, 347-364.

Cheney, Julia S., 2003: Identity Theft: A Pernicious and Costly Fraud. Discussion Paper December 2003. Philadelphia: Federal Reserve Bank of Philadelphia Payment Cards Center. $<$ http://papers.ssrn.com/sol3/papers.cfm?abstract_id=927415>

_ 2005: Identity Theft: Do Definitions Still Matter? Discussion Paper August 2005. Philadelphia: Federal Reserve Bank of Philadelphia Payment Cards Center. $<$ http://papers.ssrn.com/sol3/papers.cfm?abstract_id=815684>

Chon, Gina/Barney Jopson, 2015: US Launches Crackdown on Pension Adviser Conflicts. In: Financial Times, February 23, 2015.

Chryssikos, Demosthenes/Nikos Passas/Christopher D. Ram (eds.), 2008: The Evolving Challenge of Identity-related Crime: Addressing Fraud and the Criminal Misuse and Falsification of Identity. Milan: ISPAC (International Scientific and Professional Advisory Council of the United Nations Crime Prevention and Criminal Justice Programme).

Coffee, John C. Jr., 2002: Understanding Enron: “It's About the Gatekeepers, Stupid.” In: The Business Lawyer 57, 1403-1420.

- 2003: The Attorney as Gatekeeper: An Agenda for the SEC. In: Columbia Law Review 103, 1293-1316.

- 2004: What Caused Enron: A Capsule Social and Economic History of the 1990s. In: Cornell Law Review 89, 269-309.

- 2005: A Theory of Corporate Scandals: Why the USA and Europe Differ. In: Oxford Review of Economic Policy 21, 198-211.

Cohn, Alain/Ernst Fehr/Michel A. Maréchal, 2014: Business Culture and Dishonesty in the Banking Industry. In: Nature 516, 86-89.

Collins, M. Cary/Peter J. Nigro, 2010: Mortgage Origination Fraud. In: Criminology \& Public Policy 9, 633-640.

Comer, Michael J., 2003: Investigating Corporate Fraud. Aldershot, UK: Gower Publishing.

Comet, Catherine, 2011: Anatomy of a Fraud: Trust and Social Networks. In: Bulletin de Méthodologie Sociologique 110, 45-57.

Cronin, Julia K./Amanda R. Evansburg/Sylvia R. Garfinkle-Huff, 2001: Securities Fraud. In: American Criminal Law Review 38, 1277-1343.

Davidoff Solomon, Steven M./Alan D. Morrison/William J. Wilhelm Jr., 2012: The SEC v. Goldman Sachs: Reputation, Trust, and Fiduciary Duties in Investment Banking. In: The Journal of Corporate Law 37, 529-553. 
Deakin, Simon, et al., 2015: Legal Institutionalism: Capitalism and the Constitutive Role of Law. Legal Studies Research Paper 26/2015. Cambridge: Faculty of Law, University of Cambridge. $<$ http://papers.ssrn.com/sol3/papers.cfm?abstract_id=2601035>

Dechow, Patricia M., et al., 2011: Predicting Material Accounting Misstatements. In: Contemporary Accounting Research 28, 17-82.

Delgadillo, Lucy M./Luke V. Erickson/Kathleen W. Piercy, 2008: Disentangling the Differences between Abusive and Predatory Lending: Professionals' Perspectives. In: Journal of Consumer Affairs 42, 313-334.

Doig, Alan, 2006: Fraud. Cullompton, UK: Willan.

Dorn, Nicholas, 2010: The Governance of Securities: Ponzi Finance, Regulatory Convergence, Credit Crunch. In: British Journal of Criminology 50, 23-45.

— 2011: Reconstructing 'Conflict of Interest' in Financial Markets: Private Management, Public Challenges, Future Prospects. In: International Journal of Law, Crime and Justice 39, 161-173.

Durkin, Keith F./Richard Brinkman, 2009: 419 Fraud: A Crime without Borders in a Postmodern World. In: International Review of Modern Sociology 35, 271-283.

Dyck, I. J. Alexander/Adair Morse/Luigi Zingales, 2013: How Pervasive Is Corporate Fraud? Business Economics Working Paper 2222608. Toronto: Rotman School of Management, University of Toronto. <http://papers.ssrn.com/sol3/papers.cfm?abstract_id=2222608>

Dyson, Richard, 2014: Annuity Mis-selling Scandal: Could It Be as Big as PPI? In: The Telegraph, December 11, 2014.

Economist, The, 2014: The Dozy Watchdogs. In: The Economist, December 13, 2014, 24-26. $<$ www.economist.com/news/briefing/21635978-some-13-years-after-enron-auditors-stillcant-stop-managers-cooking-books-time-some $>$

Efendi, Jap/Anup Srivastava/Edward P. Swanson, 2007: Why Do Corporate Managers Misstate Financial Statements? The Role of Option Compensation and Other Factors. In: Journal of Financial Economics 85, 667-708.

Egler, Frederick N. Jr./Paul J. Malak, 1999: The Individual Life Insurance Sales Practice Case: A Litigation Primer. In: FICC Quarterly 50, 1-28.

Engel, Kathleen C./Patricia A. McCoy, 2002: A Tale of Three Markets: The Law and Economics of Predatory Lending. In: Texas Law Review 80, 1255-1367.

— 2007: Turning a Blind Eye: Wall Street Finance of Predatory Lending. In: Fordham Law Review 75, 101-165.

Epstein, Richard A./Thomas P. Brown, 2008: Cybersecurity in the Payment Card Industry. In: The University of Chicago Law Review 75, 203-223.

Ericson, Richard V./Aaron Doyle, 2006: The Institutionalization of Deceptive Sales in Life Insurance: Five Sources of Moral Risk. In: British Journal of Criminology 46, 993-1010.

Erturk, Ismail, et al., 2007: The Democratization of Finance? Promises, Outcomes and Conditions. In: Review of International Political Economy 14, 553-575.

Falconer, Stewart, 2005: Ethical Marketing in Financial Services: The Continuing Importance of Fiduciary Responsibility. In: Journal of Financial Services Marketing 10, 103-106.

FCA (Financial Conduct Authority), 2015: Retirement Income Market Study: Final Report - Confirmed Findings and Remedies. Market Study 14/3.3 London: Financial Conduct Authority. $<$ www.fca.org.uk/your-fca/documents/market-studies/ms14-03-3>

Ferguson, Charles, 2012: Predator Nation. New York: Crown Business.

Ferran, Eilis, 2012: Regulatory Lessons from the Payment Protection Insurance Mis-selling Scandal in the UK. In: European Business Organization Law Review 13, 247-270.

Finan, Griffin, et al., 2011: Securities Fraud. In: American Criminal Law Review 48, 1129-1200.

Fischel, Daniel R./Robert S. Stillman, 1997: The Law and Economics of Vanishing Premium Insurance. In: Delaware Journal of Corporate Law 22, 1-36.

Fisher, Jonathan, 2015: Risk, Recklessness, and Policing the Financial Markets. In: Nicholas Ryder/ Umut Turksen/Sabine Hassler (eds.), Fighting Financial Crime in the Global Economic Crisis. London: Routledge, 7-28. 
Fligstein, Neil/Alexander Roehrkasse, 2013: All the Incentives Were Wrong: Opportunism and the Financial Crisis. Conference paper. American Sociological Association Annual Meeting, New York, August 9, 2013.

Forelle, Charles/James Bandler, 2006: The Perfect Payday. In: Wall Street Journal, March 18, 2006, A1. Frankel, Tamar, 2012: The Ponzi Scheme Puzzle: A History and Analysis of Con Artists and Victims. New York: Oxford University Press.

Freeman, Richard B., 2010: Financial Crime, Near Crime, and Chicanery in the Wall Street Meltdown. In: Journal of Policy Modeling 32, 690-701.

Friedrichs, David O., 2004: Enron et al.: Paradigmatic White Collar Crime Cases for the New Century. In: Critical Criminology 12, 113-132.

_ 2007: White-Collar Crime in a Postmodern, Globalized World. In: Henry N. Pontell/Gilbert Geis (eds.), International Handbook of White-Collar and Corporate Crime. New York: Springer, $163-184$.

— 2009: Exorbitant CEO Compensation: Just Reward or Grand Theft? In: Crime, Law and Social Change 51, 45-72.

- 2010: Trusted Criminals: White Collar Crime in Contemporary Society. Belmont, CA: Wadsworth.

FTM (Follow the Money), 2014a: AFM voert druk op banken op om verkoop swaps aan MKB. May 28, 2014. <www.ftm.nl/exclusive/afm-voert-druk-banken-op-om-verkoop-swaps-mkb/>

_ _ 2014b: Oud Rabo-bankier: 'Perverse prikkels voor verkoop van renteswaps'. December 24, 2014. $<$ www.ftm.nl/exclusive/oud-rabo-bankier-perverse-prikkels-voor-verkoop-van-renteswaps/>

— 2015: Belgische toezichthouder grijpt hard in om 'plofderivaten' bij MKB. May 22, 2015. <www.ftm.nl/artikelen/belgische-toezichthouder-grijpt-hard-in-om-plofderivaten-bij-mkb>

Furman, Donald J./John S. DeJoy, 2009: Before and after Bernie: Ponzi Regulation or Lack Thereof? In: International Review of Business Research Papers 5, 63-71.

Gande, Amar/Craig M. Lewis, 2009: Shareholder-initiated Class Action Lawsuits: Shareholder Wealth Effects and Industry Spillovers. In: Journal of Financial and Quantitative Analysis 44, 823-850.

Gandel, Stephen, 2010: How the Goldman Case Sheds Light on Hedge Funds. In: Time, April 19, 2010, 15.

Gans, Kale, 2011: Anatomy of a Mortgage Meltdown: The Study of the Subprime Crisis, the Role of Fraud, and the Efficacy of the Idaho Safe Act. In: Idaho Law Review 48, 123-174.

GAO (US General Accounting Office), 2002: Financial Statement Restatements: Trends, Market Impacts, Regulatory Responses, and Remaining Challenges. GAO-03-138. Washington, DC: US General Accounting Office. <www.gao.gov/new.items/d03138.pdf>

GAO (US Government Accountability Office), US, 2006: Financial Restatements: Update of Public Company Trends, Market Impacts, and Regulatory Enforcement Activities. GAO-06-678. Washington, DC: US Government Accountability Office. <www.gao.gov/new.items/d06678.pdf>

Geckeler, Peter M., 1996: Municipal Derivatives Use and the Suitability Doctrine. In: Washington University Journal of Urban and Contemporary Law 49, 285-314.

Geeta, D. Vijaya, 2011: Online Identity Theft: An Indian Perspective. In: Journal of Financial Crime $18,235-246$.

Geis, Gilbert, 2013: Unaccountable External Auditors and Their Role in the Economic Meltdown. In: Susan Will/Stephen Handelman/David C. Brotherton (eds.), How They Got Away with It: White Collar Criminals and the Financial Meltdown. New York: Columbia University Press, 85-103.

Georgosouli, Andromachi, 2014: Payment Protection Insurance (PPI) Misselling: Some Lessons from the UK. In: Connecticut Insurance Law Journal 21, 261-288.

Gerety, Mason/Kenneth Lehn, 1997: The Causes and Consequences of Accounting Fraud. In: Managerial and Decision Economics 18, 587-599.

Gibson, Willa E., 1998: Investors, Look before You Leap: The Suitability Doctrine Is Not Suitable for OTC Derivatives Dealers. In: Loyola University Chicago Law Journal 29, 527-581.

Gill, Martin, 2011: Fraud and Recessions: Views from Fraudsters and Fraud Managers. In: International Journal of Law, Crime and Justice 39, 204-214.

Giroux, Gary, 2008: What Went Wrong? Accounting Fraud and Lessons from the Recent Scandals. In: Social Research 75, 1205-1238. 
Giroux, Gary, 2014: Accounting Fraud: Maneuvering and Manipulation, Past and Present. New York: Business Expert Press.

Glickman, Harvey, 2005: The Nigerian “419” Advance Fee Scams: Prank or Peril? In: Canadian Journal of African Studies 39, 460-489.

Goldmann, Peter, 2010: Fraud in the Markets: Why It Happens and How to Fight It. Hoboken, NJ: Wiley.

Gough, Leo, 2013: The Con Men: A History of Financial Fraud and the Lessons You Can Learn. Harlow, UK: Pearson Education.

Green, Stuart P., 2007a: Lying, Cheating, and Stealing: A Moral Theory of White-Collar Crime. New York: Oxford University Press.

— 2007b: A Normative Approach to White-Collar Crime. In: Henry N. Pontell/Gilbert Geis (eds.), International Handbook of White-Collar and Corporate Crime. New York: Springer, 223-247.

Hackethal, Andreas/Michael Haliassos/Tullio Jappelli, 2012: Financial Advisors: A Case of Babysitters? In: Journal of Banking \& Finance 36, 509-524.

Halan, Monika/Renuka Sane/Susan Thomas, 2014: The Case of the Missing Billions: Estimating Losses to Customers Due to Mis-sold Life Insurance Policies. In: Journal of Economic Policy Reform 17, 285-302.

Harrington, Brooke, 2012: The Sociology of Financial Fraud. In: Karin Knorr Cetina/Alex Preda (eds.), The Oxford Handbook of the Sociology of Finance. Oxford: Oxford University Press, 393-410.

Harris, Jared/Philip Bromiley, 2007: Incentives to Cheat: The Influence of Executive Compensation and Firm Performance on Financial Misrepresentation. In: Organization Science 18, 350-367.

Henselmann, Klaus/Stefan Hofmann, 2010: Accounting Fraud: Case Studies and Practical Implications. Berlin: Erich Schmidt Verlag.

Heron, Randall A./Erik Lie, 2007: Does Backdating Explain the Stock Price Pattern around Executive Stock Option Grants? In: Journal of Financial Economics 83, 271-295.

Heron, Randall A./Erik Lie/Tod Perry, 2007: On the Use (and Abuse) of Stock Option Grants. In: Financial Analysts Journal 63, 17-27.

Hill, Ronald P./John C. Kozup, 2007: Consumer Experiences with Predatory Lending Practices. In: The Journal of Consumer Affairs 41, 29-46.

Hudson, Alastair, 1998: The Uses and Abuses of Derivatives. Paper originally written for Cambridge Symposium on Economic Crime. Self-published. <www.alastairhudson.com/financelaw/use abusederivatives.pdf>

Huisman, Wim, 2011: Corporate Crime and Crisis: Causation Scenarios. In: Mathieu Deflem (ed.), Economic Crisis and Crime. Bingley: Emerald, 107-125.

Hyde, Dan/Katie Morley, 2014: Pension Mis-selling: Scandal Hits 100,000 Retired Savers a Year. In: The Telegraph, November 21, 2014.

Ianelli, Nicholas/Aaron Hackworth, 2007: Botnets as a Vehicle for Online Crime. In: The International Journal of Forensic Computer Science 1, 19-39.

Inderst, Roman/Marco Ottaviani, 2009: Misselling through Agents. In: The American Economic Review 99, 883-908.

Instefjord, Norvald/Patricia Jackson/William Perraudin, 1998: Securities Fraud: It Is a Matter of Incentives from Bottom to Top. In: Economic Policy 13, 585-623.

Issacharoff, Samuel/Erin F. Delaney, 2006: Credit Card Accountability. In: The University of Chicago Law Review 73, 157-182.

Jackson, Howell E., 2008: The Trilateral Dilemma in Financial Regulation. Harvard Public Law Working Paper 08-58. Cambridge, MA: Harvard Law School. <http://papers.ssrn.com/sol3/papers. cfm?abstract_id=1300419>

Jagatic, Tom N., et al., 2007: Social Phishing. In: Communications of the ACM 50, 94-100.

Jeffers, Agatha E., 2011: How Lehman Brothers Used Repo 105 to Manipulate Their Financial Statements. In: Journal of Leadership, Accountability, and Ethics 8, 44-55.

Jeffers, Agatha E./Marion S. Mogielnicki, 2010: The Line between Illegality \& Unethical Behavior in the Goldman Sachs Subprime Mortgage Securities Case. In: International Journal of Business Research 10(4), 159-169. 
Johansson, Tobias, 2010: Regulating Credit Rating Agencies: The Issue of Conflicts of Interest in the Rating of Structured Finance Products. In: Journal of Banking Regulation 12, 1-23.

Johnson, Shane A./Harley E. Ryan/Yisong S. Tian, 2009: Managerial Incentives and Corporate Fraud: The Sources of Incentives Matter. In: Review of Finance 13, 115-145.

Joint Forum, 2008: Customer Suitability in the Retail Sale of Financial Products and Services. (The Joint Forum is made up of the Basel Committee on Banking Supervision, the International Organization of Securities Commissions, and the International Association of Insurance Supervisors). Basel: Bank for International Settlements. <www.bis.org/publ/joint20.pdf>

Jones, Michael J., 2011: Creative Accounting, Fraud and International Accounting Scandals. Chichester: Wiley.

Kane, Edward J./Kimberly DeTrask, 1999: Breakdown of Accounting Controls at Barings and Daiwa: Benefits of Using Opportunity-Cost Measures for Trading Activity. In: Pacific-Basin Finance Journal 7, 203-228.

Karpoff, Jonathan M./D. Scott Lee/Gerald S. Martin, 2008: The Cost to Firms of Cooking the Books. In: The Journal of Financial and Quantitative Analysis 43, 581-611.

Kat, Micha/Pieter Lakeman, 2010: Boekhoudfraude: 13 schokkende fraudezaken in binnen-en buitenland. Den Dolder, Netherlands: Belfra Publishers for Success.

Kedia, Simi/Thomas Philippon, 2009: The Economics of Fraudulent Accounting. In: Review of Financial Studies 22, 2169-2199.

Khalique, Farah, 2015a: Mis-selling: The Importance of Crestsign v RBS. In: Euromoney, April 17, 2015. <www.euromoney.com/article/3445742/mis-selling-the-importance-of-crestsign-vrbs.html>

_ 2015b: Mis-selling: FX Hedges in the Spotlight. In: Euromoney, April 30, $2015 . \quad<\mathrm{w} w \mathrm{w}$. euromoney.com/article/3449553/mis-selling-fx-hedges-in-the-spotlight.html>

Kindleberger, Charles P./Robert Z. Aliber, 2005: Manias, Panics and Crashes: A History of Financial Crises. 5th Edition. Hoboken, NJ: Wiley.

Krawiec, Kimberly D., 2000: Accounting for Greed: Unraveling the Rogue Trader Mystery. In: Oregon Law Review 79, 301-338.

- 2009: The Return of the Rogue. In: Arizona Law Review 51, 127-174.

La Porta, Rafael, et al., 1998: Law and Finance. In: Journal of Political Economy 106, 1113-1155.

Laffort, Emmanuel/Emmanuelle Cargnello-Charles, 2014: Reducing the Risk of Fraud in Financial Market: Psychosocial Drivers and Enactment-based Perspective. In: World Journal of Social Sciences 4(2), 1-13.

Lanchester, John, 2013: Are We Having Fun Yet? In: London Review of Books 35(13), 3-8.

Langenderfer, Jeff/Terence A. Shimp, 2001: Consumer Vulnerability to Scams, Swindles, and Fraud: A New Theory of Visceral Influences on Persuasion. In: Psychology \& Marketing 18, 763-783.

Langevoort, Donald C., 1997: Organized Illusions: A Behavioral Theory of Why Corporations Mislead Stock Market Investors (and Cause Other Social Harms). In: University of Pennsylvania Law Review 146, 101-172.

Leap, Terry, 2007: Dishonest Dollars: The Dynamics of White-Collar Crime. Ithaca, NY: Cornell University Press.

Lehmann, Matthias, 2014: Civil Liability of Rating Agencies: An Insipid Sprout from Brussels. LSE Law, Society and Economy Working Paper 15/2014. London: London School of Economics. $<$ http://papers.ssrn.com/sol3/papers.cfm?abstract_id=2456953>

Levi, Michael, 2009: Financial Crime. In: Michael Tonry (ed.), Oxford Handbook of Crime and Public Policy. New York: Oxford University Press, 223-246.

Lewis, Mervyn K., 2012: New Dogs, Old Tricks: Why Do Ponzi Schemes Succeed? In: Accounting Forum 36, 294-309.

Lewis, Michael, 2011: The Big Short: Inside the Doomsday Machine. London: Penguin.

Lie, Erik, 2005: On the Timing of CEO Stock Option Awards. In: Management Science 51, 802-812.

Lokanan, Mark E., 2014: The Demographic Profile of Victims of Investment Fraud: A Canadian Perspective. In: Journal of Financial Crime 21, 226-242. 
Lomnicka, Eva, 2008: Investor Protection in Securities Markets. In: Peter Cane/Joanne Conaghan (eds.), The New Oxford Companion to Law. Online edition. Oxford: Oxford University Press. <www.oxfordreference.com/view/10.1093/acref/9780199290543.001.0001/acref-9780 199290543-e-1212>

Lovet, Guillaume, 2006: Dirty Money on the Wires: The Business Models of Cyber Criminals. Conference paper. 16th Virus Bulletin International Conference, Montreal, October 11-13, 2006.

Luyendijk, Joris, 2015: Swimming with Sharks: My Journey into the World of the Bankers. London: Guardian Books.

Lynch, Jennifer, 2005: Identity Theft in Cyberspace: Crime Control Methods and Their Effectiveness in Combating Phishing Attacks. In: Berkeley Technology Law Journal 20, 259-300.

Maas, David A., 2011: Policing the Ratings Agencies: The Case for Stronger Criminal Disincentives in the Credit Rating Market. In: The Journal of Criminal Law and Criminology 101, 1005-1038.

MacDonald, Ross, 2012: Setting Examples, Not Settling: Toward a New SEC Enforcement Paradigm. In: Texas Law Review 91, 419-447.

MacLean, Tammy L., 2008: Framing and Organizational Misconduct: A Symbolic Interactionist Study. In: Journal of Business Ethics 78, 3-16.

Markham, Jerry W., 1995: Protecting the Institutional Investor: Jungle Predator or Shorn Lamb? In: The Yale Journal on Regulation 12, 345-386.

Markopolos, Harry, 2010: No One Would Listen: A True Financial Thriller. Hoboken, NJ: Wiley.

Marshall, Paul, 2014: Interest Rate Swaps and the Sale of the Unknown: Blind Alleys, an Enfeebled Equity and the Triumph of Certainty over Fairness. In: Butterworths Journal of International Banking and Financial Law 29, 9-15.

Mayntz, Renate, 2016: Illegal Markets: Boundaries and Interfaces between Legality and Illegality. MPIfG Discussion Paper 16/4. Cologne: Max Planck Institute for the Study of Societies.

McConnell, Patrick, 2014: Dissecting the JPMorgan Whale: A Post-mortem. In: The Journal of Operational Risk 9, 59-100.

McConnell, Patrick/Keith Blacker, 2012: Systemic Operational Risk: The UK Payment Protection Insurance Scandal. In: The Journal of Operational Risk 7, 79-139.

McCoy, Patricia A., 2005: A Behavioral Analysis of Predatory Lending. In: Akron Law Review 38, 725-739.

McNulty, Kevin, 2008: The Relationship between Identity-related Crime and Economic Fraud. In: Demosthenes Chryssikos/Nikos Passas/Christopher D. Ram (eds.), The Evolving Challenge of Identity-related Crime: Addressing Fraud and the Criminal Misuse and Falsification of Identity. Milan: ISPAC (International Scientific and Professional Advisory Council of the United Nations Crime Prevention and Criminal Justice Programme), 87-93.

Mehran, Hamid/René M. Stulz, 2007: The Economics of Conflicts of Interest in Financial Institutions. In: Journal of Financial Economics 85, 267-296.

Michel, Picard, 2008: Financial Crimes: The Constant Challenge of Seeking Effective Prevention Solutions. In: Journal of Financial Crime 15, 383-397.

Mitchell, Olivia S./Kent Smetters, 2013: The Market for Retirement Financial Advice: An Introduction. In: Olivia S. Mitchell/Kent Smitters (eds.), The Market for Retirement Financial Advice. New York: Oxford University Press, 1-10.

Moore, Tyler/Richard Clayton/Ross Anderson, 2009: The Economics of Online Crime. In: The Journal of Economic Perspectives 23, 3-20.

Moore, Tyler/Jie Han/Richard Clayton, 2012: The Postmodern Ponzi Scheme: Empirical Analysis of High-Yield Investment Programs. In: Angelos D. Keromytis (ed.), Financial Cryptography and Data Security. Berlin: Springer, 41-56.

Morley, Katie, 2015: Is This the Worst Pension Mis-selling Ever? Ariva Knew This Customer Was Ill. In: The Telegraph, March 28, 2015.

Muhtaseb, Majed R./Chun “Sylvia” Yang, 2008: Portraits of Five Hedge Fund Fraud Cases. In: Journal of Financial Crime 15, 179-213.

Mulford, Charles M./Eugene E. Comiskey, 2002: The Financial Numbers Game: Detecting Creative Accounting Practices. New York: Wiley. 
Mulki, Jay, 2015: The Ethics of the Selling Process in Financial Services. In: Tina Harrison/Hooman Estelami (eds.), The Routledge Companion to Financial Services Marketing. New York: Routledge, 520-535.

Mullainathan, Sendhil/Markus Noeth/Antoinette Schoar, 2012: The Market for Financial Advice: An Audit Study. NBER Working Paper 17929. Cambridge, MA: National Bureau of Economic Research. <www.nber.org/papers/w17929>

Mundheim, Robert H., 1965: Professional Responsibilities of Broker-Dealers: The Suitability Doctrine. In: Duke Law Journal 3, 445-480.

Nash, Rebecca/Martin Bouchard/Aili Malm, 2013: Investing in People: The Role of Social Networks in the Diffusion of a Large-scale Fraud. In: Social Networks 35, 686-698.

Naylor, R. Thomas, 2007: The Alchemy of Fraud: Investment Scams in the Precious-metals Mining Business. In: Crime, Law and Social Change 47, 89-120.

Neisius, Jens/Richard Clayton, 2014: Orchestrated Crime: The High Yield Investment Fraud Ecosystem. Conference paper. APWG (Anti-Phishing Working Group) E-Crime Research Symposium, Birmingham, AL, September 23-25, 2014.

Nesvetailova, Anastasia/Ronen Palan, 2013: Minsky in the Shadows: Securitization, Ponzi Finance, and the Crisis of Northern Rock. In: Review of Radical Political Economics 45, 349-368.

Nesvetailova, Anastasia/Andrei Sandu, 2015: The Good, the Bad and the Fraud: Securitisation and Financial Crime in Light of the Global Financial Crisis. In: Nicholas Ryder/Umut Turksen/Sabine Hassler (eds.), Fighting Financial Crime in the Global Economic Crisis. New York: Routledge, 128-143.

Newman, Graeme R./Megan M. McNally, 2005: Identity Theft Literature Review. (Grant report.) Washington, DC: National Institute of Justice, United States Department of Justice. $<$ www.ncjrs.gov/pdffiles1/nij/grants/210459.pdf>

Nguyen, Tomson H./Henry N. Pontell, 2010: Mortgage Origination Fraud and the Global Economic Crisis. In: Criminology \& Public Policy 9, 591-612.

— 2011: Fraud and Inequality in the Subprime Mortgage Crisis. In: Mathieu Deflem (ed.), Economic Crisis and Crime. Bingley: Emerald, 3-24.

Nolasco, Claire Angelique R. I./Michael S. Vaughn/Rolando V. del Carmen, 2013: Revisiting the Choice Model of Ponzi and Pyramid Schemes: Analysis of Case Law. In: Crime, Law and Social Change 60, 375-400.

Norton, Simon D./Michael J. Jones, 2011: Bank Failures and Accounting during the Financial Crisis of 2008-2009. In: Michael J. Jones (ed.), Creative Accounting, Fraud and International Accounting Scandals. Chichester: Wiley, 425-452.

O’Brien, Justin, 2003: Wall Street on Trial: A Corrupted State? Chicester: Wiley.

— , 2013: The Façade of Enforcement: Goldman Sachs, Negotiated Prosecution, and the Politics of Blame. In: Susan Will/Stephen Handelman/David C. Brotherton (eds.), How They Got Away with It: White Collar Crime and the Financial Meltdown. New York: Columbia University Press, $178-202$.

O'Gara, J. D., 2004: Corporate Fraud: Case Studies in Detection and Prevention. Hoboken, NJ: Wiley.

Oppenheimer, Jerry, 2009: Madoff with the Money. Hoboken, NJ: Wiley.

Oppenheimer, Pete H., 2011: Legal and Accounting Issues of Manipulating the Timing of Stock Option Grants. In: Journal of Financial Crime 18, 63-75.

Overdahl, James/Barry Schachter, 1995: Derivatives Regulation and Financial Management: Lessons from Gibson Greetings. In: Financial Management 24, 68-78.

Ozaki, Kuniko, 2008: Keynote Address. In: Demosthenes Chryssikos/Nikos Passas/Christopher D. Ram (eds.), The Evolving Challenge of Identity-related Crime: Addressing Fraud and the Criminal Misuse and Falsification of Identity. Milan: ISPAC (International Scientific and Professional Advisory Council of the United Nations Crime Prevention and Criminal Justice Programme), 9-18.

Palmrose, Zoe-Vonna/Vernon J. Richardson/Susan Scholz, 2004: Determinants of Market Reactions to Restatement Announcements. In: Journal of Accounting and Economics 37, 59-89. 
Partnoy, Frank, 2002: Infectious Greed: How Deceit and Risk Corrupted the Financial Markets. New York: Times Books.

Paterson, Jeannie Marie/Gerard Brody, 2014: “Safety Net” Consumer Protection: Using Prohibitions on Unfair and Unconscionable Conduct to Respond to Predatory Business Models. In: Journal of Consumer Policy 38, 331-355.

Patterson, Laura A./Cynthia A. Koller, 2011: Diffusion of Fraud Through Subprime Lending: The Perfect Storm. In: Mathieu Deflem (ed.), Economic Crisis and Crime. Bingley: Emerald, 25-45.

Perols, Johan L./Barbara A. Lougee, 2011: The Relation between Earnings Management and Financial Statement Fraud. In: Advances in Accounting 27, 39-53.

Perri, Frank S./Richard G. Brody, 2012: The Optics of Fraud: Affiliations that Enhance Offender Credibility. In: Journal of Financial Crime 19, 305-320.

Pickett, K. H. Spencer/Jennifer M. Pickett, 2002: Financial Crime Investigation and Control. New York: Wiley.

Piskorski, Tomasz/Amit Seru/James Witkin, 2013: Asset Quality Misrepresentation by Financial Intermediaries: Evidence from the RMBS Market. NBER Working Paper 18843. Cambridge, MA: National Bureau of Economic Research. <www.nber.org/papers/w18843>

Podgor, Ellen S., 1999: Criminal Fraud. In: American University Law Review 48, 729-768.

Polat, Ali, 2012: Corporate Letters of Credit and Their Usage as an Instrument for Fraud. In: Journal of Financial Crime 19, 213-225.

Policastro, Christina/Brian K. Payne, 2014: Can You Hear Me Now? Telemarketing Fraud Victimization and Lifestyles. In: American Journal of Criminal Justice 40, 620-638.

Pontell, Henry N., 1984: The Capacity to Punish: The Ecology of Crime and Punishment. Bloomington: Indiana University Press.

Pontell, Henry N./William K. Black/Gilbert Geis, 2014: Too Big to Fail, Too Powerful to Jail? On the Absence of Criminal Prosecutions after the 2008 Financial Meltdown. In: Crime, Law and Social Change 61, 1-13.

Pontell, Henry N./Kitty Calavita/Robert Tillman, 1994: Corporate Crime and Criminal Justice System Capacity: Government Response to Financial Institution Fraud. In: Justice Quarterly 11, 383-410.

Pontell, Henry N./Alexander Frid, 2000: International Financial Fraud: Emerging Trends and Issues. In: Delbert L. Rounds (ed.), International Criminal Justice: Issues in a Global Perspective. Needham Heights, MA: Allyn \& Bacon, 32-47.

Pontell, Henry N./Gilbert Geis, 2007: New Times, New Crimes: “Blocking” Financial Identity Fraud. In: Frank Bovenkerk/Michael Levi (eds.), The Organized Crime Community. New York: Springer, 45-58.

— 2014: The Trajectory of White-Collar Crime Following the Great Economic Meltdown. In: Journal of Contemporary Criminal Justice 30, 70-82.

Poovey, Mary, 2009: Writing about Finance in Victorian England: Disclosure and Secrecy in the Culture of Investment. In: Nancy Henry/Cannon Schmitt (eds.), Victorian Investments: New Perspectives on Finance and Culture. Bloomington: Indiana University Press, 39-57.

Povel, Paul/Rajdeep Singh/Andrew Winton, 2007: Booms, Busts, and Fraud. In: Review of Financial Studies 20, 1219-1254.

Pressman, Steven, 1998: On Financial Frauds and Their Causes. In: American Journal of Economics and Sociology 57, 405-421.

Ram, Christopher D., 2008: Identity Related Crime as a Global Issue: The Nature, Concept and Types of Identity Related Crime. In: Demosthenes Chryssikos/Nikos Passas/Christopher D. Ram (eds.), The Evolving Challenge of Identity-Related Crime: Addressing Fraud and the Criminal Misuse and Falsification of Identity. Milan: ISPAC (International Scientific and Professional Advisory Council of the United Nations Crime Prevention and Criminal Justice Programme), 53-62.

Ramamoorti, Sridhar/William Olsen, 2007: Fraud: The Human Factor. In: Financial Executive 23, $53-55$.

Renda, Andrea, et al., 2009: Tying and Other Potentially Unfair Commercial Practices in the Retail Financial Service Sector. Final Report Submitted to the European Commission, DG Internal 
Market and Services. ETD/2008/IM/H3/78. Brussels: Centre for European Policy Studies.

$<$ http://ec.europa.eu/internal_market/consultations/docs/2010/tying/report_en.pdf>

Renuart, Elizabeth, 2004: An Overview of the Predatory Mortgage Lending Process. In: Housing Policy Debate 15, 467-502.

Reurink, Arjan, 2016: From Elite Law-breaking to Financial Crime: The Evolution of the Concept of White-Collar Crime. Submitted to MPIfG Discussion Paper series. Cologne: Max Planck Institute for the Study of Societies.

Rhode, Deborah L./Paul D. Paton, 2002: Lawyers, Ethics, and Enron. In: Stanford Journal of Law, Business \& Finance 8, 9-38.

Roberts, Lyle, 1996: Suitability Claims under Rule 10b-5: Are Public Entities Sophisticated Enough to Use Derivatives? In: The University of Chicago Law Review 63, 801-835.

Rose, Amanda M., 2010: The Multienforcer Approach to Securities Fraud Deterrence: A Critical Analysis. In: University of Pennsylvania Law Review 158, 2173-2231.

Rosenthal, Jason M., 1996: Incorporation May Not Mean Sophistication: Should There Be a Suitability Requirement for Banks Selling Derivatives to Corporations? In: Chicago-Kent Law Review $71,1249-1270$.

Rosoff, Stephen/Henry Pontell/Robert Tillman, 2014: Profit without Honor: White-Collar Crime and the Looting of America. Upper Saddle River, NJ: Pearson Education.

Rutledge, Susan L., 2010: Consumer Protection and Financial Literacy: Lessons from Nine Country Studies. Policy Research Working Paper 5326. Washington, DC: World Bank. < http://papers. ssrn.com/sol3/papers.cfm?abstract_id=1619168>

Ryder, Nicholas, 2014: The Financial Crisis and White Collar Crime: The Perfect Storm? Cheltenham: Edward Elgar Publishing.

Ryley, Philip/John Virgo, 1999: Mis-selling of Personal Pension Plans: A Legal Perspective. In: Journal of Pension Management 5, 18-36.

Sale, Hillary A., 2004: Banks: The Forgotten Partners in Fraud. In: University of Cincinnati Law Review 73, 139-177.

Sander, Peter J., 2009: Madoff: Corruption, Deceit, and the Making of the World's Most Notorious Ponzi Scheme. Guilford, CT: Lyons Press.

Schaffer, Deborah, 2012: The Language of Scam Spams: Linguistic Features of "Nigerian Fraud” EMails. In: et Cetera 69, 157-179.

Schaper, Michael T./Paul Weber, 2012: Understanding Small Business Scams. In: Journal of Enterprising Culture 20, 333-356.

Schechter, Danny, 2010: The Crime of Our Time: Why Wall Street Is Not Too Big to Jail. New York: Disinformation.

Schipka, Maksym, 2007: The Online Shadow Economy: A Billion Dollar Market for Malware Writers. White Paper. New York: MessageLabs. <www.legis.iowa.gov/DOCS/LSA/IntComHand/2009/ IHEGC012.PDF>

Schmedlen, Daniel G. Jr., 1995: Broker-dealer Sales Practice in Derivatives Transactions: A Survey and Evaluation of Suitability Requirements. In: Washington \& Lee Law Review 52, 1441-1474.

Schulz, James, 2000: The Risks of Pension Privatization in Britain. In: Challenge 43, 93-104.

Scopino, Gregory, 2014: Regulating Fairness: The Dodd-Frank Act's Fair Dealing Requirement for Swap Dealers and Major Swap Participants. In: Nebraska Law Review 93, 31-88.

Sen, Sunanda, 2009: Speculation, Scams, Frauds and Crises: Theory and Facts. In: Economic and Political Weekly 44(12), 15-19.

Shah, Atul K., 1997: Regulatory Arbitrage through Financial Innovation. In: Accounting, Auditing \& Accountability Journal 10, 85-104.

Shapiro, David, 2013: Generating Alpha Return: How Ponzi Schemes Lure the Unwary in an Unregulated Market. In: Susan Will/Stephen Handelman/David C. Brotherton (eds.), How They Got Away with It: White Collar Criminals and the Financial Meltdown. New York: Columbia University Press, 130-147.

Shapiro, Susan, 1984: Wayward Capitalists: Target of the Securities and Exchange Commission. New Haven: Yale University Press. 
Shepherd, Matthew J./Scott N. Wagner/Natasha M. Williams, 2001: Financial Institutions Fraud. In: American Criminal Law Review 38, 843-890.

Shichor, David/Henry N. Pontell/Gilbert Geis, 2011: Illegally Backdated Stock Options. In: Matthieu Deflem (ed.), Sociology of Crime, Law and Deviance. Bingley: Emerald, 127-142.

Shover, Neal/Glenn S. Coffey/Dick Hobbs, 2003: Crime on the Line: Telemarketing and the Changing Nature of Professional Crime. In: British Journal of Criminology 43, 489-505.

Shover, Neal/Glenn S. Coffey/Clinton R. Sanders, 2004: Dialing for Dollars: Opportunities, Justifications, and Telemarketing Fraud. In: Qualitative Sociology 27, 59-75.

Shover, Neal/Andy Hochstetler/Tage Alalehto, 2012: Choosing White-Collar Crime. In: Francis T. Cullen/Pamela Wilcox (eds.), Oxford Handbook of Criminological Theory. Oxford: Oxford University Press, 475-493.

Smith, James Charles, 2010: The Structural Causes of Mortgage Fraud. In: Syracuse Law Review 60, 473-501.

Snider, Laureen, 2008: Corporate Economic Crimes. In: John Minkes/Leonard Minkes (eds.), Corporate and White-Collar Crime. London: Sage, 39-60.

Soltani, Bahram, 2014: The Anatomy of Corporate Fraud: A Comparative Analysis of High Profile American and European Corporate Scandals. In: Journal of Business Ethics 120, 251-274.

Stadler, William A., 2011: Predatory Lending: Is the Credit CARD Act Enough? In: Journal of Financial Crime 19, 99-111.

Stajano, Frank/Paul Wilson, 2011: Understanding Scam Victims: Seven Principles for Systems Security. In: Communications of the ACM 54, 70-75.

Stoneman, Trace Pride/Douglas J. Schulz, 2002: Brokerage Fraud: What Wall Street Doesn't Want You to Know. Chicago: Dearborn Trade Publishing.

Straney, Louis L., 2011: Securities Fraud: Detection, Prevention and Control. Hoboken, NJ: Wiley.

Strober, Deborah Hart/Gerald S. Strober, 2009: Catastrophe: The Story of Bernard L. Madoff, the Man Who Swindled the World. Beverly Hills, CA: Phoenix Books.

Subramanian, Revathi, 2014: Bank Fraud: Using Technology to Combat Losses. Hoboken, NJ: Wiley.

Summers, Lawrence H., 2014: US Economic Prospects: Secular Stagnation, Hysteresis, and the Zero Lower Bound. In: Business Economics 49, 65-73.

Swartz, Mimi/Sherron Watkins, 2003: Power Failure: The Inside Story of the Collapse of Enron. New York: Doubleday.

Swedberg, Richard, 2005: Conflicts of Interests in the US Brokerage Industry. In: Karin Knorr Cetina/Alex Preda (eds.), The Sociology of Financial Markets. New York: Oxford University Press, 187-203.

Taek Yi, Ho/Alan J. Dubinsky/Chae Un Lim, 2012: Determinants of Telemarketer Misselling in Life Insurance Services. In: Journal of Services Marketing 26, 403-418.

Taibbi, Matt, 2009: The Great American Bubble Machine. In: Rolling Stone, July 9, 2009. $<$ www.rollingstone.com/politics/news/the-great-american-bubble-machine-20100405? page $=8>$

— 2013: The Last Mystery of the Financial Crisis. In: Rolling Stone, June 19, 2013. <www.rolling stone.com/politics/news/the-last-mystery-of-the-financial-crisis-20130619?page $=5>$

Taylor, James, 2007: Company Fraud in Victorian Britain: The Royal British Bank Scandal of 1856. In: The English Historical Review 122, 700-724.

— 2012: Watchdogs or Apologists? Financial Journalism and Company Fraud in Early Victorian Britain. In: Historical Research 85, 632-650.

Thomas, C. William, 2002: The Rise and Fall of Enron. In: Journal of Accountancy 193, 41-48.

Tillman, Robert, 2002: Global Pirates: Fraud in the Offshore Insurance Industry. Boston: Northeastern University Press.

— 2009: Reputations and Corporate Malfeasance: Collusive Networks in Financial Statement Fraud. In: Crime, Law and Social Change 51, 365-382.

Tillman, Robert/Michael Indergaard, 2005: Pump and Dump: The Rancid Rules of the New Economy. New Brunswick: Rutgers University Press. 
Tillman, Robert/Michael Indergaard, 2007: Corporate Corruption in the New Economy In: Henry N. Pontell (ed.), International Handbook of White-Collar and Corporate Crime. New York: Springer, $474-489$.

Tomasic, Roman, 2011: The Financial Crisis and the Haphazard Pursuit of Financial Crime. In: Journal of Financial Crime 18, 7-31.

Tombs, Steve, 2013: Corporate Theft and Fraud: Business as Usual. In: Criminal Justice Matters 94, 14-15.

Trahan, Adam/James W. Marquart/Janet Mullings, 2005: Fraud and the American Dream: Toward an Understanding of Fraud Victimization. In: Deviant Behavior 26, 601-620.

Treanor, Jill, 2015: Lloyds Banking Group Facing £100m Fine for Mishandling PPI Payouts. In: The Guardian, June 4, 2015.

Turner, John A./Bruce W. Klein, 2014: Retirement Savings Flows and Financial Advice: Should You Roll Over Your 401(k) Plan? In: Benefits Quarterly 30, 42-54.

van Gestel, Barbra, 2010: Mortgage Fraud and Facilitating Circumstances. In: Karen Bullock/Ronald V. Clarke/Nick Tilley (eds.), Situational Prevention of Organised Crimes. Cullompton: Willan, 111-129.

Vasek, Marie/Tyler Moore, 2015: There’s No Free Lunch, Even Using Bitcoin: Tracking the Popularity and Profits of Virtual Currency Scams. In: Rainer Böhme/Tatsuaki Okamoto (eds.), Financial Cryptography and Data Security. Heidelberg: Springer, 44-61.

Velikonja, Urska, 2013: The Cost of Securities Fraud. In: William \& Mary Law Review 54, 1887-1957.

Viaene, Stijn/Guido Dedene, 2004: Insurance Fraud: Issues and Challenges. In: The Geneva Papers on Risk and Insurance: Issues and Practice 29, 313-333.

Vishwanath, Arun, et al., 2011: Why Do People Get Phished? Testing Individual Differences in Phishing Vulnerability within an Integrated, Information Processing Model. In: Decision Support Systems 51, 576-586.

Vittal, J. Anthony, 2005: Phishing, Pharming, and Other Scams. In: GPSolo 22(8), 26-32.

Walter, Ingo, 2004: Conflicts of Interest and Market Discipline among Financial Service Firms. In: European Management Journal 22, 361-376.

Wang, Ke, 2010: Securities Fraud, 1996-2001: Incentive Pay, Governance, and Class Action Lawsuits. El Paso: LFB Scholarly Publishing.

Ward, Sue, 2000: Personal Pensions in the UK, the Mis-selling Scandal and the Lessons to Be Learnt. In: Gerard Hughes/Jim Stewart (eds.), Pensions in the European Union: Adapting to Economic and Social Change. New York: Springer Science + Business Media, 139-146.

Wawoe, Kilian, 2010: Bonus: Een nederlandse bankier vertelt. Amsterdam: De Bezige Bij.

Weber, Bruce, 2011: High Frequency Trading: The Growing Threat of Rogue Trading. In: Business Strategy Review 20, 50-53.

Wexler, Mark N., 2010: Financial Edgework and the Persistence of Rogue Traders. In: Business and Society Review 115, 1-25.

White, Alan M./Cathy L. Mansfield, 2002: Literacy and Contract. In: Stanford Law \& Policy Review $13,233-267$.

Will, Susan 2013: America's Ponzi Culture. In: Susan Will/Stephen Handelman/David C. Brotherton (eds.), How They Got Away with It: White Collar Criminals and the Financial Meltdown. New York: Columbia University Press, 45-67.

Willis, Lauren E., 2006: Decisionmaking and the Limits of Disclosure: The Problem of Predatory Lending: Price. In: Maryland Law Review 65, 707-840.

Wilson, Sarah, 2006: Law, Morality and Regulation: Victorian Experiences of Financial Crime. In: British Journal of Criminology 46, 1073-1090.

—, 2014: The Origins of Modern Financial Crime: Historical Foundations and Current Problems in Britain. New York: Routledge.

Wright, Kai, 2008: The Subprime Swindle: How the Mortgage Industry Stole Black America's Hardwon Wealth. In: The Nation 287, 11-22. 
Young, Jock, 2013: Bernie Madoff, Finance Capital, and the Anomic Society. In: Susan Will/Stephen Handelman/David C. Brotherton (eds.), How They Got Away with It: White Collar Criminals and the Financial Meltdown. New York: Columbia University Press, 68-81.

Young, Michael R., 2006: Accounting Irregularities and Financial Fraud: A Corporate Governance Guide. 3rd edition. Chicago: CCH.

Yu, Xiaoyun, 2013: Securities Fraud and Corporate Finance: Recent Developments. In: Managerial and Decision Economics 34, 439-450.

Zack, Gerard M., 2013: Financial Statement Fraud: Strategies for Detection and Investigation. Hoboken, NJ: Wiley.

Zeissler, Arwin G./Rosalind L. Bennett/Andrew Metrick, 2014: JPMorgan Chase London Whale Z: Background \& Overview. Yale Program on Financial Stability, Case Study 2014-2Z-V1. New Haven: Yale School of Management. <http://papers.ssrn.com/sol3/papers.cfm?abstract_id=2577 839>

Zepeda, Rodrigo, 2013: Derivatives Mis-selling by British Banks and the Failed Legacy of the FSA. In: Journal of International Banking Law and Regulation 28, 209-220.

Zhang, Yanan, 2012: Documentary Letter of Credit Fraud Risk Management. In: Journal of Financial Crime 19, 343-354.

, 2014: Documentary Letter of Credit Fraud under Criminal Law Regime in England and China. In: Journal of Financial Crime 21, 433-446. 


\section{Recent Titles in the Publication Series of the MPIfG}

\section{MPIfG Discussion Papers}

DP $16 / 4$

R. Mayntz

Illegal Markets: Boundaries and Interfaces between Legality

and Illegality

\section{DP $16 / 3$}

L. Elsässer, A. Schäfer

Group Representation

for the Working Class?

Opinion Differences among

Occupational Groups in

Germany

DP $16 / 2$

M. Dewey

Porous Borders: The Study

of Illegal Markets from a

Sociological Perspective

DP $16 / 1$

L. Haffert

Permanent Budget Surpluses

as a Fiscal Regime

DP $15 / 11$

M. Höpner, A. Spielau

Diskretionäre

Wechselkursregime:

Erfahrungen aus dem

Europäischen Währungssystem, 1979-1998

DP $15 / 10$

A. Maatsch

Empowered or Disempowered?

The Role of National

Parliaments during the

Reform of European

Economic Governance

MPIfG Books

DP $15 / 9$

\section{E. Carter}

Constructing Quality: Producer Power, Market Organization, and the Politics of High ValueAdded Markets

DP $15 / 8$

P. Korom, M. Lutter, J. Beckert The Enduring Importance of Family Wealth: Evidence from the Forbes 400, 1982 to 2013

DP $15 / 7$

A. Leendertz

Das Komplexitätssyndrom: Gesellschaftliche "Komplexität" als intellektuelle und politische Herausforderung in den 1970er-Jahren

DP $15 / 6$

M. Höpner, B. Jurczyk

How the Eurobarometer Blurs the Line between Research and Propaganda

DP $15 / 5$

A. Daoud, B. Halleröd,

D. Guha Sapir

Quality of Government and the Relationship between Natural Disasters and Child Poverty: A Comparative Analysis
J. Beckert

Imagined Futures:

Fictional Expectations and

Capitalist Dynamics

Harvard University Press, 2016

T. Ergen

Große Hoffnungen und

brüchige Koalitionen: Industrie, Politik und die schwierige Durchsetzung der Photovoltaik

Campus, 2015

B. E. Fulda

Immer weniger Kinder?

Soziale Milieus und regionale

Geburtenraten in Deutschland

Campus, 2016

L. Haffert

Freiheit von Schulden -

Freiheit zum Gestalten? Die

Politische Ökonomie von

Haushaltsüberschüssen

Campus, 2015

A. Leendertz, W. Meteling (Hg.)

Die neue Wirklichkeit:

Semantische Neuvermessungen und Politik seit den 1970er-

Jahren

Campus, 2016

P. Mader

The Political Economy of

Microfinance: Financializing

Poverty

Palgrave Macmillan, 2015

R. Mayntz (ed.)

Negotiated Reform: The Multilevel Governance of Financial Regulation

Campus, 2015

\section{Ordering Information}

MPIfG Discussion Papers

Order printed copies from the MPIfG (you will be billed) or download PDF files from the MPIfG website (free).

\section{MPIfG Books}

At bookstores; abstracts on the MPIfG website.

www.mpifg.de

Go to Publications.

\section{New Titles}

Consult our website for the most complete and up-to-date information about MPIfG publications and publications by MPIfG researchers. To sign up for newsletters and mailings, please go to Service on the MPIfG website. Upon request to info@ mpifg.de, we will be happy to send you our Recent Publications brochure.

\section{ERPA}

MPIfG Discussion Papers and MPIfG Working Papers in the field of European integration research are included in the European Research Papers Archive (ERPA), which offers full-text search options: http://eiop.or.at/erpa. 
Das Max-Planck-Institut für Gesellschaftsforschung ist eine Einrichtung der Spitzenforschung in den Sozialwissenschaften. Es betreibt anwendungsoffene Grundlagenforschung mit dem Ziel einer empirisch fundierten Theorie der sozialen und politischen Grundlagen moderner Wirtschaftsordnungen. Im Mittelpunkt steht die Untersuchung der Zusammenhänge zwischen ökonomischem, sozialem und politischem Handeln. Mit einem vornehmlich institutionellen Ansatz wird erforscht, wie Märkte und Wirtschaftsorganisationen in historische, politische und kulturelle Zusammenhänge eingebettet sind, wie sie entstehen und wie sich ihre gesellschaftlichen Kontexte verändern. Das Institut schlägt eine Brücke zwischen Theorie und Politik und leistet einen Beitrag zur politischen Diskussion über zentrale Fragen moderner Gesellschaften.

The Max Planck Institute for the Study of Societies conducts advanced basic research on the governance of modern societies. It aims to develop an empirically based theory of the social and political foundations of modern economies by investigating the interrelation between economic, social and political action. Using primarily an institutional approach, it examines how markets and business organizations are embedded in historical, political and cultural frameworks, how they develop, and how their social contexts change over time. The institute seeks to build a bridge between theory and policy and to contribute to political debate on major challenges facing modern societies. 